\title{
Analysis of aluminium based alloys by calorimetry: quantitative analysis of reactions and reaction kinetics
}

\section{J. Starink*}

Differential scanning calorimetry (DSC) and isothermal calorimetry have been applied extensively to the analysis of light metals, especially Al based alloys. Isothermal calorimetry and differential scanning calorimetry are used for analysis of solid state reactions, such as precipitation, homogenisation, devitrivication and recrystallisation; and solid-liquid reactions, such as incipient melting and solidification, are studied by differential scanning calorimetry. In producing repeatable calorimetry data on Al alloys, sample preparation, reproducibility and baseline drift need to be considered in detail. Calorimetry can be used effectively to study the different solid state reactions and solid-liquid reactions that occur during the main processing steps of Al based alloys (solidification, homogenisation, precipitation). Also, devitrivication of amorphous and ultrafine grained Al based powders and flakes can be studied effectively. Quantitative analysis of the kinetics of reactions is assessed through reviewing the interrelation between activation energy analysis methods, equivalent time approaches, impingement parameter approaches, mean field models for precipitation, the Johnson-Mehl-Avrami-Kolmogorov model, as well as novel models which have not yet found application in calorimetry. Differential scanning calorimetry has occasionally been used in attempts to measure the volume fractions of phases present in Al based alloys, and attempts at determining volume fractions of intermetallic phases in commercial alloys and amounts of devitrified phase in glasses are reviewed. The requirements for the validity of these quantitative applications are also reviewed.

Keywords: Differential scanning calorimetry, Precipitation, Aluminium, Modelling, Transformation

IMR/419

\section{Introduction}

Calorimetry is an analysis technique that is part of a group of techniques collectively known as thermal analysis methods. In its broadest sense, thermal analysis refers to the measurement of changes in properties of substances under a controlled temperature program. Thermal analysis techniques can be classified according to the type of temperature program that the sample is subjected to and the measured (output) signal. The most commonly used temperature programs are either isothermal hold or heating (scanning) at constant rate, while more recently, temperature modulated scanning and reaction controlled heating have also found application. The signals measured in thermal analysis can include heat flows, temperature changes, mass, evolved gasses, length changes, elastic modulus, and many other properties that characterise properties or reactions of interest. Calorimetry refers to thermal analysis methods that measure the heat evolution

*Materials Research Group, School of Engineering Sciences, University of Southampton, Southampton S017 1BJ, email m.j.starink@soton.ac.uk from a sample under a controlled temperature program. The two most often applied calorimetry techniques are isothermal calorimetry and differential scanning calorimetry (DSC), which, as the name suggests, is by definition non-isothermal (i.e. a temperature scan).

Apart from the more common applications to polymers, glasses and pharmaceuticals, calorimetry has also been applied extensively to the analysis of light metals; especially $\mathrm{Al}$ based alloys, but also $\mathrm{Ti}$ and $\mathrm{Mg}$ based alloys. For light metals for structural applications, DSC is used mostly for analysis of solid-solid reactions, including precipitation, dissolution and recrystallisation, for determining temperatures of incipient melting, and for solidification studies. The present paper presents a review of the techniques and analysis methods of isothermal calorimetry and DSC that are relevant to the study of Al based alloys. The aim is to bring together and critically review the published work that is of direct use to researchers working in the field of calorimetry of light metals. The focus is mostly on work published in the past 10 years.

Aluminium based alloys studied by calorimetry can broadly be divided into three groups. The most often 
studied group of alloys are commercial wrought and cast alloys and alloys that are related to these, e.g. experimental alloys designed to be used as commercial wrought and cast alloys, variants and high purity versions, or model alloys. The calorimetry studies on these alloys generally focus on the analysis of the processing steps involved, solidification, homogenisation, solution treatments and aging. A second group of alloys studied by calorimetry involves Al based alloys containing transition metals and rare earth elements that are candidates for the development of ultrafine grained (nanostructured) materials, which can possess enhanced properties. ${ }^{1}$ The achievement of such a microstructure depends on the processing conditions and may be achieved by the formation of an amorphous structure through rapid solidification (typical cooling rate $10^{5} \mathrm{~K} \mathrm{~s}^{-1}$ ), high energy ball milling or wire electrical explosion $^{2}$ followed by controlled heat treatment. In calorimetry work on this second group of $\mathrm{Al}$ based alloys, the structural relaxation (devitrivication, recovery, (re-)crystallisation) is often the main objective of the study. A third group of alloys concerns alloys that have no commercial or potential commercial application, and which are studied as part of theoretical work to establish thermodynamic properties which can be used in verification of the predicted phase diagrams and are assessed and predicted using approaches collectively termed CALPHAD (CALculation of PHase Diagrams). In the present work, the focus is on studies that are relevant for the first two groups of materials.

Judging from the number of publications applying thermal analysis techniques, DSC is probably the most popular of all such techniques. Differential scanning calorimetry is applied to a wide range of materials and substances, with applications in the field of chemistry accounting for the majority of research output. The reasons for this popularity are related to speed, convenience, accuracy and versatility (see 'Experimental aspects of calorimetry' below). The advantages of nonisothermal calorimetry experiments are well known, but these temperature scanning methods have their own particular drawbacks and associated difficulties. On the experimental side, temperature inhomogeneities in the apparatus or in the sample can upset the controlled sample conditions aimed for. Further, analysis of nonisothermal experiments is generally more complicated than isothermal experiments, particularly because the changing temperature will influence reaction rates, and it can do this in a complex manner. This added complexity has in the past made several researchers adopt a very cautious and often dismissive attitude towards the analysis of thermally activated reactions using nonisothermal methods. ${ }^{3}$ However, after more than four decades of research into the analysis of non-isothermal thermal analysis methods, a vast amount knowledge has been gathered, and it has become increasingly clear that linear heating rate experiments, such as DSC, can be analysed to reliably characterise many details of reactions. The latter positive assessment is true under the proviso that appropriate and verified analysis techniques are applied to DSC data. This, however, can be a daunting task as the amount of publications on the theory of analysis of thermal analysis data, and linear heating rate experiments in particular, is vast and very diverse in nature. Hence, the present paper aims to bring

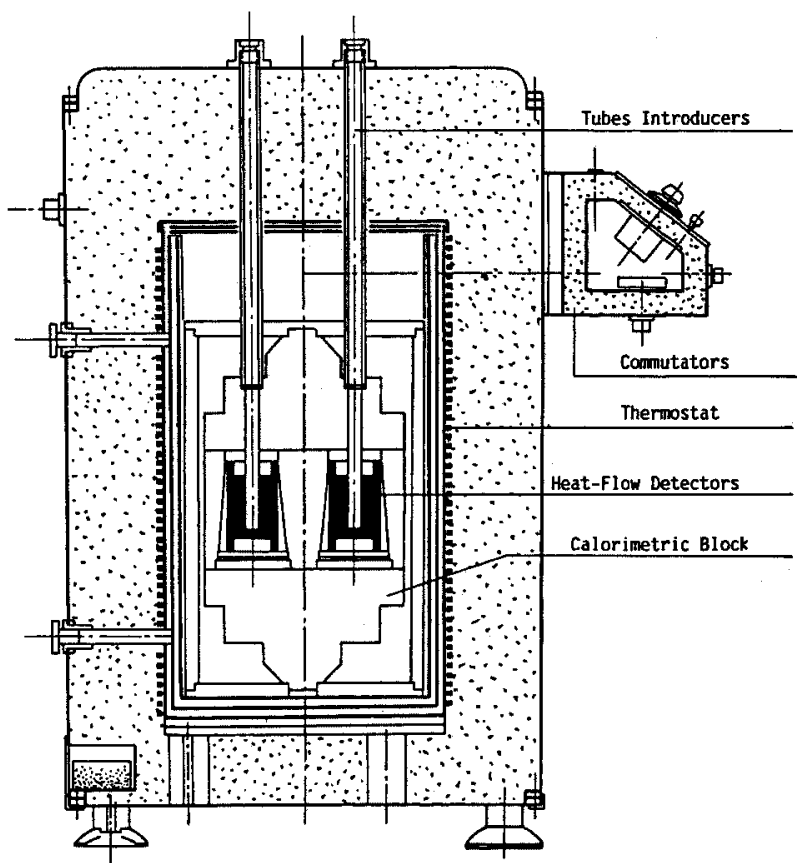

1 Schematic cross-section of Tian-Calvet type microcalorimeter (figure supplied by SETARAM, Caluire, France)

together and critically review the published work that is important for researchers working in the field of calorimetry of Al based alloys.

The paper is divided into sections as follows:

- the experimental aspects of thermal analysis, including equipment and sample preparation

- the different materials properties and reactions that can be measured with calorimetry, referring especially to Al based alloys

- the analysis and modelling methods for thermally activated reactions

- the quantitative analysis of volume fractions of precipitates, intermetallics and other phases.

Throughout the review, the literature most relevant to the aims of the analysis will be discussed. For practical reasons, examples will mostly be drawn from the author's own work.

\section{Experimental aspects of calorimetry Experimental aspects of isothermal calorimetric analysis}

Isothermal calorimetry can be performed with two types of instruments: differential isothermal calorimetry (DIC) uses the differential signal between a sample and reference, while standard isothermal calorimetry measures the signal straight from the sample without using a reference. As many reactions in Al based alloys cause relatively small heat flows, the higher sensitivity of differential isothermal calorimetry is often needed. Differential isothermal calorimetry can be carried out either with a standard power compensation differential scanning calorimeter (DSC) used in the isothermal mode or in a much larger calorimeter, generally referred to as the Tian-Calvet microcalorimeter (TCM) (Fig. 1). The high sensitivity of the latter type of apparatus is related to the use of a sample and a reference symmetrically positioned within a large volume of thermal mass, which 


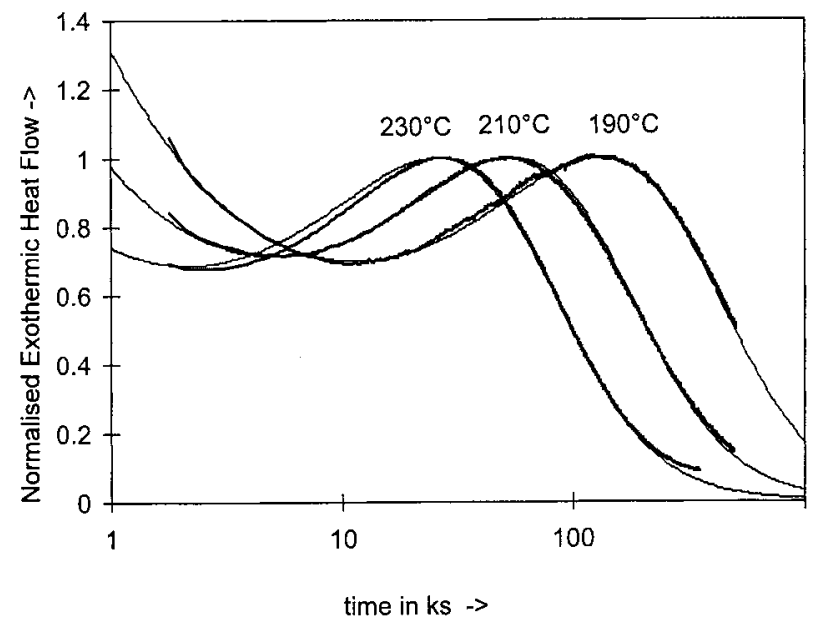

2 Isothermal calorimetry curves (normalised with respect to peak heat flow) of furnace cooled Al-6Si (at.-\%) alloy at temperatures $190-230^{\circ} \mathrm{C}$ (thicker lines) with fits obtained: exothermic reactions are due to $\mathrm{Si}$ precipitation (from Ref. 11.)

is isolated from external (thermal) disturbances. ${ }^{4}$ Heat exchange of sample and reference are measured by heat flux transducers consisting of several hundreds of thermocouples, which line the surface of the sample holder. ${ }^{4,5}$ In such an arrangement, heat flows as small as $0.1 \mathrm{~mW}$ can be detected. The large thermal mass of the equipment also has a drawback, as it is responsible for a substantial thermal lag. This means that on introduction of a sample into the isothermal calorimeter the heat flows in the calorimeter are disturbed, during which no reproducible measurement of heat flow is possible. Depending on type of calorimeter and mass of sample and calorimeter, this time lag varies and can be up to $0.5 \mathrm{~h}$ for a Tian-Calvet type calorimeter. In isothermal calorimetry using the power compensation DSC, the total thermal mass of the equipment is smaller, and hence the time of instability is shorter, in the order of $1 \mathrm{~min}$.

As an example of the results that can be obtained with isothermal calorimetry analysis of Al based alloys, in Fig. 2 isothermal calorimetry curves obtained with a Tian-Calvet microcalorimeter on quenched samples of an $\mathrm{Al}-\mathrm{Si}$ alloy are presented.

\section{Experimental aspects of differential scanning calorimetry}

Both differential thermal analysis (DTA) and differential scanning calorimetry (DSC) are concerned with the measurement of heat evolved from a substance during heating (or, in some cases, cooling). The word 'differential' emphasises that measurements involve the determination of the relative behaviour of a substance itself and a reference material. The main distinction between DTA and DSC is that in DSC the equipment can be calibrated such that the heat evolution from the sample can be measured quantitatively, while this is often not possible for DTA. ${ }^{6}$ Differential scanning calorimetry (or calibrated DTA) has proven to be a very useful and reproducible technique for the study of phase transformations and has been widely applied to study precipitation in $\mathrm{Al}$ alloys. Besides the basic scientific interest of these studies, their underlying aim is to use calorimetry as an effective and rapid tool to
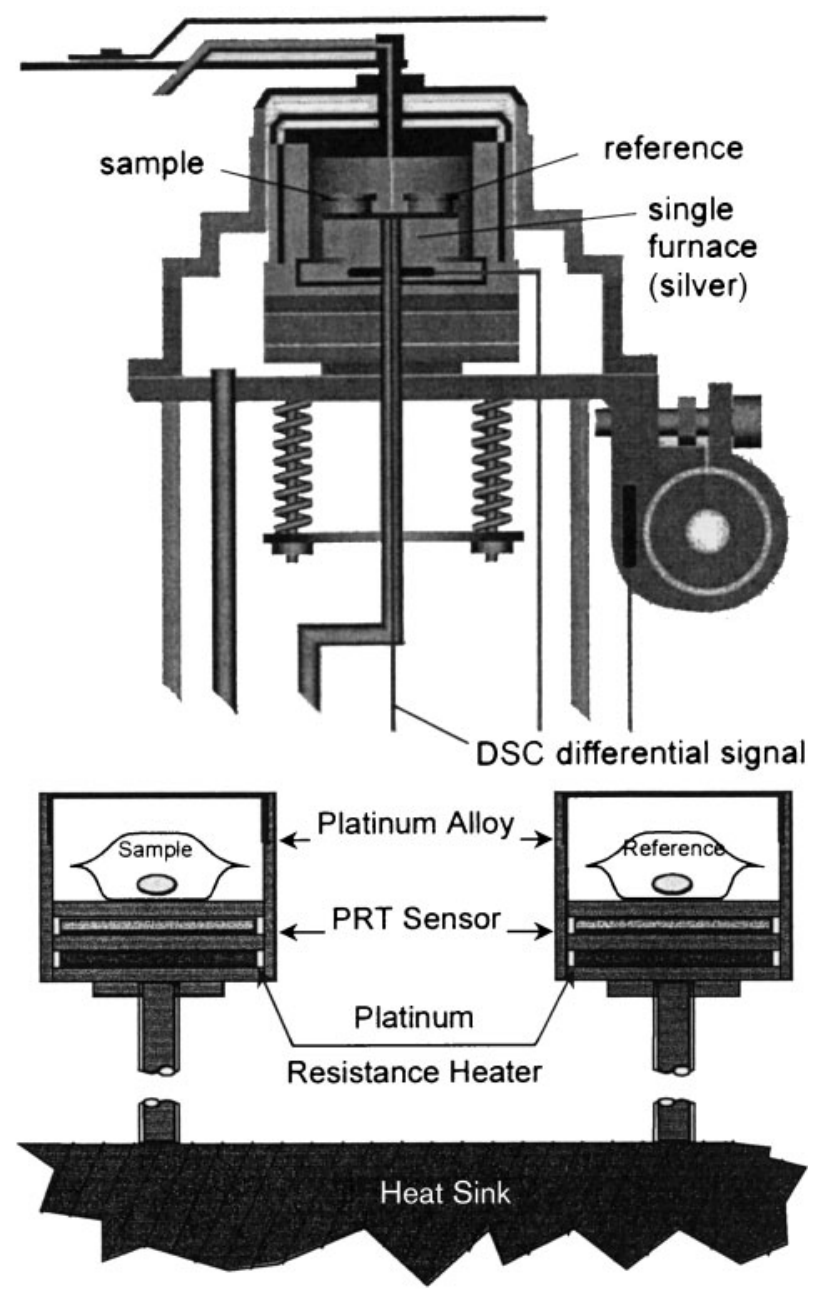

top: heat flux DSC (figure supplied by Mettler-Toledo); bottom: power compensation DSC (figure supplied by Perkin-Elmer)

3 Schematic cross-section of two types of differential scanning calorimeter

investigate various characteristics of commercial materials. For example, in Al based alloys, volume fractions of precipitates, the melting temperature of specific phases and the activation energy of reactions can, in most cases, be determined by the DSC technique.

There are two types of DSC: the heat flux DSC and the power compensation DSC, ${ }^{7}$ the working principles of the two methods are illustrated in Fig. 3. For power compensation DSC, the signal is related to the differential heat provided to keep the sample and the reference to the same temperature. For heat flux DSC, the signal derives directly from the difference of temperature between the sample and the reference, and in that sense a heat flux DSC is similar to a DTA. For the heat flux DSC, the heat flux measurement has to be calibrated by performing calibration runs with materials that display a reaction for which the heat evolution is well known. ${ }^{8}$ In practice, substances such as pure In and pure $\mathrm{Zn}$ are often used. Thus, a heat flux DSC is essentially a DTA instrument that can be calibrated.

\section{Sample preparation for calorimetry of light metal alloys}

Sample preparation for isothermal calorimetry and DSC studies of light metal alloys is often a simple process. If 
the material to be studied is in the form of powder or ribbons, e.g. from rapidly solidification processing, a sample of the powder or small flakes can be taken and put directly in a crucible. If bulk material is to be studied, suitably sized disc-shaped samples can be readily obtained either by punching from thin plate or sheet or by cutting (slicing) from machined cylinders. In isothermal calorimetry using a Tian-Calvet type instrument, the sample is either a cylinder which nearly fills the cavity in the calorimeter ${ }^{9}$ or a batch of 10-20 disc-shaped samples with spacers to keep them apart. ${ }^{10-12}$ In the latter case, the batch consists of discs having a thickness of about $1 \mathrm{~mm}$ and diameter of about 10-20 mm; this type of sample is to be preferred if high and homogeneous cooling/quenching rates are needed. Sizes are selected such that the sample will fit the cylindrical cavity lined with thermocouples that is the sample holder. In DSC or DIC using a heat compensation DSC apparatus, total sample mass is smaller, and generally a sample consisting of a single disc of about $0.5-2 \mathrm{~mm}$ thickness and $5-8 \mathrm{~mm}$ diameter is employed. ${ }^{26}$ In most calorimetric studies, the effects of sample preparation on the data are not a concern, and the ease of sample preparation using a range of methods is considered as a benefit for the method. However, it is well known that punching, grinding, machining and cutting all introduce deformation in $\mathrm{Al}$ based alloys, and this influences precipitation in most heat treatable Al based alloys by providing sites for heterogeneous nucleation, and by annihilating quenched-in excess vacancies. ${ }^{13,14}$ Treatments at relatively high temperatures can cause oxidation, or other surface reactions, and might cause loss of alloying elements to the atmosphere or to the reaction products formed in a surface reaction. For calorimetry samples, the thickness of the sample determines to a large extent the relative importance of the surface reactions, and also surface roughness can play a part. If any of these effects have a significant influence on reactions occurring during a calorimetry experiment, the sample preparation technique will cause variations in the measured data.

For $\mathrm{Al}$ based alloys, precipitation reactions are known to be particularly sensitive to sample preparation, and the effects of sample preparation have been studied for an 8090 (Al-Li-Cu-Mg-Zr) and a 2011 (Al-Cu) alloy. ${ }^{15-17}$ For the 2011 (Al-Cu) alloy, it was shown ${ }^{15}$ that for a sample prepared by punching and grinding after solution treatment, the $\theta^{\prime}\left(\mathrm{Al}_{2} \mathrm{Cu}\right)$ precipitation effect was shifted to lower temperatures as compared to a sample solution treated after punching and grinding.

The DSC curves of solution treated 8090 (Al- $\mathrm{Li}-\mathrm{Cu}-$ $\mathrm{Mg}-\mathrm{Zr}$ ) alloys show the precipitation of several phases with different precipitation mechanisms operating, and hence these alloys are very suitable for study of the influence of sample preparation on reactions. For the 8090 alloy, punching and grinding after solution treatment appeared to enhance the formation of semicoherent $\mathrm{S}$ phase precipitates $\left(\mathrm{Al}_{2} \mathrm{CuMg}\right)^{18-20 *}$ and

*The rod or lath shaped precipitates in Al-Cu-Mg alloys, which have often (especially up to the mid-1990s) been indicated by $S^{\prime}$, are not a separate phase: they are a slightly strained semicoherent version of the (incoherent) $\mathrm{S}$ phase. This is in contrast to precipitation in Al-Cu alloys, where the $\theta^{\prime}$ has a different crystal structure from the equilibrium $\theta$, as well as a distinctly lower solvus. Several researchers ${ }^{18-20}$ have thus discontinued the use of the indication $S^{\prime}$. In the present paper, the term $S^{\prime}$ phase will not be used; instead, the indication 'semicoherent $S$ phase precipitates' is used. The presence of a possible $S^{\prime \prime}$ phase distinct from $S^{\prime} / S$ is controversial.

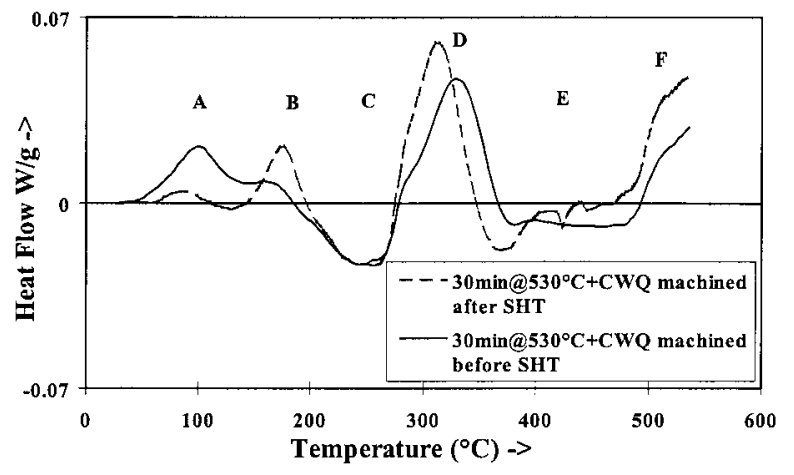

4 Differential scanning calorimetry (DSC) curves of solution treated and cold water quenched (CWQ) 8090 (Al$\mathrm{Li}-\mathrm{Cu}-\mathrm{Mg}$ ) alloy, machined before and after solution heat treatment (SHT): exothermic heat flow on positive $y$ axis (adapted from Ref. 17, in which effect $A$ was interpreted to be due to GPB zone formation, B due to $\delta^{\prime}$ phase formation, C due to dissolution of $\delta^{\prime}$ phase and zones, $D$ is due to $S /$ semicoherent $S$ phase formation, $E$ is due to $S$ phase dissolution, $F$ is due to a surface reaction)

$\delta^{\prime}\left(\mathrm{Al}_{3} \mathrm{Li}\right)$, while formation of the structures often termed Guinier-Preston-Bagaryatski (GPB) zones appeared to be very much reduced (see Fig. 4). (Guinier-Preston and Guinier-Preston-Bagaryatski zones are structures that are fully coherent with the matrix and harden the alloy, but have a limited stability, dissolving at a temperature about $200-300 \mathrm{~K}$ lower than the stable precipitate phases. ${ }^{21}$ ) The changes in precipitation resulting from grinding and punching are generally believed to be caused by the introduction of dislocations in the sample, which in turn can reduce vacancy concentrations due to annihilation of vacancies on the dislocation. The reduction in GPB zone formation was interpreted as being due to a reduced vacancy concentration, which reduces both the stability of the zones and the diffusion rates of $\mathrm{Cu}$ and $\mathrm{Mg}$ atom migration to the zones. The enhanced $\mathrm{S}$ phase formation was interpreted as being due to an increased density of dislocations and $\delta^{\prime}$ precipitates, both of which act as nucleation sites for $\mathrm{S}$ phase. The enhancement of $\delta^{\prime}$ formation by the presence of dislocations generated either by grinding and punching after heat treatment or, in the case of an $8090 / 20$ wt- $\%$ SiC metal matrix composite (MMC), by misfitting $\mathrm{SiC}$ particles, is consistent with various observations in the literature. ${ }^{22,23}$ The mechanisms for this are not well understood, but it was suggested that $\delta^{\prime}$ formation occurs via the formation of a short range ordered (SRO) state and that the presence of this $\delta^{\prime}$ precursor in monolithic Al-Li based alloys retards the subsequent formation of the $\delta^{\prime}$ phase. ${ }^{24}$

For Al-Li based alloys, Li loss in the surface layers of solution treated specimens may be expected to influence the DSC curves. The DSC curves in Fig. 5 were obtained from 8090 samples machined before solution heat treatment at $530^{\circ} \mathrm{C}$, but with varying thickness and solution treatment time in order to demonstrate the effect of varying Li depletion. The curves are of similar shape with the effects occurring at approximately the same temperatures. However, the magnitudes of effects A-D appear to decrease in the following order: standard thickness $(0.8 \mathrm{~mm})$ and $5 \mathrm{~min}$ at $530^{\circ} \mathrm{C}$, standard 


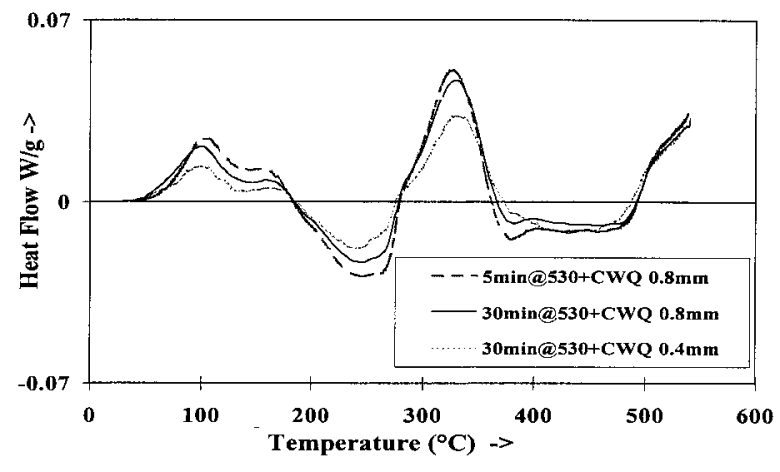

5 DSC curves of 8090 samples machined prior to solution treatment and quench, with varying thickness and solution treatment time: exothermic heat flow on positive $y$ axis (adapted from Ref. 17)

thickness and $30 \mathrm{~min}$ at $530^{\circ} \mathrm{C}$, half thickness and $30 \mathrm{~min}$ at $530^{\circ} \mathrm{C}$. The heat content of the $\delta^{\prime}$ formation effect in these specimens decreases with increasing volume fraction of Li depleted layer, indicating that this effect can be accounted for by Li loss. Interestingly, the magnitudes of the GPB zone and S formation effects also decrease with increasing $\mathrm{Li}$ loss. A convincing explanation for this has proved elusive, although it has been noted that the charge in GPB zone heat effect might be caused by Li being incorporated in GPB zones.

In studies of heat treatable solution treated alloys that are sensitive to quenching rate, sample preparation can further influence calorimetric analysis through the thickness of the specimen influencing the quenching rates. Thus, thin samples machined before solution treatment will experience a high quenching rate, which can cause relatively high precipitation rates during subsequent thermal analysis. If calorimetry samples are machined from larger blocks of quenched material, the lower quenching rates experienced can reduce the subsequent precipitation rates during thermal analysis, provided the material is substantially quench sensitive in the quench rate regime considered.

Taken together, the results indicate that sample preparation can have a marked influence on precipitation effects in the DSC. Especially the introduction of dislocations and the loss of alloying elements during solutionising of the samples are by-products of sample preparation that need to taken into account when deciding on the means of sample preparation, and comparison and analysis of DSC data.

\section{Baseline correction in calorimetry} Initial transient

Although modern isothermal calorimeters and DSCs are reliable instruments that can achieve remarkably high accuracies in measurements of heat evolution, no instrument is perfect and parasitic effects will always occur. In calorimetry, parasitic effects are often induced by disturbances from outside of the measuring cell causing transients in heat flows within the zones where heat evolution from the sample and reference are measured. In the experimental aspects of isothermal calorimetry section above, the transient heat flows that occur on introduction of a sample in a Tian-Calvet type microcalorimeter and on heating a sample in a power compensation type DSC in isothermal mode to the test

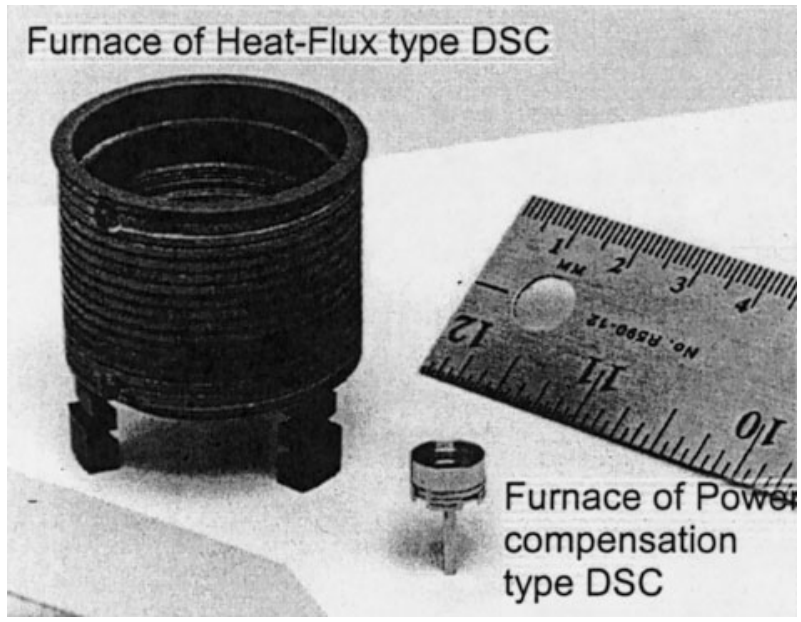

6 Typical furnaces for heat flux DSC and power compensation DSC (figure supplied by Perkin-Elmer)

temperature have already been considered. Differential scanning calorimetry in scanning mode will have an initial transient period in which measurements are unreliable because in the very first phase of the experiment the heating rate will accelerate from zero to the target heating rate. During this phase of accelerating heating, the heat flow is variable (it depends on sample, pan and initial equipment temperature) and measured heat flows are not suited for analysis. In practice, this initial phase of the experiment, which can last approximately from $20 \mathrm{~s}$ to $1 \mathrm{~min}$, is generally disregarded. The duration of this transient is dependent on the thermal mass (heat capacity $\times$ mass) of the sample and oven, with the larger ovens having a larger transient. Power compensation DSCs will in general have a lower thermal mass in the heated parts as compared to heat flux DSCs (Fig. 6). Due to the reduced thermal mass in the oven section, power compensation DSCs have the advantage of a shorter transient. In DSCs with a larger furnace, mass transients of around $1 \mathrm{~min}$ can occur, and at a heating rate of $100 \mathrm{~K} \mathrm{~min}^{-1}$ this would result in a transient stretching over a range of $100 \mathrm{~K}$. Thus, these transients will limit the heating rate that can be used.

\section{Baseline variability and drift}

After the initial transient, reliable calorimetry measurements are possible, provided calorimetry baseline and baseline drift are properly accounted for. In DIC curves, baseline drift results from thermal imbalances between the sample and reference of the calorimeter, causing modest changes in baseline position during the course of an experiment. This drift is mostly negligible for TianCalvet type instruments provided the instrument is placed in a climatised room with stable temperature, but can become significant for smaller instruments when very weak heat evolutions and/or experiments of extremely long duration (many hours) are involved, such as precipitation reactions in Al based alloys. Some methods to correct for loss of early time data during calorimeter instability and baseline drift have been investigated. $^{25,26}$

In analysing linear heating experiments, the baseline of the DSC needs to be carefully considered, as baselines will generally be a temperature and time dependent. ${ }^{27}$ The importance of baseline analysis can be illustrated 
by plotting DSC curves measured using either inert substances as sample and reference or by using no sample at all, and repeating these experiments over an extended period (e.g. several months). This type of work was performed by Zahra and $\mathrm{Zahra}^{27}$ for a Perkin-Elmer 1020 series thermal analysis system, and substantial variations in baseline over the period of a year were identified. Unless the heat flows due to reactions that are to be measured are significantly larger than the variability in the baseline, a correction for the temperature and time dependence of the baseline needs to be carried out. The standard procedure is to perform a DSC run with either empty inert pans, or an inert substance as sample and reference. Such a baseline run should be performed at the heating rate that will be used for the actual experiment with a real sample, and is carried out just before or just after the actual experiment with a real sample. In the post-analysis, the heat flow measured in the baseline run will be subtracted from the heat flow in the experiment on the real sample. The required frequency of baseline runs will be determined by the time dependency of the baseline.

While the above shows the importance of analysing the baseline of DSC curves, there are many examples of publications in which DSC curves are presented without providing an explicit indication of the position of the baseline. Such work is not suitable for a quantitative analysis of the heat flows, but can provide some qualitative information.

Solid state reactions in Al based alloys generally cause relatively small heat effects and thus baseline correction procedures are critical and baselines will need to be checked regularly for these reactions. Solid-liquid and liquid-solid reactions, on the other hand, will generally cause much larger heat flows and baseline correction is less important, or can even be omitted.

Even though the baseline correction procedure will, in many cases, be able to correct for baseline variation, this procedure is sometimes not sufficient to correct for all spurious effects when very small heat effects are being studied.

\section{Combined baseline variability and heat capacity effects in DSC}

Especially for solid state reactions in Al based alloys, the heat effects due to reactions will be of the same order of magnitude or smaller than heat effects due to the heat capacity difference of sample and reference. Thus, if the heat effects due to the solid state reactions are to be studied, a correction for the heat effect due to heat capacity difference will need to be performed. In principle, the heat effects due to the heat capacity difference of sample and reference can be calculated on the basis of the weights and a weighted average of heat capacities of the elements part of the alloy. In practice, however, this cumbersome procedure is often avoided, and the heat capacity effects are corrected for in conjunction with the baseline variability. This is possible because the heat capacity of $\mathrm{Al}$ in the solid state is, in good approximation, a linear function of the temperature. Hence, if the baseline of the DSC apparatus is a linear function of the temperature, the combined effect of the baseline variability and heat capacity is also a linear function, and correction for both contributions to the DSC signal can be corrected for by subtracting a linear function. If two well-spaced temperatures on the DSC curve where no reactions occur can be identified, the linear correction function is readily obtained. Unless a reaction occurs immediately on starting the DSC run, one of these points is often readily defined as the point where the DSC first reaches a stable heating rate, e.g. a few tens of degrees beyond the start of heating. A second point will need to be taken at the point where a reaction has completed. If baselines are second order polynomial functions, a similar procedure can be followed, but now three sections where no reaction occurs will need to be identified.

While a more or less accurate determination of the baseline is generally possible, it should be noted that the procedures always leave some residual error which can be negligible or significant in comparison to the effects that are measured. Uncertainties concerning the position of the baseline can occur particularly for materials in which reactions take place over the whole of the measured DSC curve, or materials in which heat effects due to reactions are small as compared to baseline variability.

\section{Applications of thermal analysis for Al based alloys}

Using DSC, a range of materials properties and reactions can be studied. In the present section, several of these measurements and materials properties are considered, focusing especially on applications for $\mathrm{Al}$ based alloys.

\section{Identification of thermal effects}

In subsequent sections, it will be shown that calorimetry is a very valuable and efficient technique to analyse a number of reactions that occur in Al based alloys. However, before these applications are considered, attention should first be given to how the reaction that occurs during a calorimetry experiment and the phases involved in it can be identified. As a calorimetry experiment in itself cannot identify the phases involved in the reactions, other techniques, such as (high resolution) electron microscopy and (electron) diffraction, should be used to identify these phases. To identify the phase changes unambiguously one would heat treat a sample to a condition that corresponds to the start of the thermal effect and a second sample would be heat treated to a condition that corresponds to the end of the thermal effect, and preferably further samples would be heat treated to intermediate stages. In this procedure, samples will generally be rapidly quenched once the heat treatment is completed. (Unless a slow cooling experiment is the specific objective of the calorimetry study.) These samples would then be analysed using a technique that provides conclusive information on the phases suspected to be involved in the reaction. For example, precipitation reactions would generally be identified using atom probe analysis, high resolution transmission electron microscopy (HREM), or transmission electron microscopy (TEM) with selected area diffraction (SAD) and/or chemical analysis, for instance, by electron dispersive X-ray spectroscopy (EDS). Several of these studies have been reported. ${ }^{28-32}$ Recrystallisation is mostly evidenced by using high resolution scanning electron microscopy (SEM) in combination with electron 

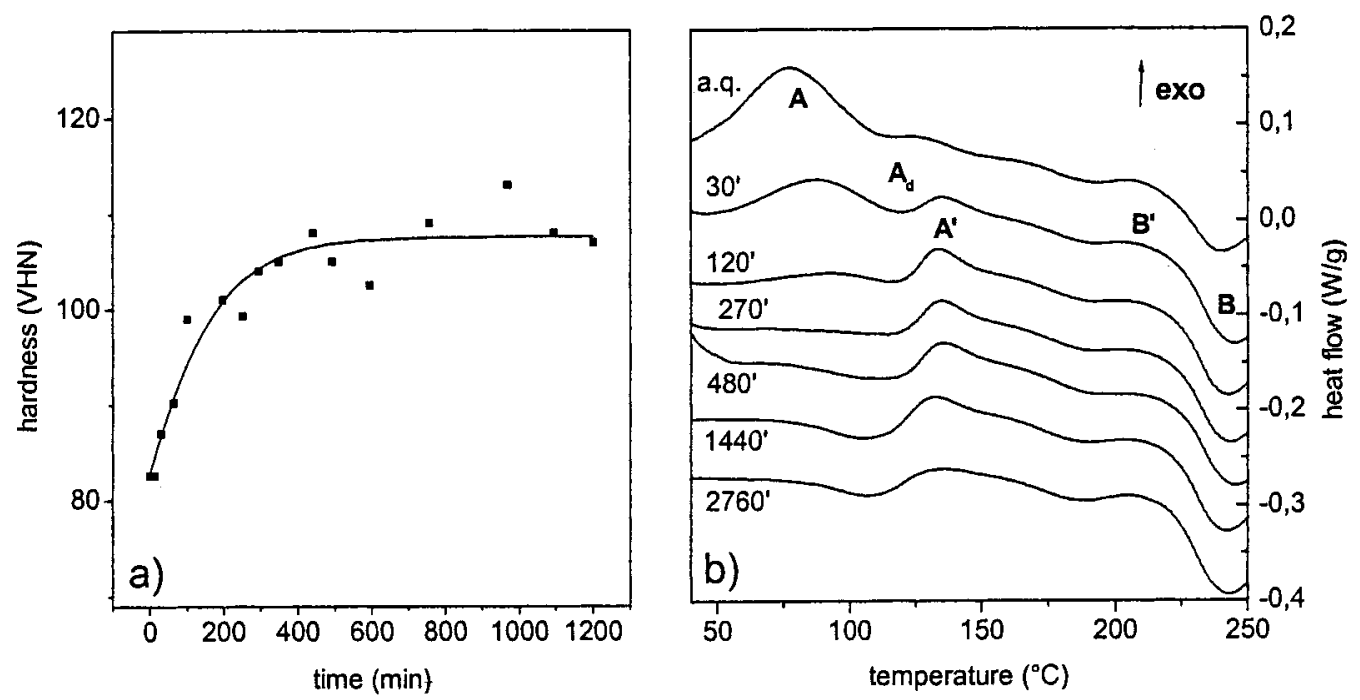

7 a Hardness and $b$ DSC traces from as quenched (a. q.) and room temperature aged (times on traces in minutes) high purity $\mathrm{Al}-4 \cdot 4 \mathrm{Cu}-1 \cdot 7 \mathrm{Mg}$ (wt-\%) alloy samples (from Ref. 33): DSC traces show low temperature cluster/GPB zone formation and their subsequent dissolution; $A, A_{d}$, B, etc. highlight several peaks (see Ref. 33)

backscatter diffraction (EBSD); crystallisation and devitrivication is best evidenced by X-ray diffraction; and nanocrystallisation is evidenced by TEM with SAD. Melting reactions can often be indirectly evidenced by studying eutectic structures in a sample that is rapidly solidified by quenching after having (partially) melted, using SEM (possibly in combination with EDS).

While the above procedures are vital to conclusively identify phases involved in reactions detected by calorimetry, many published works on calorimetric analysis of metals do not contain a detailed microstructural analysis and many do not contain any direct microstructural analysis at all. Instead, a range of other, indirect, approaches have been used to tentatively identify reacting phases. These unproven interpretations should be approached with caution.

One example of a contested interpretation is that of the exothermic effect at about $60-100^{\circ} \mathrm{C}$ that occurs in DSC scans of quenched $\mathrm{Al}-\mathrm{Cu}-\mathrm{Mg}$ alloys with $\mathrm{Cu}$ and $\mathrm{Mg}$ contents about $1-2$ at.- $\%$ (see Fig. 7). ${ }^{33}$ This reaction is important as it is the cause of the rapid hardening encountered in important $\mathrm{Al}-\mathrm{Cu}-\mathrm{Mg}$ alloys such as the 2024 alloy. Many authors have studied this reaction in DSC and attributed it to so-called GPB zones, but this was mostly achieved without conclusive microstructural evidence. Recently, three-dimensional atom probe (3DAP) analysis of an $\mathrm{Al}-1 \cdot 1 \mathrm{Cu}-1 \cdot 7 \mathrm{Mg}$ (at.- $\%$ ) alloy has indicated ${ }^{18,34,35}$ that GPB zones form much later in the aging process, while SAD in a TEM of a sample heated to the peak of the exothermic effect revealed no evidence of GPB zone formation. Threedimensional atom probe (3DAP) analysis showed that a high density of $\mathrm{Cu}-\mathrm{Mg}, \mathrm{Cu}-\mathrm{Cu}$, and $\mathrm{Mg}-\mathrm{Mg}$ clusters had developed after $5 \mathrm{~min}$ aging at $150^{\circ} \mathrm{C}$, thus strongly suggesting that the exothermic effect is due to the formation of these clusters and not to GPB zones. Other researchers presented HREM data on an $\mathrm{Al}-0 \cdot 87 \mathrm{Cu}-$ $1.44 \mathrm{Mg}$ (at.- $\%$ ) alloy aged for $4 \mathrm{~h}$ at $190^{\circ} \mathrm{C}$ and $4 \mathrm{~h}$ at $200^{\circ} \mathrm{C}$ which was purported to show GPB zones, and this was suggested to support that GPB zones (not clusters) were responsible for the exothermic peak at $60-100^{\circ} \mathrm{C} .^{12,36} \mathrm{But}$, as aging $4 \mathrm{~h}$ at 190 or $200^{\circ} \mathrm{C}$ is considerably different to heating at about $10 \mathrm{~K} \mathrm{~min}^{-1}$ to $100^{\circ} \mathrm{C}$, the latter interpretation has to be considered to be tentative. However, the interpretation in favour of GPB zone formation received support from a DSC and TEM study on quenched $\mathrm{Al}-4 \cdot 4 \mathrm{Cu}-1 \cdot 7 \mathrm{Mg}(\mathrm{wt}-\%)$ aged for $2760 \mathrm{~min}$ at room temperature, which showed evidence for diffraction effects due to GPB zones. ${ }^{33}$ Clearly, the identification of this exothermic effect has not been conclusively established, and DSC work which was not supported by electron microscopy or atom probe work $^{37-40}$ and which tentatively ascribed it to GPB zones still awaits confirmation from further microstructural observations.

\section{Heat capacity determination}

In heat capacity measurement of a material using DSC, a sample of the material to be investigated is placed in the DSC with a reference of known heat capacity $c_{\mathrm{p}, \mathrm{ref}}(T)$. The heat capacity of the sample can then be determined from heat flow $\dot{q}$ from the DSC as ${ }^{41}$

$$
c_{\mathrm{p}, \text { sample }}(T)=\dot{q} \beta+c_{\mathrm{p}, \mathrm{ref}}(T)
$$

where $\beta$ is the heating rate. As heat capacities of many substances are well known, the determination of heat capacity can also be used to calibrate the heat flow measurement in the DSC.

\section{Solid state reactions}

\section{Homogenisation and solution treatment studies}

For heat treatable Al based alloys, the best balance of properties is obtained if the solution treatment is carried out such that a maximum of alloying elements is dissolved, while no melting occurs. Hence, solution treatment is carried out just below the start temperature of incipient melting. In studies of homogenisation and solution treatment of heat treatable Al based alloys, DSC is generally the technique of choice. In these studies, DSC is effective because it provides a rapid assessment of the temperature range for dissolution of soluble phases as well as providing the onset temperature of incipient melting. 

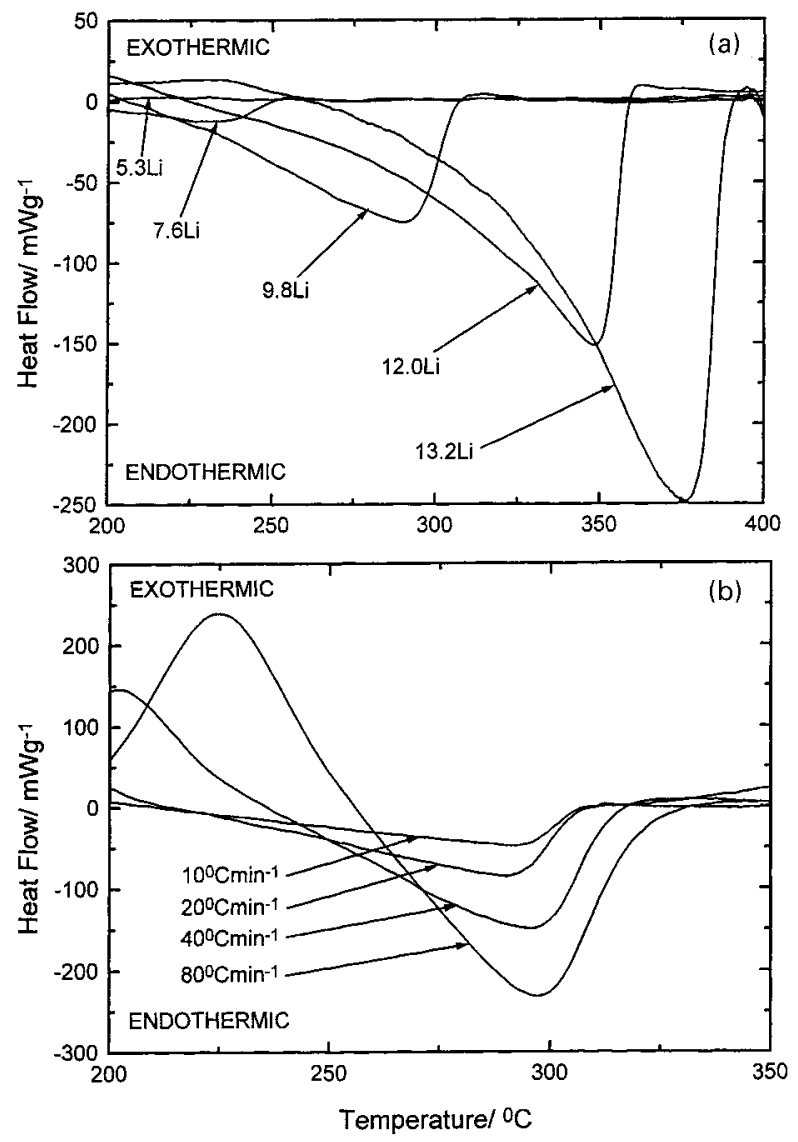

a $\mathrm{Al}-\mathrm{Li}$ (at.-\%) alloys studied at heating rate of $20 \mathrm{~K} \mathrm{~min}^{-1} ; b$ effect of heating rate on DSC thermogram of Al-9.8Li (at.-\%) alloy

8 DSC curves of Al- $\mathrm{Li}$ alloys (exothermic heat flow on positive $y$ axis): heat effects are due to formation and dissolution of $\delta^{\prime}$ phase (from Ref. 42.)

The heat effect due to the dissolution of precipitate phases during DSC experiments can be analysed to yield data on the solvus of the phases, even if those phases are metastable. An example for the determination of the solvus of $\delta^{\prime}\left(\mathrm{Al}_{3} \mathrm{Li}\right)$ precipitates in $\mathrm{Al}-\mathrm{Li}$ alloys is provided by Noble and Bray. ${ }^{42}$ In this work, the dissolution of the $\delta^{\prime}$ is measured for various $\mathrm{Al}-\mathrm{Li}$ alloys at a range of heating rates (Fig. 8). As dissolution is a diffusion process that requires some finite time to be completed, the temperature where the endothermic reaction finishes is an overestimate of the solvus temperature, but by extrapolating the measured solvus temperature to a zero heat rate, the true solvus temperature can be found. The solvus data obtained from DSC were in agreement with data obtained from resistivity measurements and allowed the determination of the solvus of the metastable $\delta^{\prime}$ phase over a range of temperatures.

Dissolution reactions in multicomponent heat treatable $\mathrm{Al}$ alloys can also be analysed to some detail using DSC. Figure 9 shows DSC curves from three $\mathrm{Al}-\mathrm{Zn}-$ $\mathrm{Mg}-\mathrm{Cu}$ alloys with compositions close to those of commercial 7000 type alloys such as 7010. The DSC curves reveal that the three alloys have different temperatures for the onset of incipient melting: one alloy melts from about $480^{\circ} \mathrm{C}$, another from about $490^{\circ} \mathrm{C}$, and the third does not melt below $510^{\circ} \mathrm{C}$. The final stage of dissolution is very different between the three alloys, with for one alloy the dissolution being

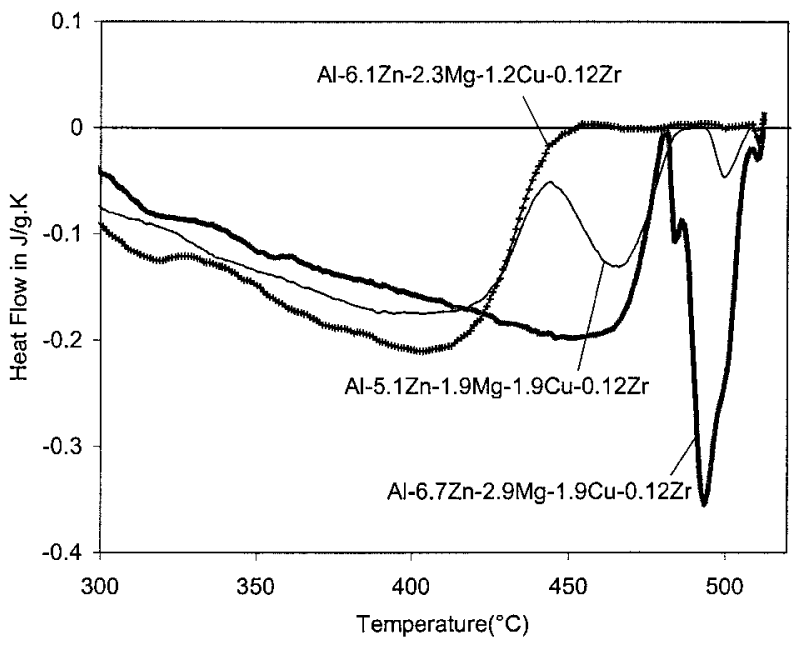

9 DSC curves of Al-Zn-Mg-Cu alloys (wt-\%) revealing differences in last stages of dissolution effect (up to $\sim 475^{\circ} \mathrm{C}$ ) and the onset of melting (from about $475{ }^{\circ} \mathrm{C}$ ): exothermic heat flow on positive $y$ axis (adapted from Ref. 45)

completed at about $440^{\circ} \mathrm{C}$, while for the other two alloys dissolution continues up to about $470-475^{\circ} \mathrm{C}$. The cause for these complex differences lies in the presence of varying amounts of the $\mathrm{S}\left(\mathrm{Al}_{2} \mathrm{CuMg}\right), \eta\left(\mathrm{Mg}(\mathrm{Cu}, \mathrm{Zn})_{2}\right)$, and $\mathrm{T}$ phases that can occur at these temperatures either as equilibrium phase ${ }^{43}$ or as non-equilibrium remnants from the eutectics formed during solidification. This means that the optimal solution treatment temperatures will differ for the three alloys. The effect of particle size on dissolution kinetics has also been studied by DSC. ${ }^{44}$

Analysis of dissolution and (the onset of) incipient melting can also be used to explore optimisation of alloying content. For example, the optimisation of $\mathrm{Zn}$ and $\mathrm{Mg}$ content for 7000 alloys has been explored. ${ }^{45}$ The DSC curves indicate that for an $\mathrm{Al}-6 \cdot 1 \mathrm{Zn}-2 \cdot 3 \mathrm{Mg}-$ $1.9 \mathrm{Cu}-0.12 \mathrm{Zr}$ (wt- $\%$ ) alloy, $\eta$ phase dissolution is completed at about $460^{\circ} \mathrm{C}$, i.e. before the solution treatment temperature or incipient melting temperatures are reached. Hence, provided quench sensitivity is not an issue, there is some scope for increasing the alloying content of the alloy. A reasonable estimate can be obtained directly from the DSC data. For this, the $\eta$ phase dissolution effect was approximated by a triangle, as illustrated in Fig. 10. (Dissolution effects of



10 DSC curves of $\mathrm{Al}-6 \cdot 1 \mathrm{Zn}-2 \cdot 3 \mathrm{Mg}-1 \cdot 9 \mathrm{Cu}-0.12 \mathrm{Zr}$ (wt-\%) alloy aged for $4 \mathrm{~h}$ at $170^{\circ} \mathrm{C}$ after solution treatment, together with approximation of heat of $\eta$ dissolution using triangular heat effect: exothermic heat flow on positive $y$ axis (from Ref. 45) 
equilibrium phases in many $\mathrm{Al}$ based alloys roughly approximate this shape. ${ }^{46,47}$ ) It was estimated

$$
\frac{x_{\mathrm{Zn} \text { (opt.alloy) }}^{\mathrm{g}}}{x_{\mathrm{Zn}(\text { alloyB })}^{\mathrm{g}}}=\frac{\Delta Q_{(\text {opt.alloy })}}{\Delta Q_{(\text {alloyB })}}=\frac{\left(T_{\mathrm{e}(\text { alloyB })}-T_{1}\right)^{2}}{\left(T_{\mathrm{ST}}-T_{1}\right)^{2}}
$$

where $x_{\mathrm{Zn} \text { (opt.alloy) }}^{\mathrm{g}}$ and $x_{\mathrm{Zn} \text { (alloyB) }}^{\mathrm{g}}$ are the gross $\mathrm{Zn}$ content of the optimised alloy and the alloy in Fig. 10 respectively, $\Delta Q$ is the integrated evolved heat, $T_{\mathrm{ST}}$ is the solutionising temperature, and $T_{\mathrm{e}}$ and $T_{1}$ are defined in Fig. 10. Using $T_{\mathrm{ST}}=475^{\circ} \mathrm{C}$, this estimate indicates that both the $\mathrm{Zn}$ and $\mathrm{Mg}$ content can be increased by about $12 \%$. However, it should additionally be considered that $\mathrm{Mg}$ (and $\mathrm{Cu}$ ) content should remain below the $\mathrm{S}$ phase solvus, and hence $\mathrm{Cu}, \mathrm{Mg}$, and $\mathrm{Zn}$ composition should be limited. Thus, in order to optimise the balance of properties, alloy compositions around $\mathrm{Al}-7 \mathrm{Zn}-2 \cdot 3 \mathrm{Mg}-$ $1.7 \mathrm{Cu}(\mathrm{wt}-\%)$ should be considered. If processing can be carried out such that incipient melting below $490^{\circ} \mathrm{C}$ is avoided, the solution treatment temperature can be increased (to about $485^{\circ} \mathrm{C}$, providing a safety margin of about $5 \mathrm{~K}$ ), and alloying content can be further increased.

Apart from the dissolution effect itself, the subsequent melting of intermetallic phases also provides information on the progress of homogenisation and solution treatment, because the magnitude of these incipient melting effects increases with increasing amount of intermetallic phase present. Lasa and Rodriguez-Ibabe ${ }^{48}$ used this to study the homogenisation of two $\mathrm{Al}-\mathrm{Si}-\mathrm{Cu}-$ $\mathrm{Mg}$ alloys with very similar compositions that were cast using different procedures. The DSC curves of a conventionally cast $\mathrm{Al}-12 \mathrm{Si}-4 \cdot 4 \mathrm{Cu}-1 \cdot 3 \mathrm{Mg}(\mathrm{wt}-\%)$ ingot sample and a thixoformed $\mathrm{Al}-15 \mathrm{Si}-4 \cdot 4 \mathrm{Cu}-0 \cdot 6 \mathrm{Mg}(\mathrm{wt}-\%)$ alloy heat treated for various times at $500^{\circ} \mathrm{C}$ all show a melting effect with onset temperatures between about 507 and $511^{\circ} \mathrm{C}$ (Fig. 11). These endothermic effects were ascribed to the reaction ${ }^{48,49}$

$$
\alpha(\mathrm{Al})+\mathrm{Si}+\mathrm{Al}_{2} \mathrm{Cu}+\mathrm{Al}_{5} \mathrm{Mg}_{8} \mathrm{Cu}_{2} \mathrm{Si}_{6} \rightarrow \text { Liquid }
$$

with a possible small contribution from the reaction

$$
\mathrm{Al}+\mathrm{CuMgAl} l_{2}+\mathrm{Al}_{2} \mathrm{Cu} \rightarrow \text { Liquid }
$$

The total heat content was used as a measure of the amount of $\mathrm{Al}_{2} \mathrm{Cu}$ present after homogenisation, and thus the DSC data indicate that for the conventionally cast alloy at least $2 \mathrm{~h}$ were necessary to achieve the maximum amount of dissolution of $\mathrm{Al}_{2} \mathrm{Cu}$ and achieve equilibrium. The curves obtained for the thixoformed alloy show that the dissolution of $\mathrm{Al}_{2} \mathrm{Cu}$ was much faster in this alloy. This was probably due to the finer $\mathrm{Al}_{2} \mathrm{Cu}$ particle size found in this alloy after thixoforming, and $0.5 \mathrm{~h}$ at $500^{\circ} \mathrm{C}$ was almost enough to reach equilibrium. For further analysis, see 'Volume fraction of intermetallic phases measured from solid-liquid reactions' below.

\section{Precipitation studies - qualitative analysis}

Differential scanning calorimetry and isothermal calorimetry are used extensively to study precipitation reactions in heat treatable Al based alloys. Recent work has focused on quench sensitivity of precipitation hardened alloys, ${ }^{50-52}$ the effect of room temperature (pre-)aging and the formation of clusters and zones, ${ }^{33,53-55}$ the heat affected zone in welds, ${ }^{56,57}$ influence of thermal shock on
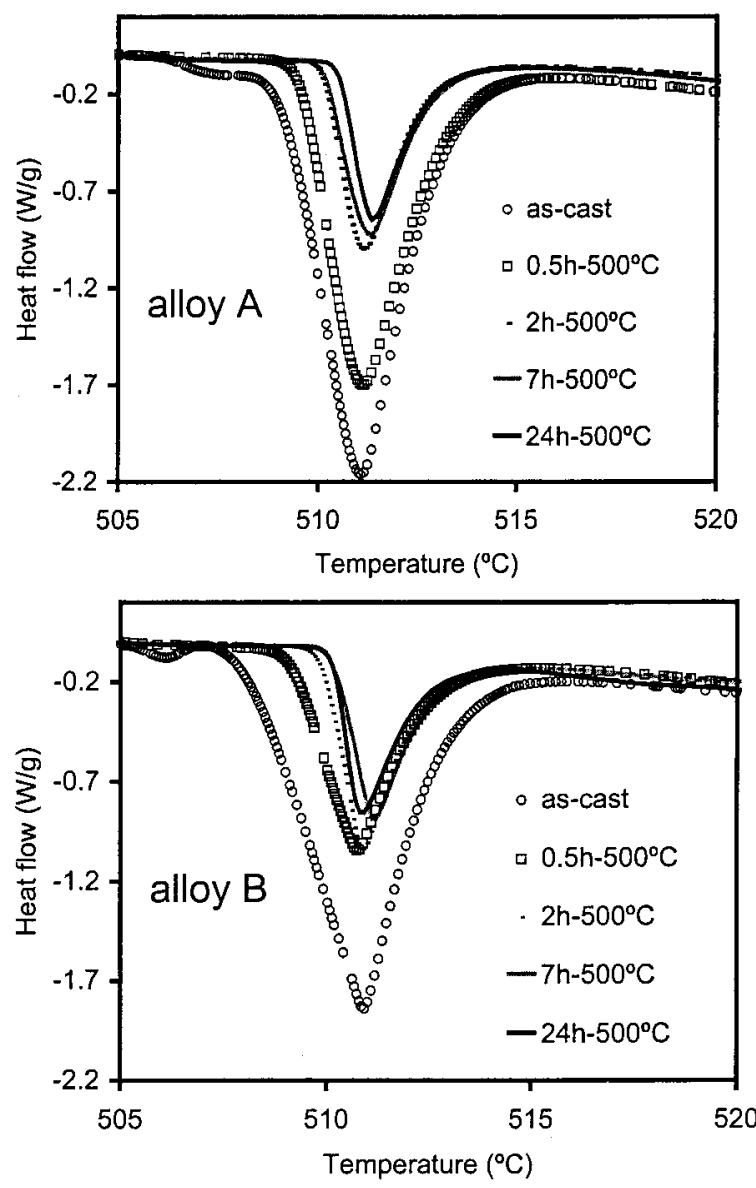

11 Part of DSC curves of conventionally cast Al-12Si4.4Cu-1-3Mg (wt-\%) ingot sample (alloy $A$ ) and thixoformed Al-15Si-4-4Cu-0.6Mg (wt-\%) alloy (alloy B) showing incipient melting: exothermic heat flow on positive $y$ axis (from Ref. 48)

precipitation, ${ }^{58}$ and influence of microalloying on precipitation. ${ }^{59}$ Following on from the extensive work on Al based MMCs in the 1980s and 1990s, the influence of the addition of ceramic reinforcement on precipitation has continued to be extensively studied by DSC. ${ }^{60-63}$ In this section, the main aspects of qualitative analysis are described, with an overview of aspects of detailed quantitative analysis being presented in subsequent sections.

In precipitation studies using thermal analysis, it should be borne in mind that precipitation can occur before, during, and after the thermal analysis experiment, and hence the measurement follows only a portion of the process that is studied. In practice, this leads to two different strategies of thermal analysis studies of precipitation. If an alloy is solution treated and quenched and then isothermal calorimetry or DSC is performed immediately after quenching, the main objective will be the study of the precipitation reactions from their start, i.e. the aim will be to study precipitation from start to finish in the calorimeter. However, if the alloy is solution treated, quenched, and then aged before the DSC or calorimetry experiment, mostly being studied will be the further transformations of a precipitate structure that has been formed before the calorimetry experiment is started. In the former case, the first reaction will be exothermic and, in the latter case, 


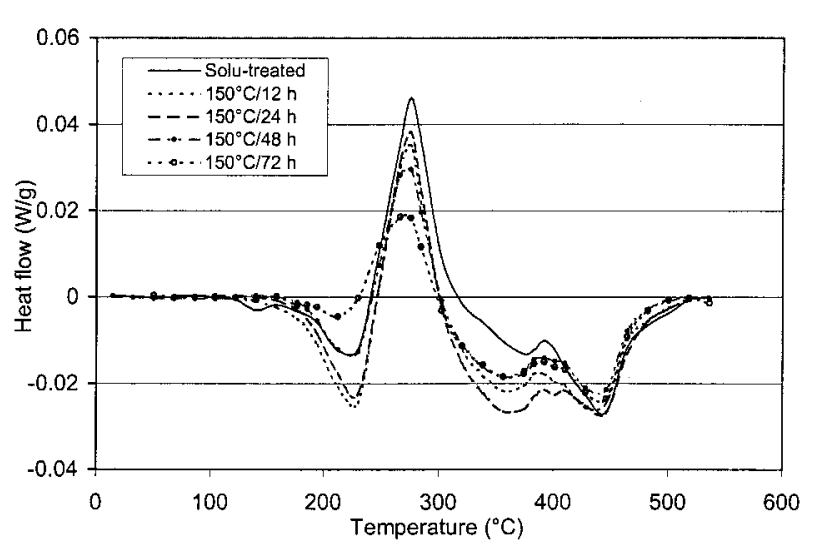

12 DSC curves of solution treated and stretched Al$1 \cdot 18 \mathrm{Cu}-0.51 \mathrm{Mg}-0.21 \mathrm{Mn}$ (at.-\%) alloy aged for various times at $150^{\circ} \mathrm{C}$ : exothermic heat flow on positive $y$ axis (from Ref. 64)

the first reaction to occur can be either exothermic or endothermic, depending on the state of precipitation at the start of the calorimetry experiment and the temperature (range) at which it is performed.

In isothermal calorimetry work, one would usually aim to start the experiment as soon as possible after quenching and aim to measure the heat evolution during as much of the transformation as can practically be achieved. An example of an isothermal calorimetry study is provided in Fig. 2, which shows isothermal calorimetry data of precipitation in an $\mathrm{Al}-\mathrm{Si}$ alloy. In DSC studies of precipitation, one can also perform experiments that are started immediately after completion of the quench. If experiments are limited to just this, only a limited insight into processes occurring during isothermal aging would be obtained because limitations on heating rate would mean that only relatively fast processes can be studied. For example, if a reaction would occur only at temperatures below $200^{\circ} \mathrm{C}$ and that reaction would occur after isothermal aging for at least $2 \mathrm{~h}$ in the temperature range $100-200^{\circ} \mathrm{C}$, then that reaction would not occur during the DSC experiment, because DSC would scan through that range typically in $1 \mathrm{~min}$ to $1 \mathrm{~h}$. For this reason, a detailed DSC study of precipitation will generally involve multiple DSC experiments on samples that have received a range of aging treatments. An example involving the aging of a solution treated, stretched and subsequently first naturally aged (for several months) and then artificially aged $\mathrm{Al}-\mathrm{Cu}-\mathrm{Mg}$ alloy is shown in Fig. 12. These thermograms show that during the final aging for $12-72 \mathrm{~h}$ at $150^{\circ} \mathrm{C}$, the endothermic effect in the range $120-240^{\circ} \mathrm{C}$ due to cluster/zone dissolution first increases and subsequently decreases, whereas the exothermic effect in the range $240-300^{\circ} \mathrm{C}$ due to $\mathrm{S}$ phase formation continuously decreases. This allows a quantitative or semiquantitative assessment of the formation and/or dissolution of zones/clusters and S phase. ${ }^{64}$ This type of assessment of precipitation by DSC on pre-aged samples has found wide application. ${ }^{65-67}$

\section{Determination of thermal history/fingerprinting of heat treated alloys}

The use of DSC for determination of thermal history of a heat treated alloy, is an application that is closely

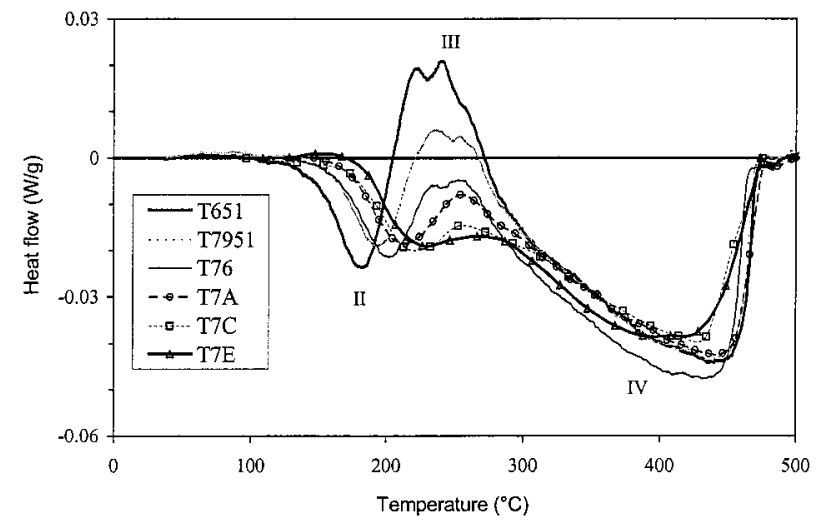

effect II: mostly $\eta^{\prime}$ dissolution and dissolution of fine $\eta$; effect III: precipitation and coarsening of $\eta$; effect IV: mostly dissolution of $\eta$

13 DSC curves at heating rate of $10 \mathrm{~K} \mathrm{~min}^{-1}$ of solution treated and aged samples of 7449 (Al-Zn-Mg-Cu-Zr) alloy: T651 is peak aged and T7951-T7E represent aging treatments with increasing overaging: exothermic heat flow on positive $y$ axis (adapted from Ref. 69)

related to the precipitation studies described in the previous section. The difference is that in determination of thermal history the aim is not to study the nature of the reactions that cause the heat effects in detail, but rather to use the DSC as a tool for investigating a sample that has undergone an unknown or ill defined heat treatment. The application of this technique can be found in quality control of aging treatments, e.g. in verification of industrial heat treatments, and in this case the application is sometimes termed DSC fingerprinting. ${ }^{67,68}$ Another application is in assessing heat treatments that parts of materials that are inaccessible for recording of temperature history have undergone. An example of the latter is the study of heat affected zones in welds of heat treatable Al based alloys. ${ }^{56}$

For an alloy in which a multistage aging sequence occurs, the DSC curve will generally be complex, containing several endothermic and exothermic effects. In the course of the heat treating of an alloy in which a multistage aging sequence occurs, the DSC curve will change in a complex manner, an example of this is provided in Fig. 13 for an 7449 alloy heat treated to various commercially applied and non-commercial treatments. ${ }^{69}$

\section{Precipitate coarsening - qualitative analysis}

The kinetics of precipitation and dissolution reactions in heat treatable Al based alloys will in general depend on the size of the precipitates, and thus DSC is sensitive to size of precipitates. The exothermic heat effect due to coarsening is caused by two factors. First, the reduction of precipitate/matrix interfacial area will reduce the total interfacial area of the system, and, second, the reduction of the interfacial energy per precipitate will reduce the metastable solubility of elements dissolved in the matrix, thus allowing an increase in the volume fraction of precipitates. The latter is described by the GibbsThompson-Freundlich relation, which gives the ratio between the equilibrium concentration of solute in the matrix $c_{\mathrm{m}, \text { eq }}$ and the metastable solubility in the vicinity 


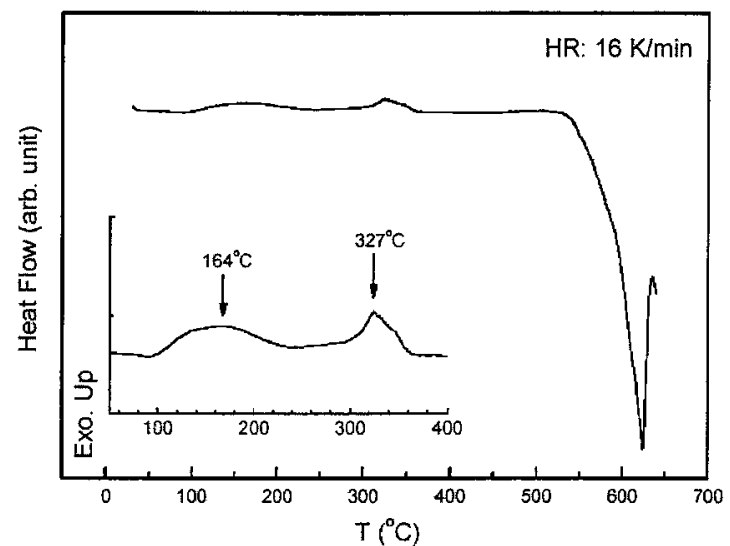

14 DSC curves for as milled Al-6.9Mg (wt-\%) alloy (16 $\mathrm{K} \mathrm{min}^{-1}$ heating rate): inset is enlarged portion of DSC curve (from Ref. 73.)

of a spherical particle $c_{\mathrm{m}}$ as

$$
\frac{c_{\mathrm{m}}}{c_{\mathrm{m}, \mathrm{eq}}}=\exp \left(\frac{2 \gamma V_{\mathrm{m}}}{R T r_{\mathrm{p}}}\right)
$$

where $\gamma$ is the interfacial energy, $r_{\mathrm{p}}$ is the particle radius, $V_{\mathrm{m}}$ is the atomic volume of the particles, and $R$ is the gas constant. However, due to small heat effects involved, it is often difficult to perform meaningful analyses of coarsening of precipitates in Al based alloys using DSC. It should also be noted that evidencing coarsening involves the measurement of change of sizes and volume fractions of precipitates, for example by TEM. Especially the change in volume fraction can be small and difficult to determine reliably, and thus evidencing all the factors influencing the heat effects due to coarsening can be difficult, certainly in comparison with reactions that involve phase changes.

In DSC studies on peak aged and overaged samples of a $7050 \mathrm{Al}$ based alloy $(\mathrm{Al}-6 \cdot 45 \mathrm{Zn}-2 \cdot 1 \mathrm{Mg}-2 \cdot 15 \mathrm{Cu}$ (wt- $\%) ; \quad \mathrm{Al}-2 \cdot 8 \mathrm{Zn}-2 \cdot 45 \mathrm{Mg}-0.95 \mathrm{Cu} \quad($ at. $-\%))^{70}$ and a range of other $\mathrm{Al}-\mathrm{Zn}-\mathrm{Mg}-\mathrm{Cu}$ based alloys, ${ }^{45,69,71,72}$ it was observed that with increasing overaging the peak and end temperature of the endothermic dissolution peak of the main strengthening precipitates (effect II in Fig. 13) shift to higher temperatures, while the start is about constant and equal to the prior aging temperature $\left(170^{\circ} \mathrm{C}\right)$. One study ${ }^{71}$ considered that this change in effect II was directly related to coarsening, but in another work $^{72}$ it was suggested that the changes in the DSC curves are caused by a reduction in the size of effect III, which was ascribed to the exothermic coarsening reaction, implying that the underlying dissolution reactions (effects II and IV) remain largely unchanged. With no direct microstructural evidence of the evolution of precipitate volume fractions and sizes during linear heating available, there is no conclusive evidence to support either interpretation. In these works, the coarsening reaction was used to quantitatively explain the change in strength on overaging.

\section{Defect annihilation, recovery and recrystallisation in wrought alloys}

An example of a DSC study on a deformed non-heattreatable alloy is the work on a nanocrystalline Al7.6at.- $\% \mathrm{Mg}(\mathrm{Al}-6 \cdot 9 \mathrm{wt}-\% \mathrm{Mg})$ alloy powder that was

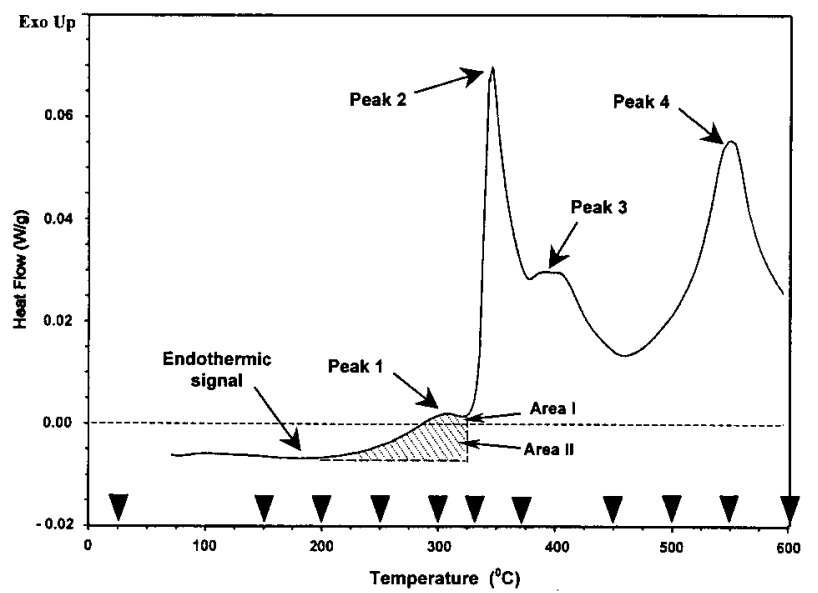

peak 1: recovery; peak 2, 3, 4: formation (precipitation) of intermetallic phases $\mathrm{Al}_{6} \mathrm{Fe}, \mathrm{Al}_{3} \mathrm{Ti}$, and $\mathrm{Al}_{13} \mathrm{Cr}_{2}$ (and possibly $\mathrm{Al}_{13} \mathrm{Fe}_{4}$ ), respectively

15 Non-reversing heat flow from modulated DSC experiments on as milled $\mathrm{Al}_{93} \mathrm{Fe}_{3} \mathrm{Ti}_{2} \mathrm{Cr}_{2}$ alloy powder in hermetic Al pan with heating rate of $2 \mathrm{~K} \mathrm{~min}^{-1}$ (from Ref. 74.)

produced by ball milling at liquid nitrogen temperatures ('cryomilling'). ${ }^{73}$ The DSC curve of this powder (Fig. 14) shows two relatively small exothermic effects prior to the occurrence of melting from about $530^{\circ} \mathrm{C}$. As X-ray diffraction (XRD) analysis of the ball milled samples after aging at $230^{\circ} \mathrm{C}$ had shown a significant reduction in lattice strain, the first exothermic effect between 100 and $230^{\circ} \mathrm{C}$ was ascribed to recovery (the removing and clustering of dislocations) and elimination of twins. The second effect, between 300 and $360^{\circ} \mathrm{C}$ was ascribed to recrystallisation.

For heat treatable Al based alloys, the heat effects due to vacancy annihilation, recovery and recrystallisation are generally much smaller than heat effects due to precipitation or dissolution of precipitates, and they generally occur in overlapping temperature ranges. Hence, the exothermic heat effects due to vacancy annihilation, recovery and recrystallisation can often not be determined in heat treatable $\mathrm{Al}$ based alloys. In deformed $\mathrm{Al}$ alloys for which no precipitation or dissolution reactions occur (pure Al or dilute nonheat-treatable alloys) recovery and recrystallisation might be detectable in DSC.

Modulated differential scanning calorimetry (MDSC) has also been applied to reveal recovery in the mechanically alloyed $\mathrm{Al}_{93} \mathrm{Fe}_{3} \mathrm{Ti}_{2} \mathrm{Cr}_{2}$ alloy in the as milled condition (see Fig. 15). ${ }^{74}$ It was indicated by TEM and XRD that this as milled material is composed of an Al based supersaturated solid solution with high internal strains. With the aid of XRD, the DSC curve has been interpreted as revealing recovery (effect 1 ) and formation (precipitation) of intermetallic phases $\mathrm{Al}_{6} \mathrm{Fe}$, $\mathrm{Al}_{3} \mathrm{Ti}$ and $\mathrm{Al}_{13} \mathrm{Cr}_{2}$ (and possibly $\mathrm{Al}_{13} \mathrm{Fe}_{4}$ ) (effects 2, 3, and 4 ).

\section{Devitrivication; nanocrystallisation}

Aluminium based alloys containing transition metals and rare earth elements are candidates for the development of ultrafine grained (nanostructured) materials. The achievement of such a microstructure depends on 


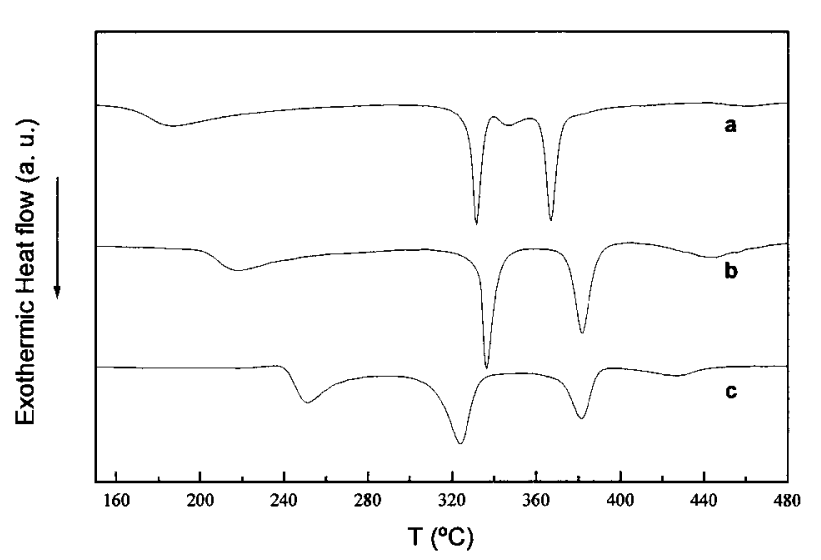

curve a: $\mathrm{Al}_{90} \mathrm{Ni}_{4} \mathrm{Sm}_{6}$; curve b: $\mathrm{Al}_{88} \mathrm{Ni}_{6} \mathrm{Sm}_{6}$; curve c: $\mathrm{Al}_{88} \mathrm{Ni}_{4} \mathrm{Sm}_{8}$ (all curves show three exothermic heat effects)

16 DSC curves (40 K min $\mathrm{K}^{-1}$ heating rate) of amorphous Al-Ni-Sm alloys (from Ref. 82)

the processing conditions and may be achieved by controlled heat treatment of amorphous alloys. The amorphous and nanostructured alloys show different (usually enhanced) physical, chemical, and mechanical properties from those of either the conventional polycrystalline or amorphous state, including a high strength $(1500 \mathrm{MPa})$ and excellent high strength/weight ratio. Differential scanning calorimetry has proved to be the most effective method for characterising the kinetics of devitrivication including the nanocrystallisation in these amorphous alloys and is applied in a large number of studies, ${ }^{75-80}$ although isothermal calorimetry has also been applied. ${ }^{81}$

An instructive application of DSC to the study of devitrivication is the work by Gich et al. ${ }^{82}$ on the devitrivication of a range of rapidly solidified amorphous Al-Ni-Sm ternary alloys. The DSC curves of three of the alloys are shown in Fig. 16, and these curves show three exothermic effects that have been ascribed to the following reactions

\section{A: amorphous $\rightarrow \alpha-\mathrm{Al}+$ amorphous $^{\prime}$ \\ (primary crystallisation) \\ B: amorphous ${ }^{\prime} \rightarrow \alpha-\mathrm{Al}+$ intermatallic phases \\ (eutectoid crystallisation) \\ $\mathrm{C}$ : transformation of intermetallic phases}

where amorphous' signifies the amorphous phase with increased alloying content, resulting from the rejection of alloying elements from the $\alpha$-Al phase. ${ }^{83}$ In fact, this identification of these three types of reaction on heating of amorphous $\mathrm{Al}$ based alloys is common to many amorphous $\mathrm{Al}$ based alloys. The types of intermetallic phases formed are dependent on the alloying additions; for example, in the Al-Ni-Sm ternary alloys shown in Fig. 16, intermetallic phases were identified as $\mathrm{Al}_{3} \mathrm{Sm}$ (formed in reaction $\mathrm{B}$ ) and $\mathrm{Al}_{11} \mathrm{Sm}_{3}$ (formed in reaction C). The temperature ranges of the heat effects as well as the activation energies (see subsection 'Measured activation energies in Al based alloys' below) depend strongly on the composition, revealing how composition affects the relative stability of the amorphous, the nanocrystalline, and the intermetallic phases.

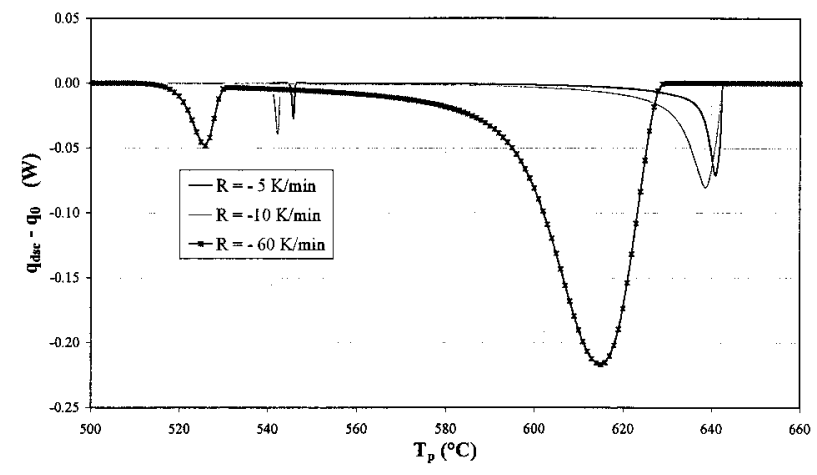

17 DSC curves of solidification of $\mathrm{Al}-4 \cdot 5 \mathrm{Cu}$ (wt-\%) alloy at cooling rates of 5,10 , and $60 \mathrm{~K} \mathrm{~min}^{-1}$ (from Ref. 91)

\section{Multilayers and interfacial reactions}

Differential scanning calorimetry has been applied to the study of reactive diffusion in metallic multilayers containing Al layers, a detailed overview of experimental procedures and of pre-1997 work is provided by Michaelsen et al..$^{7}$ The evolution of microstructure and the associated transformation kinetics in reacting thin films, and particularly transition metals and Al polycrystalline thin films, are highly relevant to the semiconductor industry where such reactions occur in the production of integrated circuits. Layered systems studied by calorimetry include: $\mathrm{Nb} / \mathrm{Al},{ }^{84,85} \mathrm{Ti} / \mathrm{Al},{ }^{86} \mathrm{Ni} / \mathrm{Al},{ }^{87} \mathrm{Zr} / \mathrm{Al},{ }^{7}$ and $\mathrm{Co} / \mathrm{Al}{ }^{88}$ Isothermal calorimetry and DSC have been employed to study the reaction between ceramic reinforcements and $\mathrm{Al}$ matrix in $\mathrm{Al}$ based composites. ${ }^{89,90}$

\section{Solid-liquid and liquid-solid reactions Solidification}

In studies of solidification of Al based alloys, DSC or DTA performed at constant cooling rate is often a key technique. With DSC, it is possible to track the solidification process, by virtue of the large endothermic heats produced by the liquid-solid transformation. For pure $\mathrm{Al}$, the heat effect due to solidification will be a sharp exothermic peak starting at a temperature below the equilibrium melting temperature. The difference between liquidus and onset of solidification $\Delta T$ is the undercooling, which is an important factor determining the microstructure of the solidified alloy. An illustration of an application of DSC to a relatively simple binary $\mathrm{Al}$ based alloy, is the study of solidification in an $\mathrm{Al}-4 \cdot 5 \mathrm{Cu}$ (wt-\%) alloy by Larouche et al. ${ }^{91}$ The DSC curves for cooling at different rates, shown in Fig. 17, reveal the solidification of the $\mathrm{Al}$ rich phase, which occurs mostly between 643 and $600^{\circ} \mathrm{C}$, and is dependent on cooling rate. With the eutectic temperature being located at $547^{\circ} \mathrm{C}$, the reactions occurring just below that temperature are the solidification of the eutectic.

The influence of preparation of the melt on solidification of Al-Sr alloys was studied by Zhang et al. ${ }^{92} \mathrm{In}$ their work, the solidification of two Al-10Sr (wt- $\%$ ) alloys, one prepared by molten salt electrolysis and one prepared by a direct mixing method were investigated. The resulting DSC curves, shown in Fig. 18, reveal that the undercooling at which solidification starts is significantly different for the two alloys, and this was shown to correspond to a significantly different dendritic solidification structure. It was speculated that the 


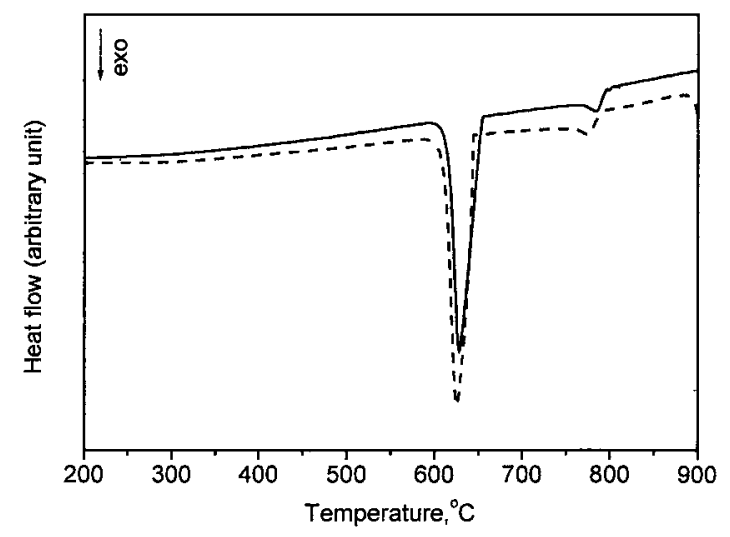

18 DSC traces of Al-10Sr (wt-\%) alloy prepared by electrolysis (dashed line) and mixing (solid line) during solidification at cooling rate of $20 \mathrm{~K} \mathrm{~min}^{-1}$ (from Ref. 92)

intensive current and electromagnetic field in the electrolysis process would have had a significant effect on the liquid of the $\mathrm{Al}-\mathrm{Sr}$ melt and the subsequent solidification process and the microstructure.

An illustration of application to a more complex alloy can be found in the study of Hsu et al. ${ }^{93}$ on solidification in an $\mathrm{Al}-0.6 \mathrm{Si}-0 \cdot 8 \mathrm{Mg}-0 \cdot 3 \mathrm{Fe}(\mathrm{wt}-\%)$ alloy. In this work, the authors employed the entrained droplet technique, ${ }^{94}$ in which 1-1000 nm liquid droplets are entrained in a solid matrix which acts as a heterogeneous nucleation catalyst, and their solidification is monitored using DSC.

It should, in principle, be possible to compare the heat effects during cooling with the thermodynamic and phase diagram predictions made by the approaches collectively termed CALPHAD (CALculation of PHase Diagrams). Some success has been obtained in studies of mixing and dissolution of liquids and elemental powders, but reports on successful analysis of enthalpies of solidification reactions in $\mathrm{Al}$ based alloys are largely absent from the literature. One study carried out by Youssef et al. ${ }^{95}$ compared the latent heat of solidification of a commercial purity Al alloy and a commercial purity alloy with additions of $\mathrm{TiB}_{2}$ particles. It was observed that even though $\mathrm{TiB}_{2}$ particles were presumed, the latent heat of solidification of the Al was significantly different for the metal matrix composite as compared to the commercial purity $\mathrm{Al}$ alloy. The difference was spectulatively ascribed to the creation of elastic strain energy during solidification.

\section{Melting and incipient melting}

Depending on complexity and alloying content, the heating of an $\mathrm{Al}$ alloy can give rise to one or a range of endothermic melting effects. ${ }^{96}$ A DSC trace of melting of pure Al showing a single peak due to melting of the Al rich phase is depicted in Fig. 19. In Al alloys which contain intermetallic phases, the melting of the Al rich phase is often preceded by melting of one or more of those minority phases, and this type of melting is often termed 'incipient melting'. Illustrations of application to more complex alloys are studies by Sha et al. ${ }^{97}$ on melting in an $\mathrm{Al}-0 \cdot 6 \mathrm{Si}-0 \cdot 8 \mathrm{Mg}-0.3 \mathrm{Fe}(\mathrm{wt}-\%)$ alloy and by Wang et al. ${ }^{49}$ on $\mathrm{Al}-11 \mathrm{Si}-x \mathrm{Cu}-0 \cdot 3 \mathrm{Mg}$ (wt-\%) alloys. In Fig. 20, DSC scans showing the melting reactions in

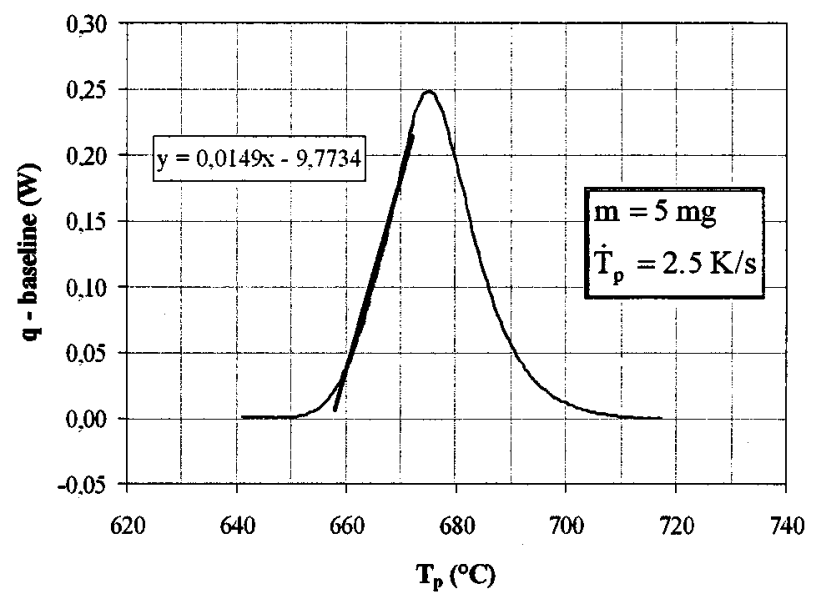

19 DSC traces of melting of $99.999 \%$ pure $\mathrm{Al}$ at heating rate of $2.5 \mathrm{~K} \mathrm{~min}^{-1}$ (from Ref. 91)

conventionally mould cast $\mathrm{Al}-11 \mathrm{Si}-x \mathrm{Cu}-0 \cdot 3 \mathrm{Mg}$ (wt- $\%$ ) alloys are presented. The four reaction peaks (labelled 1, $\left.2,2^{\prime}, 3\right)$ that can be observed in these DSC scans were attributed to

$$
\begin{aligned}
& 1: \alpha(\mathrm{Al})+\mathrm{Si}\left(+\mathrm{Al}_{5} \mathrm{SiFe}+\ldots\right) \leftrightarrows \mathrm{Liq} . \\
& 2: \alpha(\mathrm{Al})+\mathrm{CuAl}_{2}+\mathrm{Si} \leftrightarrows \mathrm{Liq} . \\
& 2^{\prime}: \alpha(\mathrm{Al})+\mathrm{Si}+\mathrm{Mg}_{2} \mathrm{Si} \leftrightarrows \mathrm{Liq} . \\
& 3: \alpha(\mathrm{Al})+\mathrm{CuAl}_{2}+\mathrm{Si}+\mathrm{Cu}_{2} \mathrm{Mg}_{8} \mathrm{Si}_{6} \mathrm{Al}_{5} \leftrightarrows \mathrm{Liq}
\end{aligned}
$$

Microalloying with $\mathrm{Na}, \mathrm{Sr}$, or Be has a distinct effect on the as cast microstructures of these alloys, and also influences subsequent remelting. This is illustrated in Fig. 21. Modification with $\mathrm{Na}$ has little effect on the position of peak 3 , but with $\mathrm{Be}$ and $\mathrm{Sr}$ modification, which both enhance the mechanical properties of these alloys, the beginning temperature of peak 3 shifts to about $512-513^{\circ} \mathrm{C}$. This DSC study thus revealed that the restrictive solution temperature to avoid incipient

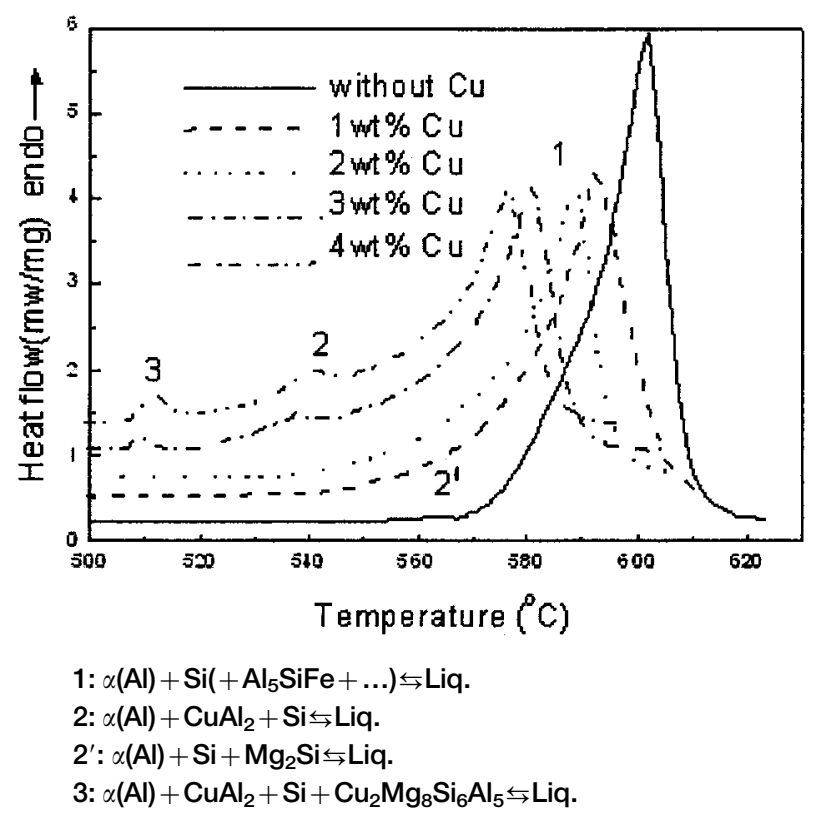

20 Heating DSC curves for as cast samples of Al-11Si$x \mathrm{Cu}-0.3 \mathrm{Mg}$ (wt-\%) alloys showing melting peaks (from Ref. 49) 


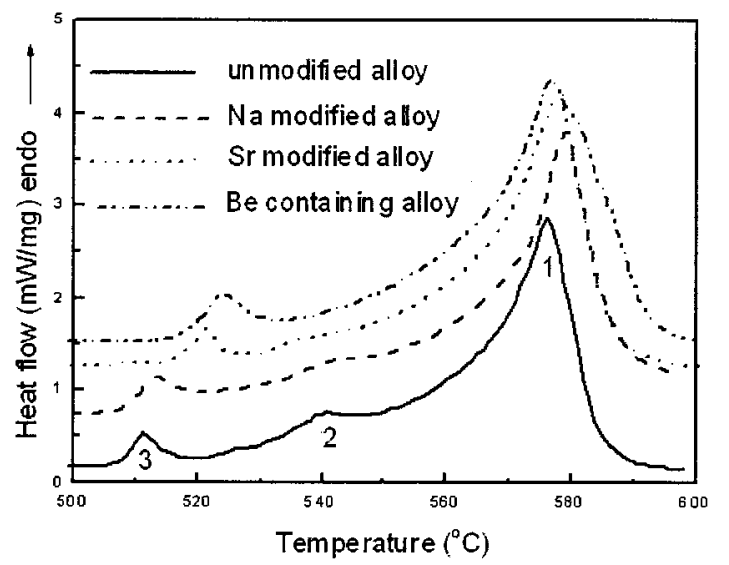

21 Effect of microelements on DSC curves of Al-11Si$4 \mathrm{Cu}-0.3 \mathrm{Mg}$ alloy (wt-\%): all effects are due to melting of phases (from Ref. 49)

melting of intermetallic phases could be increased by about $5 \mathrm{~K}$ in the latter modified alloys.

Sha et al. ${ }^{97}$ showed that DSC can also be used to study the effect of solidification rates on the solidification reactions and the final solidified microstructure. In Fig. 22, DSC heating curves for $\mathrm{Al}-0.6 \mathrm{Si}-0.8 \mathrm{Mg}-0 \cdot 3 \mathrm{Fe}$ (wt- $\%$ ) alloy samples that were solidified at growth velocities in the range $5-120 \mathrm{~mm} \mathrm{~min}^{-1}$ in a Bridgman type furnace are compared with a sample that was slowly solidified at a rate of $10 \mathrm{~K} \mathrm{~min}^{-1}$. These DSC curves show four endothermic reactions (indicated ' $a$ ', 'b', 'c', 'd') and through comparison with known temperatures of invariant reactions, and with the aid TEM and XRD work, these effects were identified. Effect ' $b$ ' corresponds to $\alpha$-AlFeSi eutectic melting

$$
\alpha(\mathrm{Al})+\alpha-\mathrm{AlFeSi} \leftrightarrows \mathrm{Liq}
$$

effect 'c' corresponds to $\alpha$-AlFeSi peritectic melting

$$
\alpha(\mathrm{Al})+\alpha-\mathrm{AlFeSi} \leftrightarrows \text { Liq. }+\mathrm{Al}_{13} \mathrm{Fe}_{4}
$$

effect ' $\mathrm{d}$ ' corresponds to eutectic melting of $\mathrm{Al}_{13} \mathrm{Fe}_{4}$ (also indicated as $\mathrm{Al}_{3} \mathrm{Fe}$ )

$$
\alpha(\mathrm{Al})+\mathrm{Al}_{13} \mathrm{Fe}_{4} \leftrightarrows \text { Liq }
$$

The DSC trace from the alloy solidified at $10 \mathrm{~K} \mathrm{~min}^{-1}$ shows that only effects ' $c$ ' and ' $d$ ' are present during the heating cycle. The amount of heat released at effect ' $b$ ' of the specimen grown at $5 \mathrm{~mm} \mathrm{~min}{ }^{-1}$ is much less than that for the specimen grown at $120 \mathrm{~mm} \mathrm{~min}^{-1}$, indicating that at higher growth velocities in the range 80 $120 \mathrm{~mm} \mathrm{~min}^{-1}$, more $\alpha$-AlFeSi phase is formed by the eutectic reaction. These results therefore suggested that the more non-equilibrium the solidification, the more likely the $\alpha-\mathrm{AlFeSi}$ is to form via the eutectic rather than the peritectic reaction. Effect ' $a$ ' in the DSC traces corresponds to the melting of the metastable $\beta$-AlFeSi phase. The alloy solidified at $10 \mathrm{~K} \mathrm{~min}^{-1}$ shows neither effect 'a' nor 'b'. Sha et al. ${ }^{97}$ explained this observation by noting that because it is not an equilibrium phase in the alloy it is unlikely that $\beta$-AlFeSi forms at such a slow cooling rate.

Determination of heat of incipient melting has also been used to define alloys and processing combinations in patents on 2000, 6000, and 7000 type $\mathrm{Al}$ based alloys. $^{98,99}$ The patent on high strength 7000 alloys $^{99}$

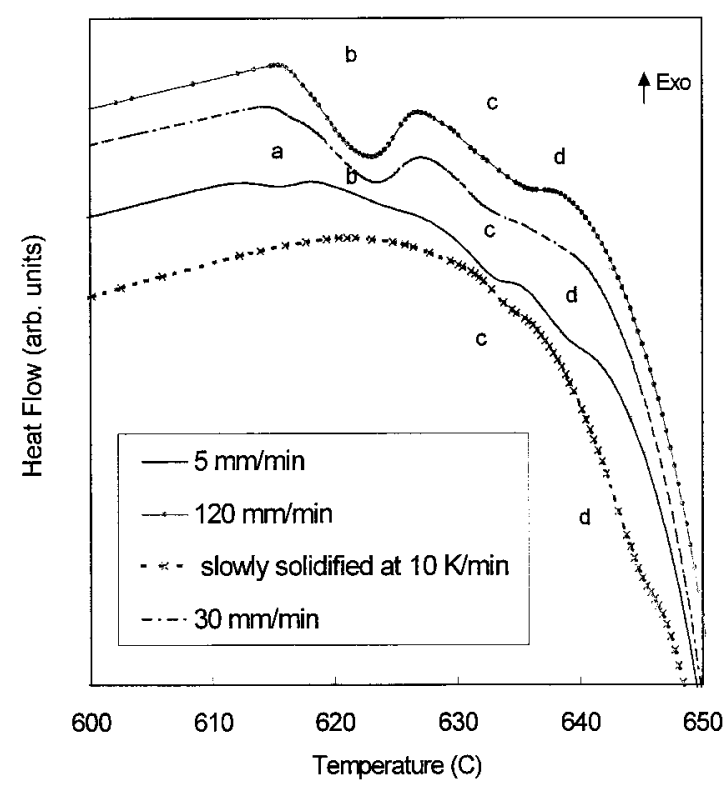

effect a: melting of metastable $\beta$-AIFeSi phase; effect b: $\alpha$-AIFeSi eutectic melting; effect c: $\alpha$-AlFeSi peritectic melting; effect d: eutectic melting of $\mathrm{Al}_{13} \mathrm{Fe}_{4}$

22 DSC heating traces of $\mathrm{Al}-0.6 \mathrm{Si}-0.8 \mathrm{Mg}-0.3 \mathrm{Fe}$ (wt-\%) alloy solidified at different growth velocities: DSC heating rate is $10 \mathrm{~K} \mathrm{~min}^{-1}$ (adapted from Ref. 97)

specifically states: 'The alloys contain, by weight, 7 to $13.5 \% \mathrm{Zn}, 1$ to $3.8 \% \mathrm{Mg}, 0.6$ to $2.7 \% \mathrm{Cu}, 0$ to $0.5 \% \mathrm{Mn}$, 0 to $0.4 \% \mathrm{Cr}, 0$ to $0.2 \% \mathrm{Zr}$, others up to $0.05 \%$ each and $0 \cdot 15 \%$ total, and remainder Al. Either wrought or cast alloys can be obtained, and the specific energy associated with the DEA melting signal* of the product is lower than $3 \mathrm{~J} / \mathrm{g}$.'

Partial melting is an important part of the sintering process as used for the consolidation to near full density of Al alloy powders. The DSC technique has been employed in studies of sintering to determine temperature ranges for partial melting of the alloys. ${ }^{43,100}$

\section{CALPHAD; mixing and dissolution of powders and liquids}

For obtaining thermodynamic functions of liquid and solids, DSC, DTA, and isothermal calorimetry are important tools. Such measurements can be used in verification of the predicted phase diagrams and are assessed and predicted using the approaches collectively termed CALPHAD. Especially onset of melting of phases during heating ${ }^{101-103}$ is used to support predicted phase diagrams, and measurement of enthalpies of formation of intermetallic phases from reaction of elemental powders ${ }^{104}$ or through drop solution calorimetry ${ }^{105-108}$ is used to directly determine formation enthalpies. Also, DSC data on precipitation reactions can be used in assessing phase diagrams. ${ }^{109}$ Enthalpies of mixing of liquid phases are measured by high temperature calorimetry. ${ }^{110-112}$ Further thermodynamic data can be obtained by measuring the enthalpies of dissolution of elements in liquid Al. ${ }^{113}$

*DEA melting signal in this case refers to the heat content of the incipient melting peak in a DSC experiment. 


\section{Modelling of thermally activated reactions}

\section{Introduction: general objectives}

In many cases, calorimetry data obtained for metals have been analysed in a purely qualitative manner, i.e. by relating the presence of endothermic or exothermic effects to particular reactions without attempting to obtain quantitative information on these reactions, their progress, or the mechanisms involved. Quantitative analysis is more often performed for isothermal experiments as compared to linear heating experiments. This is related to the availability of isothermal models, which are mathematically simpler than their non-isothermal equivalents. In the present section, these quantitative analysis methods are reviewed, and their applicability assessed.

The type of modelling of thermally activated reactions that has been used in conjunction with calorimetry, or that can be applied to calorimetry, is of a broad and diverse nature. Modelling approaches can mostly be classified as one of three types:

- generic analysis models, which are models that use relatively simple expressions that provide the fraction transformed as a function of time or reaction rate as a function of fraction transformed, and that are applicable to a wide range of reactions

- simplified physically based models, which are models that are specifically based on considerations of the physical or chemical process, often with adjustable process-related parameters, such as impingement parameters, that allow some flexibility in analysing data

- simulations, which are models that make predictions, often using extensive computer time, with all model parameters being fixed.

In using generic analysis models, the aim would be to find an adequate description of the progress of the reaction as a function of time and temperature, with limited consideration being given to the physical basis. On the other extreme, simulations are based on the presumption of a complete understanding of the physical process with all process and kinetic parameters known, and in this case calorimetry or any other experimental work is not used to analyse a reaction but instead to validate a model. Simplified physically based models with adjustable process-related parameters aim to analyse experimental data with due regard to the physical processes, while making as little as possible presumption about the process.

This section focuses on modelling methods that can be used to analyse calorimetry (especially DSC) data in terms of physical processes, without making too many presumptions about the process. Hence, physically based models with adjustable process-related parameters are the focus of discussion, and assessments are made of how these approaches relate to more specific models, such as simulations, and also of how they fit into more generic analysis methods. Thus, analysis methods that have some inherent flexibility that allows them to cope with different types of reactions are mainly considered rather than discussing in detail computer based simulations that are very specific to the reaction considered and depend on prior knowledge of the physical parameters involved. The emphasis is on developments that have appeared over the past 10 years and that are suited for analysis of thermally activated reactions in $\mathrm{Al}$ based alloys.

A general objective of the modelling of thermally activated reactions by generic analysis methods and physically based methods is the derivation of a complete description of the progress of a reaction that is valid for any thermal treatment, be it isothermal, by linear heating or any other non-isothermal treatment. In the case of physically based methods, an additional aim is to be able to use the analysis to understand the processes involved in the reaction. At the outset, it should be realised that for many reactions these objectives are daunting. Especially for solid state reactions, any given reaction might progress through a range of mechanisms and intermediate stages, all of which will, in general, have a different temperature dependency. To come to terms with this complexity, simplifying assumptions are often made, and throughout the subsequent sections several analysis methods based on simplifications are reviewed.

\section{Single state variable approaches (single Arrhenius term)}

The most popular way of dealing with the complexity of thermally activated reactions is through the assumption that the transformation rate during a reaction is the product of two functions, one depending solely on the temperature $T$ and the other depending solely on the fraction transformed $\alpha$ (Refs. 114-117)

$$
\frac{\mathrm{d} \alpha}{\mathrm{d} t}=f(\alpha) k(T)
$$

The temperature dependent function is generally assumed to follow an Arrhenius type dependency

$$
k=k_{\mathrm{o}} \exp \left(-\frac{E}{R T}\right)
$$

where $E$ is the activation energy of the reaction. Thus, to describe the progress of the reaction at all temperatures and for all temperature-time programmes, the function $f(\alpha)$, and the constants $k_{\mathrm{o}}$ and $E$ need to be determined. In general, the reaction function $f(\alpha)$ is unknown at the outset of the analysis. A range of standard functions which represent particular idealised reaction models have been proposed ${ }^{118,119}$ (see Table 1). Through selection of specific $f(\alpha)$, the formalism described by the above two equations describes specific types of reaction kinetics. For example, the formalism can incorporate Johnson-Mehl-Avrami-Kolmogorov (JMAK) kinetics for

$$
f(\alpha)=n[-\ln (1-\alpha)]^{(\mathrm{n}-1) / \mathrm{n}}(1-\alpha)
$$

Within this concept, the description of the progress of a reaction is reduced to finding appropriate values for $E$, $k_{\mathrm{o}}$, and the function $f(\alpha)$ - the so-called kinetic triplet. In the sections 'Activation energy determination' and 'Single stage reaction models', below, techniques for analysing DSC and isothermal calorimetry data based on equations (6) and (7) are considered, but first an approach that allows comparison of progress of isothermal reactions with non-isothermal reactions through the 'equivalent time' concept is discussed. Studies from the past 5-10 years are mainly considered; 
for an extensive overview of pre-1996 work, the reader is referred to the work by Galwey and Brown. ${ }^{119}$

\section{Equivalent time, state variable, and temperature integral}

The equivalent time concept refers to a method designed to describe any non-isothermal treatment with temperature path $T(t)$ by a single variable termed the equivalent time. It thus allows comparison of the progress of a reaction when samples are exposed to different temperature paths $T(t)$, e.g. compare the progress of a reaction under linear heating conditions with the progress during isothermal annealing. The equivalent time approach is valid if the progress of a reaction can be described by a single state variable, and in the following subsection the state variable approach is reviewed and the expression for equivalent time is derived

\section{State variable approach and equivalent times}

In the state variable approach, we consider that the fraction transformed is a unique function of a state variable $\omega$. If there is one single temperature dependent process operating, $\omega$ is given by

$$
\omega=\int_{\mathrm{t}=0}^{\mathrm{t}_{\mathrm{e}}} k \mathrm{~d} t
$$

For isothermal reactions at $T_{\text {iso }}$ it simply follows

$$
\omega=k t_{\mathrm{e}}
$$

The state variable approach is justified in the case that equation (6) is valid, i.e. the transformation rate during a reaction is the product of two functions, one depending solely on the temperature and the other depending solely on the fraction transformed. In this case, we can integrate the above equation

$$
\int_{\mathrm{t}=0}^{\mathrm{t}_{\mathrm{e}}} \frac{\mathrm{d} \alpha}{f(\alpha)}=\int_{\mathrm{t}_{\mathrm{o}}}^{\mathrm{t}_{\mathrm{e}}} k(T) \mathrm{d} t
$$

and, as the left-hand side of this equation is a unique function of the fraction transformed, we can define a state variable as

$$
\omega=\int_{\mathrm{t}=0}^{\mathrm{t}_{\mathrm{e}}} \frac{\mathrm{d} \alpha}{f(\alpha)}
$$

One result from these equations is the derivation of the equivalent time, which is defined as the time at temperature $T_{\text {iso }}$ needed to complete the same amount of the reaction during a non-isothermal anneal. Considering that in many cases $k$ can be assumed to be an Arrhenius expression, the equivalent time is given as

$$
t_{\text {eq }}=\int_{\mathrm{t}=0}^{t_{\mathrm{e}}} \exp \left(-\frac{E}{R T(t)}\right) \mathrm{d} t\left[\exp \left(-\frac{E}{R T_{\text {iso }}}\right)\right]^{-1}
$$

For linear heating, we can derive

$$
\int_{\mathrm{t}=0}^{\mathrm{t}_{\mathrm{e}}} \exp \left(-\frac{E}{R T(t)}\right) \mathrm{d} t=\frac{E}{R \beta} \int_{\mathrm{y}=\mathrm{y}_{\mathrm{f}}}^{\infty} \frac{\exp (-y)}{y^{2}} \mathrm{~d} y
$$

where $y=E / R T, y_{\mathrm{f}}=E / R T_{\mathrm{e}}\left(T_{\mathrm{e}}\right.$ being the temperature reached during the linear heating), and $\beta$ is the heating rate. Thus, to obtain the equivalent time for linear heating, we need to calculate the integral

$$
\int_{\mathrm{y}=\mathrm{y}_{\mathrm{f}}}^{\infty} \frac{\exp (-y)}{y^{2}} \mathrm{~d} y=p\left(y_{\mathrm{f}}\right)
$$

\begin{tabular}{|c|c|c|c|c|}
\hline Reaction & Code & $f(\alpha)$ & $\alpha(t)$ & Ref. \\
\hline $\begin{array}{l}\text { Random nucleation; unimolecular decay law } \\
\text { (1st order) }\end{array}$ & F1* & $1-\alpha$ & $1-\exp [-k t]$ & 119 \\
\hline $\begin{array}{l}\text { Phase boundary controlled reaction } \\
\text { (1st order) }\end{array}$ & $\mathrm{R} 1$ & 1 & $k t$ & 119 \\
\hline $\begin{array}{l}\text { Phase boundary controlled reaction } \\
\text { (2nd order; contracting cylinder) }\end{array}$ & $\mathrm{R} 2$ & $(1-\alpha)^{1 / 2}$ & $1-(1-k t)^{2}$ & 119 \\
\hline $\begin{array}{l}\text { Phase boundary controlled reaction } \\
\text { (3rd order; contracting sphere) }\end{array}$ & R3 & $(1-\alpha)^{2 / 3}$ & $1-(1-k t)^{3}$ & 147 \\
\hline $\begin{array}{l}\text { JMAK linear growth in 1D (e.g. growth of } \\
\text { plate) after saturation of nucleation }(n=1)\end{array}$ & $\mathrm{A} 1 *$ & $1-\alpha$ & $1-\exp [-k t]$ & $\cdots$ \\
\hline $\begin{array}{l}\text { JMAK linear growth in 2D after saturation of } \\
\text { nucleation }(n=2)\end{array}$ & A2 & $2[-\ln (1-\alpha)]^{1 / 2}(1-\alpha)$ & $1-\exp \left[-(k t)^{2}\right]$ & 119 \\
\hline $\begin{array}{l}\text { JMAK linear growth in 3D after saturation of } \\
\text { nucleation }(n=3)\end{array}$ & A3 & $3[-\ln (1-\alpha)]^{2 / 3}(1-\alpha)$ & $1-\exp \left[-(k t)^{3}\right]$ & 119 \\
\hline $\begin{array}{l}\text { JMAK diffusion controlled growth in 3D after } \\
\text { saturation of nucleation }(n=11 / 2)\end{array}$ & $A 11 / 2$ & $11 / 2[-\ln (1-\alpha)]^{1 / 3}(1-\alpha)$ & $1-\exp \left[-(k t)^{1 / 2}\right]$ & $\cdots$ \\
\hline $\begin{array}{l}\text { JMAK continuous nucleation and diffusion } \\
\text { controlled growth in 3D }(n=21 / 2)\end{array}$ & $\mathrm{A} 21 / 2$ & $21 / 2[-\ln (1-\alpha)]^{3 / 5}(1-\alpha)$ & $1-\exp \left[-(k t)^{21 / 2}\right]$ & $\cdots$ \\
\hline $\begin{array}{l}\text { Precipitate growth in 3D after saturation of } \\
\text { nucleation in mean field approximation }\end{array}$ & $\mathrm{H} 11 / 2$ & $\alpha^{1 / 3}(1-\alpha)$ & $\begin{array}{l}1-\left[(k t)^{3 / 2} / 5 \cdot 67+1\right]^{-5 \cdot 67} \\
\text { (approximation) }\end{array}$ & App. $2 \uparrow$ \\
\hline JMAK (generalised) & AGn & $n[-\ln (1-\alpha)]^{(n-1) / n}(1-\alpha)$ & $1-\exp \left[-(k t)^{\mathrm{n}}\right]$ & 114 \\
\hline Sesták-Berggren & SB & $\alpha^{\mathrm{m}}[-\ln (1-\alpha)]^{\mathrm{q}}(1-\alpha)^{\mathrm{p}}$ & $\begin{array}{l}\text { No known closed } \\
\text { expression }\end{array}$ & 115 \\
\hline Austin-Rickett (AR) equation & $\mathrm{ARn}$ & $n\left[(1-\alpha)^{-1}-1\right]^{(n-1) / n}(1-\alpha)^{2}$ & $1-\left[(k t)^{\mathrm{n}}+1\right]^{-1}$ & 116,117 \\
\hline $\mathrm{SZ}$ & SZn & $n\left[(1-\alpha)^{-1 / \eta}-1\right]^{(n-1) / n}(1-\alpha)^{(\eta+1) / \eta}$ & $1-\left[(k t)^{n} / \eta+1\right]^{-\eta}$ & 170,171 \\
\hline
\end{tabular}

This integral $p(y)$ is termed the temperature integral or Arrhenius integral.

Table 1 Selected expressions for reaction function $f(\alpha)$ : note that Šesták-Berggren model encompasses R1-R3, A1-A3, and AGn models, while the SZ model encompasses R1-R3, A1-A3, AGn, AR, and mean field models

*Note that A1 and F1 are mathematically identical.

$\uparrow$ Appendix 2 of the present paper. 


\section{Temperature integral and its approximations}

A range of approximations of the temperature integral $p(y)$ have been suggested in the literature. All the known approximations will lose accuracy for small values of $y$ (typically for $y$ below 10-15) and some lose accuracy for large values of $y$ (typically $y$ exceeding 100). To be able to appreciate the relevance of these deviations, we need to consider the range of $y$ values that can be encountered when analysing linear heating data of thermally activated reactions. In a recent work, ${ }^{120}$ it was shown that the range of $y$ values that will in practice occur is limited for various reasons. First, it was considered that reactions with high activation energy would generally occur at high temperatures and vice versa. This will tend to limit the occurrence of extremely low or extremely high values of $y(=E / R T)$. Second, it was considered that for diffusion controlled reactions, the typical diffusion distance $l$ is given by $l=(D t)^{1 / 2}$, where $D$ is the diffusion coefficient which is generally given by

$$
D=D_{\mathrm{o}} \exp \left(-\frac{E_{\mathrm{D}}}{R T}\right)
$$

and thus

$$
y=\frac{E_{\mathrm{D}}}{R T}=-\ln \left(\frac{l^{2}}{D_{\mathrm{o}} t}\right)
$$

Again, extreme values of $y$ are unlikely because: (i) $l$ and $t$ are limited due to practical considerations, and the lower limit for $l$ is defined by interatomic distance; (ii) larger diffusion distances $l$ will imply longer experiment times $t$; (iii) the logarithmic function will limit variation. It was concluded that only the range $9<y<100$ is of practical significance, while the overwhelming majority of reactions in fact occur for $15<y<60$. In this work, reactions in $\mathrm{Al}$ alloys are the major concern, and reactions will generally occur within the latter more restrictive limits for $y$.

The temperature integral can be calculated using expansions of the integral in an infinite series, of which several forms have been proposed, ${ }^{120-122}$ and a range of approximations in the form of a finite number of terms have been proposed in the literature. ${ }^{120,123-129}$ In terms of practical applicability especially approximations of the following form are useful

$$
p(y) \cong \frac{\exp (-A y+B)}{y^{\kappa}}
$$

where $\kappa$ is a constant between 0 and 2, and $A$ and $B$ are constants that depend on $\kappa$. This class of approximations is important, because it leads to single term closed form expressions for the equivalent time and also forms the basis for the derivation of a group of activation energy analysis methods (the direct methods) described in the following section. For each value of exponent $\kappa, A$ and $B$ can be optimised by minimising the deviation between the approximation function and the exact integral. From this group of methods, the approximation for which the deviation reduces to zero in the limit of very large values of $y$ is the approximation by Murray and White ${ }^{126}$

$$
p(y) \cong \frac{\exp (-y)}{y^{2}}
$$

It has been shown ${ }^{120,129}$ that from this group of

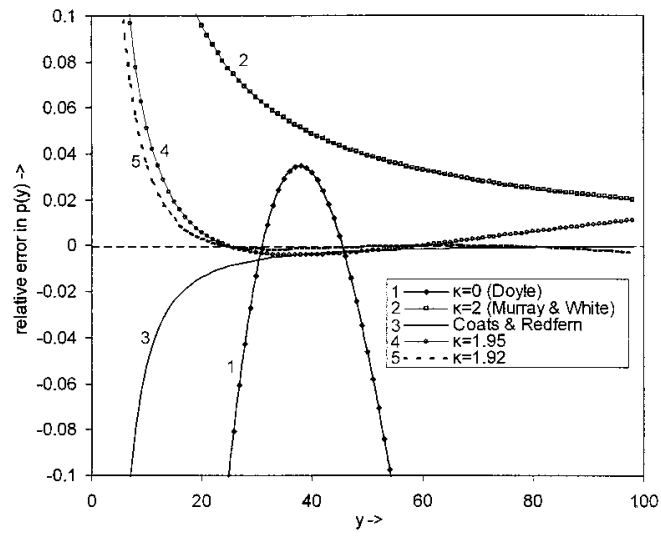

23 Relative accuracy of various approximations for temperature integral (adapted from Ref. 120)

approximations, the approximation with $A=1$ that is most accurate for $20<y<60$ is obtained with $\kappa=1.95$, which leads to

$$
p(y) \cong \frac{\exp (-y-0 \cdot 235)}{y^{1 \cdot 95}}
$$

if $A$ is not required to be equal to 1, a highly accurate approximation is given by ${ }^{120}$

$$
p(y) \cong \frac{\exp (-1 \cdot 0008 y-0 \cdot 312)}{y^{1 \cdot 92}}
$$

Analyses of accuracies of selected approximations of the temperature integral have been published in several works. ${ }^{120,130}$ Comparison of the accuracies of these approximations is straightforward, and in Fig. 23 the accuracies are compared by plotting $\ln \left(p_{\mathrm{a}} / p\right)$, where $p_{\mathrm{a}}$ is an approximation of $p$ such as those in equations (18) (21). The figure shows that the above two approximations obtained with $\kappa=1.95$ and 1.92 are highly accurate. Higher accuracies can be achieved with the more complicated expressions (such as the Senum and Yang expression ${ }^{122,128}$ ), but these are too complex to yield a transparent analysis method. The often quoted Doyle approximation ${ }^{123-125}$ proves to be the most inaccurate of the approximations tested in Fig. 23 and is not considered further in this overview.

To complete the calculation of the equivalent time for linear heating, we now need to choose which approximation of $p(y)$ is appropriate. The approximation in equation (19) has been used to this end, and leads to ${ }^{131}$

$$
t_{\text {eq }} \cong \frac{T_{\mathrm{f}}}{\beta} \frac{R T_{\mathrm{f}}}{E} \exp \left(-\frac{E}{R T_{\mathrm{f}}}\right)\left[\exp \left(-\frac{E}{R T_{\text {iso }}}\right)\right]^{-1}
$$

A better accuracy would be achieved by employing equation (20) to yield

$$
\begin{aligned}
t_{\text {eq }} \cong & 0.786 \frac{T_{\mathrm{f}}}{\beta}\left(\frac{R T_{\mathrm{f}}}{E}\right)^{0.95} \exp \left(-\frac{E}{R T_{\mathrm{f}}}\right) \\
& \times\left[\exp \left(-\frac{E}{R T_{\text {iso }}}\right)\right]^{-1}
\end{aligned}
$$

The above expressions for equivalent time can be used in many problems where the progress of a reaction during linear heating needs to be compared with the progress during isothermal aging (or linear heating at a different heating rate). For example, in work on an 8090 (Al$2 \cdot 40 \mathrm{Li}-1 \cdot 16 \mathrm{Cu}-0 \cdot 75 \mathrm{Mg}-0 \cdot 10 \mathrm{Zr}$, wt $\%$ ) metal matrix 
composite, the peak of the formation of semicoherent $\mathrm{S}$ phase during heating at $10 \mathrm{~K} \mathrm{~min}^{-1}$ was observed at $300{ }^{\circ} \mathrm{C}{ }^{132}$ Using that the peak reaction rate occurs for a fraction transformed of about $69 \%$ and that the activation energy for this reaction is $107 \mathrm{~kJ} \mathrm{~mol}^{-1}$, equation (22) predicts that, at $170^{\circ} \mathrm{C}, \mathrm{S}$ phase formation is $69 \%$ completed in about $30 \mathrm{~h}$. This was found to be consistent with isothermal aging data.

\section{Activation energy determination}

To analyse a thermally activated reaction using the approach described by equations (6) and (7), we need to obtain the kinetic triplet: $E, k_{\mathrm{o}}$, and the function $f(\alpha)$. As $f(\alpha)$ is generally not known at the outset of the analysis, and $k_{\mathrm{o}}$ is a pre-exponential factor that can be adjusted relatively easily after the other two elements of the triplet are determined, analysis is usually started by determining $E$. Once $E$ has been determined, the combination of the value of $E$ and a single transformation curve (i.e. a curve of $\alpha$ versus $t$ ) essentially provides the solution to the determination of the kinetic triplet, and thus determines the kinetics of the reaction within the simplified framework provided by equations (6) and (7). From this, it will be clear that the determination of the activation energy is the crucial step in the analysis. Another reason for the importance of the determination of the activation energy of the reaction lies in the fact that the activation energy for the overall reaction will generally be related to an activation energy for the physical process that determines the rate of the reaction. For example, if the rate determining step is diffusion of an element through a material, the activation energy of the overall process will, in most cases, be determined by the activation energy for diffusion of that element. Thus, the activation energy of the overall process will provide information on the physical process that is rate limiting, and hence the objective of activation energy analysis is not only as the first step in characterising the kinetic triplet, but it can also be an objective in itself, leading to a better understanding of the mechanisms of the thermally activated reaction.

For linear heating experiments, activation energies of reactions can be derived from a set of experiments performed at different heating rates. For this activation energy analysis, a large number methods have been proposed (a selection of methods can be found in Refs. 129, 131, 133-147). The aim of the present section is to describe the main features and accuracies of these methods, and provide recommendations about which methods are best suited for analysis of particular DSC data. It will be shown that several methods have a combination of relative simplicity of application and good accuracy, which allows them to be used for activation energy analysis in Al based alloys.

\section{Activation energy analysis using isoconversion methods}

From equations (6) and (7), it follows immediately that for transformation studies by performing experiments at constant temperature $T_{\mathrm{i}}, E$ can be obtained from the well known relation

$$
\ln t_{\mathrm{f}}=\frac{E}{R T_{\mathrm{i}}}+C_{1}
$$

where $t_{\mathrm{f}}$ is the time needed to reach a certain fraction transformed, and $C_{1}$ is a constant which depends on the reaction stage and on the kinetic model. Thus, $E$ can be obtained from two or more experiments at different values of $T$.

All reliable methods of activation energy analysis for linear heating experiments require the determination of the temperatures $T_{\mathrm{f}}(\beta)$, at which an equivalent stage of the reaction is obtained for various heating rates. ${ }^{120,143}$ Hence, the term isoconversion methods. The equivalent stage (also called the constant or fixed stage) may be defined as the stage at which a fixed amount is transformed, or at which a fixed fraction of the total amount is transformed. Isoconversion methods can be categorised into one of two main groups of methods. ${ }^{120}$ One set of methods relies on approximating the temperature integral $p(y)$ and requires data on $T_{\mathrm{f}}(\beta)$ only. This first set of methods includes the Kissinger method, ${ }^{131,133,148}$ the Kissinger-Akahira-Sunose method ${ }^{134}$ (also termed the generalised Kissinger method ${ }^{131}$ ), the Flynn-WallOzawa method, ${ }^{135-137}$ and several methods that were devised more recently. ${ }^{120,122,129}$ These methods have been termed type $\mathrm{B}$ isoconversion methods or $p(y)$ isoconversion methods. ${ }^{120}$ The approximation of the temperature integral, which is key to these methods, is here illustrated by considering the derivation of the Kissinger-Akahira-Sunose (KAS) method. In this derivation, equation (7) is inserted in equation (6) and this is integrated by separation of variables

$$
\begin{aligned}
\int_{0}^{\alpha} \frac{\mathrm{d} \alpha}{f(\alpha)} & =\frac{k_{\mathrm{o}}}{\beta} \int_{0}^{\mathrm{T}_{\mathrm{f}}} \exp \left(-\frac{E}{R T}\right) \mathrm{d} T \\
& =\frac{R E}{\beta k_{\mathrm{B}}} \int_{\mathrm{y}_{\mathrm{f}}}^{\infty} \frac{\exp (-y)}{y^{2}} \mathrm{~d} y
\end{aligned}
$$

where $T_{\mathrm{f}}$ is the temperature at an equivalent (fixed) state of transformation, and $\beta$ is the heating rate. Using the Murray and White ${ }^{126}$ approximation for $p(y)$ (equation (19)) yields

$$
\ln \int_{0}^{\alpha} \frac{\mathrm{d} \alpha}{f(\alpha)}=\ln \frac{k_{\mathrm{o}} E}{R}+\ln \frac{1}{\beta y_{\mathrm{f}}^{2}}-y_{\mathrm{f}}
$$

At constant fraction transformed $\alpha$, this leads to

$$
\ln \frac{\beta}{T_{\mathrm{f}}^{2}}=-\frac{E}{R T_{\mathrm{f}}}+C_{2}
$$

where $C_{2}$, and subsequent $C_{3}, C_{4}$, etc., are parameters that are independent of $T$ and $\beta$. According to equation (27), plots of $\ln \left(T_{\mathrm{f}}^{2} / \beta\right)$ versus $1 / T_{\mathrm{f}}$ should result in straight lines, the slope of the straight lines being equal to $E / R$. This is the basis of the KAS equation. The model can further be applied to the maximum rate, and this isoconversion model is termed the Kissinger method. ${ }^{133}$ It was shown ${ }^{73,129}$ that the KAS analysis is part of a group of methods which can be described by the generalised equation

$$
\ln \frac{\beta}{T_{\mathrm{f}}^{\kappa}}=-\frac{E_{\mathrm{a}}}{R T_{\mathrm{f}}}+C_{3}
$$

For temperatures and activation energies commonly encountered in solid state reactions $\kappa=1.95$ results in the best accuracy of activation energy determination from a plot of $\ln \left(T_{\mathrm{f}}^{\kappa} / \beta\right)$ versus $1 / T_{\mathrm{f}}{ }^{120}$

A second set of isoconversion methods ${ }^{38,139,140}$ does not make any mathematical approximation, but requires 
the rate of transformation at $T_{\mathrm{f}}(\beta)$ as well as data on $T_{\mathrm{f}}(\beta)$. These methods are referred to as type A isoconversion methods ${ }^{120}$ (or Friedman methods, after the researcher who first derived the method ${ }^{139}$ ). The method is derived by inserting equation (7) into equation (6) and taking the logarithm, yielding ${ }^{38,139}$

$$
\ln \frac{\mathrm{d} \alpha}{\mathrm{d} t}=-\frac{E}{R T_{\mathrm{f}}}-\ln f(\alpha)
$$

Thus, if a range of linear heating experiments at different heating rates $\beta$ are performed and the times at which a fixed stage of the reaction is achieved can be identified for each linear heating experiment, $f(\alpha)$ will be a constant. By measuring $T_{\mathrm{f}}$ and the transformation rate $\mathrm{d} \alpha / \mathrm{d} t$ at that fixed stage for each of the experiments, we can obtain $E$ from the slope of plots of $\ln (\mathrm{d} \alpha / \mathrm{d} t)$ versus $1 / T_{\mathrm{f}}$. As $\mathrm{d} \alpha / \mathrm{d} t$ can be difficult to measure accurately, while the heating rate is much easier to determine accurately, one usually determines $E$ from the slope of plots of $\ln (\beta \mathrm{d} \alpha / \mathrm{d} t)$ versus $1 / T_{\mathrm{f}}$.

The definition of an identical stage of the reaction, which is crucial in these methods, is best taken as the stage at which a fixed amount of heat has evolved. As the maximum reaction rate in good approximation occurs at a fixed fraction transformed, an identical stage of the reaction can also be taken as the stage at which the maximum heat evolution is observed. ${ }^{131,138,149}$ It should be noted that this involves a further approximation.

All isoconversion- $T_{\mathrm{f}}(\beta)$ methods involve the plotting of $1 / T_{\mathrm{f}}$ versus a logarithmic function which depends mostly on the heating rate; the specific expressions for the various isoconversion- $T_{\mathrm{f}}(\beta)$ methods are presented in Table 2. (It should be noted that in several pre1990 publications some authors ${ }^{133,142}$ have derived isoconversion- $T_{\mathrm{f}}(\beta)$ methods using an assumed kinetic reaction model. However, in the $1990 \mathrm{~s}$, it has been shown ${ }^{129,131}$ that such an assumption is not necessary, and hence earlier works ${ }^{133,142}$ on the derivations of isoconversion- $T_{\mathrm{f}}(\beta)$ models are now superseded.)

\section{Accuracies of isoconversion analysis methods}

In order to arrive at recommendations as to which of the many methods for activation energy analysis is most appropriate, the accuracy of these methods needs to be analysed. These accuracies are determined by six factors as follows: ${ }^{120,129}$

(i) Mathematical approximations: type $\mathrm{B}$ isoconversion methods use approximations of the temperature integral. This approximation causes inaccuracies which depend on the type of approximation chosen as well as on $y(=E /$ $R T) .{ }^{150}$ For the more accurate methods, these errors are relatively small (less than $0.3 \%$ for $y>15$, see Fig. 24).

(ii) For all methods, the temperature at constant amount transformed needs to be obtained from the measured data. This is prone to slight inaccuracies due to limitation in the accuracy of the baseline determination and minor inaccuracies in the measurement of the sample temperature. (This error will be small for maximum rate methods.)

(iii) Type A methods require experimental data on reaction rate at constant amount transformed. These data are prone to inaccuracies resulting

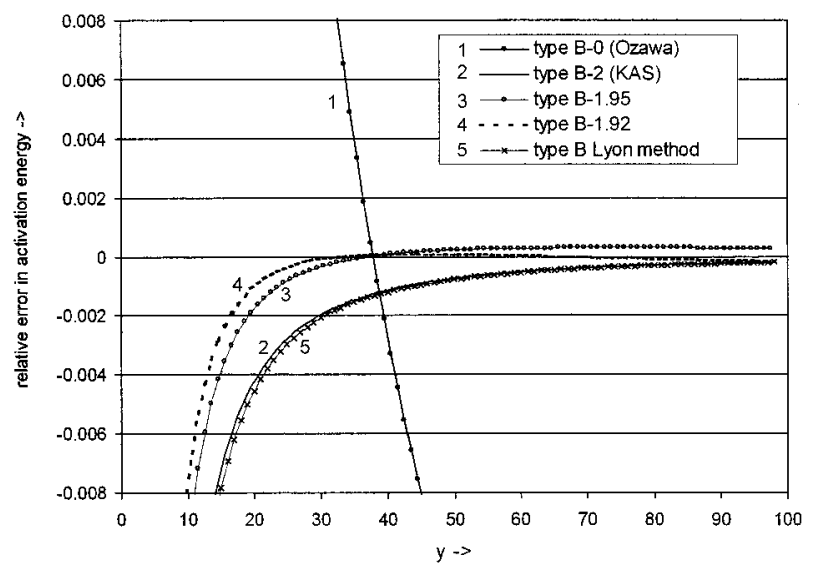

24 Relative error introduced by mathematical approximations in type B activation energy methods (adapted from Ref. 120)

from a limitation in the accuracy of the baseline determination, the determination of the temperature at constant amount transformed and signal noise.

(iv) Small fluctuations in the supposedly constant heating rate may cause errors in determination of the heating rate.

(v) In maximum rate methods, the equivalent stage defined by the maximum rate is not exactly at constant amount transformed, thus introducing a contribution to the errors. ${ }^{148,151,152}$

(vi) All methods presume that the equilibrium state is constant. In some cases, this assumption may not hold and this introduces deviations in the measured activation energies. ${ }^{149,153}$

The deviations introduced by these six factors have been analysed in some detail, and for further details the reader is referred to the corresponding publications. ${ }^{120,148,149,151,152}$

In Table 2, the main characteristics of a range of isoconversion methods are presented. In the same table, estimates of the deviations introduced by error sources (i)-(v) are presented, based on typical accuracies of determinations of the main parameters for a typical reaction in an $\mathrm{Al}$ based alloy. For the latter data, the analysis of error sources (i)-(iii) is based on work by the present author ${ }^{120}$ and the analysis of error source (v) is based on work by Criado and Ortega, ${ }^{148}$ while error source (iv) was considered to be negligible in this case. (These methods for calculation of accuracy are briefly summarised in Appendix 1.) Table 2 shows that accuracies of $E$ determination in the order of $1 \%$ should be achievable, provided one of the more accurate activation isoconversion methods such as the type B1.95 , type B-1.92, or generalised Kissinger methods is used. Also, the Friedman type method can achieve good accuracies, but this method is only recommended if accuracies of transformation rates or heat evolution in Al based alloys can be measured with an accuracy better than about $0 \cdot 2 \%,{ }^{120}$ which will mostly not be possible for thermally activated reactions in $\mathrm{Al}$ based alloys.

Apart from the isoconversion methods, a range of other methods that either assume that a particular kinetic model holds and/or that activation energies can be derived from a single experiment at one single heating rate have been suggested. These methods have been 


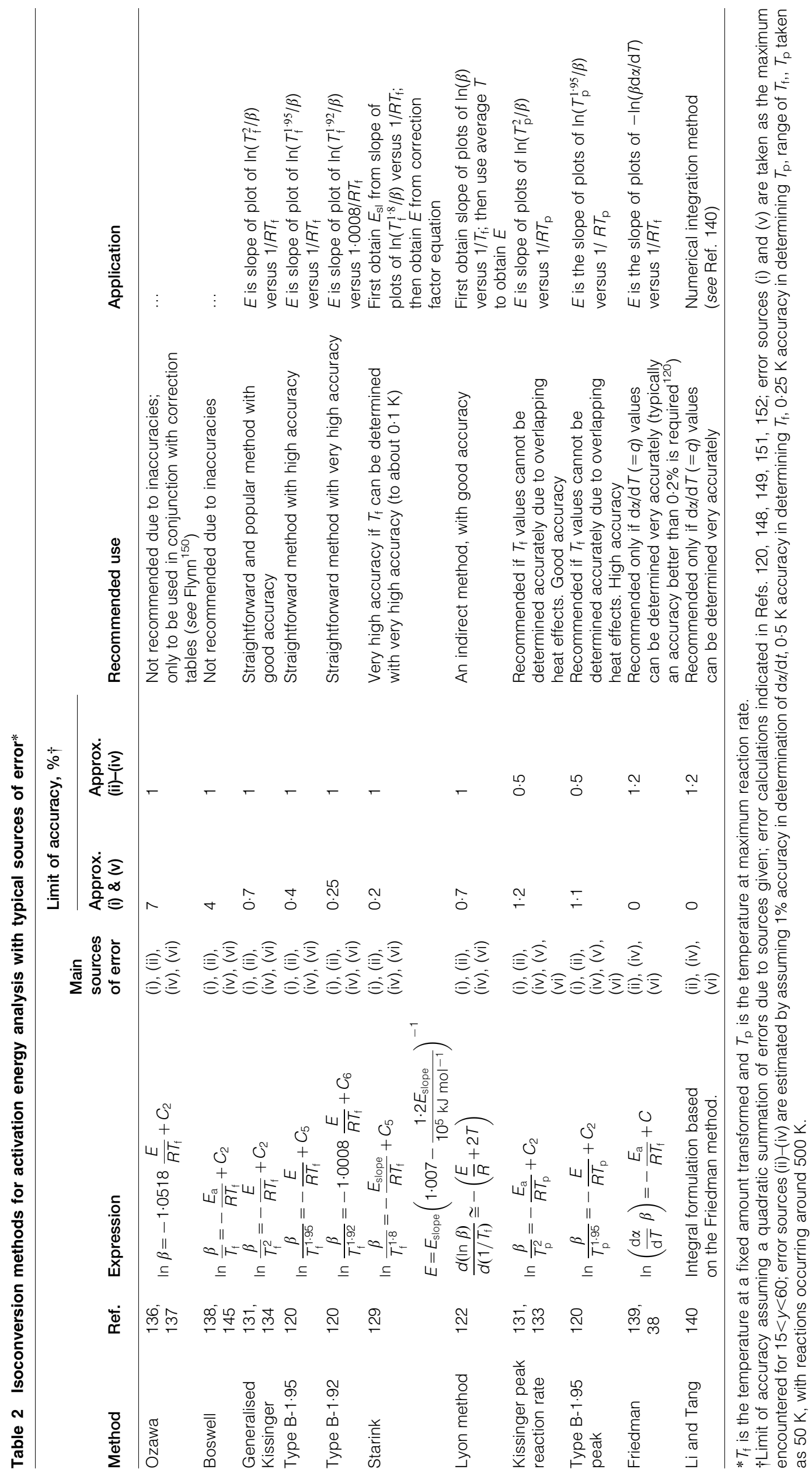


tested and reviewed by various authors, ${ }^{143,154,155}$ and are found to be generally unreliable, especially for solid state reactions where the reaction kinetic model is generally complicated, and often unknown.

\section{Measured activation energies in Al based alloys}

Calorimetry and especially DSC have been used extensively to determine activation energies of thermally activated reactions in $\mathrm{Al}$ based alloys. Observed activation energies for precipitation reactions that occur at about $200-300^{\circ} \mathrm{C}$ tend to be close to the activation energy for diffusion at equilibrium vacancy concentration of the rate determining precipitating element (for the most common alloying elements $\mathrm{Cu}, \mathrm{Mg}$, Si this is about $120-135 \mathrm{~kJ} \mathrm{~mol}^{-1}$; Ref. 156). Precipitation reactions involving elements with higher activation energies, such as $\mathrm{Fe}$ and $\mathrm{Cr}$, occur at higher temperatures (typically $300-400^{\circ} \mathrm{C}$ ), and activation energies for these reactions are generally in line with activation energies for diffusion. (As Fe and $\mathrm{Cr}$ have very low solubilities in Al, solid solutions can only be obtained through rapid solidification or ball milling.) For example, in nanostructured $\mathrm{Al}_{93} \mathrm{Fe}_{3} \mathrm{Cr}_{2} \mathrm{Ti}_{2}$ alloys prepared via ball milling of elemental powders, the activation energy for precipitation of $\mathrm{Al}_{6} \mathrm{Fe}$ is $203 \mathrm{~kJ} \mathrm{~mol}^{-1}$, whereas that for the precipitation of $\mathrm{Al}_{13} \mathrm{Fe}_{4}$ and $\mathrm{Al}_{13} \mathrm{Cr}_{2}$ is $228 \mathrm{~kJ} \mathrm{~mol}^{-1}$ (Ref. 74). These activation energies are close to the activation energies for diffusion of $\mathrm{Fe}$ and $\mathrm{Cr}$ in fcc $\mathrm{Al}$ (about 190 and $240 \mathrm{~kJ} \mathrm{~mol}^{-1}$; Ref. 74).

For precipitation reactions in quenched materials that occur at temperatures below about $150^{\circ} \mathrm{C}$, the measured activation energies are mostly about $55-70 \mathrm{~kJ} \mathrm{~mol}^{-1}$. These values are considerably lower than the activation energy for diffusion of alloying elements in $\mathrm{Al}$, and this difference is generally ascribed to the presence of vacancies, with two possible arguments generally being cited. If vacancies are key to the formation of the zones or clusters, then the activation energy for migration of (mono) vacancies (about $60 \mathrm{~kJ} \mathrm{~mol}^{-1}$ in pure $\mathrm{Al}^{157,158}$ ) can be determining the activation energy of the overall process. It has also been considered that the presence of substantial amounts of excess vacancies reduces the activation energy for diffusion of alloying elements. This is because the activation energy for diffusion is the sum of the activation energy for creation of a vacancy and the activation energy for the migration of the alloying element into the vacancy, and in the presence of excess vacancies the former term is effectively zero. Thus, activation energies for formation of zones and clusters at low temperatures are ascribed to the activation energy for migration in the presence of an excess amount of vacancies.

In dissolution reactions, the solvus concentration changes during the heating and hence the equilibrium state is not constant. Thus, the activation energy methods outlined above are not valid. The consequences of applying activation energy analysis can be illustrated by considering the data on dissolution of $\delta^{\prime}$ in $\mathrm{Al}-\mathrm{Li}$ alloys at various heating rates (Fig. 8). These data show that in the limit for decreasing heating rates, the DSC curves converge, indicating that for low heating rates the dissolution reaction is determined mostly by the metastable equilibrium solvus. (In fact Noble and Bray $^{42}$ used this to determine the metastable equilibrium solvus.) If an activation energy analysis method were to be applied, the apparent activation energy for low heating rates would be infinitely large, and also at higher heating rates very high apparent activation energies would be observed. Notwithstanding the questionable validity, activation energy analysis methods have been applied to dissolution reactions. In line with the above consideration, the activation energy found is in general substantially larger than the activation energy for diffusion at equilibrium vacancy concentration. ${ }^{159}$ Interesting examples of such a questionable approach are provided by Dorward ${ }^{70}$ and Kamp ${ }^{160}$ who both applied activation energy analysis to the dissolution effect of the main strengthening phase in $\mathrm{Al}-\mathrm{Zn}-\mathrm{Mg}-\mathrm{Cu}$ alloys (a 7050 (Al-6.45Zn-2.1Mg-2.15Cu, wt- $\%$; Al-2.8Zn-2.45Mg$0.95 \mathrm{Cu}$, at.- $\%$ ) and a 7449 alloy, respectively). This dissolution effect is effect II in Fig. 13. For the overaged 7050 alloy this reaction occurs at about $210-230^{\circ} \mathrm{C}$ and the activation energy was determined ${ }^{70}$ to be $135 \mathrm{~kJ} \mathrm{~mol}^{-1}$, while for the 7449-T6 alloy the peak in the dissolution reaction occurred at $180-200^{\circ} \mathrm{C}$ and the activation energy was determined ${ }^{160}$ to be $70 \pm$ $7 \mathrm{~kJ} \mathrm{~mol}^{-1}$. Clearly, the two activation energies are quite different, and the processes cannot be ascribed to a single thermally activated process such as diffusion of $\mathrm{Mg}$ or $\mathrm{Zn}$. In both cases, the apparent activation energy is likely to have been influenced by the coarsening reaction (effect III), which effectively determines the end of effect II. As the activation energy for coarsening is equal to the activation energy for diffusion, this can explain why in this case the apparent activation energy determined from a dissolution reaction remains limited.

Few measurements of the activation energy for recovery have appeared in the literature. One paper ${ }^{73}$ determined the activation energy for recovery in a ball milled Al-Mg powder alloy to be about $121-$ $124 \mathrm{~kJ} \mathrm{~mol}^{-1}$. In this material, the activation energy for recrystallisation was considerably higher, 189$195 \mathrm{~kJ} \mathrm{~mol}^{-1}$. The activation energy for recovery through the process of internal strain release in a mechanically alloyed $\mathrm{Al}_{93} \mathrm{Fe}_{3} \mathrm{Ti}_{2} \mathrm{Cr}_{2}$ powder (effect 1 in Fig. 15) was determined ${ }^{74}$ to be $112 \mathrm{~kJ} \mathrm{~mol}^{-1}$.

For devitrivication of amorphous Al based alloys, the three exothermic reactions have been observed to have activation energies of $233 \pm 10,156 \pm 10$, and $174 \pm 10 \mathrm{~kJ} \mathrm{~mol}^{-1}$ in a melt spun $\mathrm{Al}_{70} \mathrm{Ni}_{13} \mathrm{Si}_{17}$ (at. $-\%$ ) alloy ${ }^{161}$ and 148,336 , and $274 \mathrm{~kJ} \mathrm{~mol}^{-1}$ in gas atomised $\mathrm{Al}_{85} \mathrm{Ni}_{10} \mathrm{Y}_{2.5} \mathrm{La}_{2.5}$ alloy powder. ${ }^{162}$ In the latter alloy, the three activation energies are close to the activation energies for self-diffusion, $\mathrm{La}$ diffusion in $\mathrm{Al}$, and $\mathrm{Ni}$ diffusion in $\mathrm{Al}$, suggesting that these three processes are rate controlling for the three reactions. ${ }^{162}$ Activation energies of devitrivication are strongly dependent on composition; for example, for the three alloys $\mathrm{Al}_{90} \mathrm{Ni}_{4} \mathrm{Sm}_{6}, \mathrm{Al}_{88} \mathrm{Ni}_{6} \mathrm{Sm}_{6}, \mathrm{Al}_{88} \mathrm{Ni}_{4} \mathrm{Sm}_{8}$ in Fig. 16, the first reaction was found ${ }^{82}$ to have activation energies $220 \pm 20,320 \pm 20$, and $360 \pm 20 \mathrm{~kJ} \mathrm{~mol}^{-1}$ respectively, but in $\mathrm{AlNi}_{7} \mathrm{Nd}_{3} \mathrm{Cu}_{3}$ the activation energy for this primary recrystallisation is much lower at $138 \pm$ $10 \mathrm{~kJ} \mathrm{~mol}^{-1}$ (Ref. 76).

It is noted that for some of the activation energies cited above no error limits were provided in the original papers. It is hoped that the analysis provided in the previous subsection and elsewhere ${ }^{120}$ will contribute to more consistent analyses of error limits in measured activation energies. 


\section{Single stage reaction models}

\section{$J M A K$, mean field, and other models compatible with} $\mathrm{d} \alpha / \mathrm{d} t=f(\alpha) \mathrm{k}(T)$

Having obtained the activation energy for a thermally activated reaction, the next step in obtaining a full description of the reaction is the determination of the reaction model $f(\alpha)$. Various proposed functions $f(\alpha)$ are given in Table 1 and, in many cases, the analysis can be completed simply by determining which of the models fits best to the data. From the reactions listed in this table, the JMAK model is the one most often invoked for thermally activated reactions in Al based alloys, even to the extent that in many publications ${ }^{163,164}$ the analyses of precipitation and recrystallisation reactions are simplified by only considering the JMAK model. Also, calorimetry data on reactions in multilayers are generally investigated using the JMAK model., ${ }^{7,86}$ In such an approach, the determination of the reaction model $f(\alpha)$ is reduced to finding the Avrami exponent $n$.

The procedure for analysing isothermal data under the assumption that the JMAK kinetics is applicable uses the combination of equations (6)-(8) or the integral formulation of the JMAK equation (see Table 1). For linear heating experiments, the temperature integral needs to be approximated. Descriptions of this have been provided by various authors, ${ }^{86,163,164}$ we will here use a description that applies the Murray and White ${ }^{126}$ approximation to yield ${ }^{165}$

$$
\alpha=1-\exp \left(-\omega^{\mathrm{n}}\right)
$$

with

$$
\omega=\frac{R T^{2}}{E \beta} k(T)
$$

From the above two equations, the expression for the reaction rate during linear heating is ${ }^{164}$

$$
\frac{\mathrm{d} \alpha}{\mathrm{d} t}=n \omega \exp \left(-\omega^{\mathrm{n}}\right)\left(\frac{2}{T}+\frac{E}{R T^{2}}\right)
$$

The value of $n$ is characteristic for the type of reaction. Its value can be derived from considering the following

- In reactions in which the interface between reaction product and reactant has a constant velocity, the volume of a growing nucleus is initially (before impingement has a significant influence) proportional to the time to the power $N_{\text {dim }}$, where $N_{\text {dim }}$ is the number of dimensions into which the reaction product is growing, i.e. for a growing sphere $N_{\text {dim }}$ is 3 , for a growing cylinder with fixed length that is much larger than its radius $N_{\text {dim }}$ is 2 .

- In diffusion controlled reactions, the position of the interface is a function of the square root of time and hence the volume of the reaction product grows initially as $t^{\mathrm{Ndim} / 2}$

Thus, if nucleation during the course of the reaction is negligible, the equation for $n$ is ${ }^{116,149}$

$$
n=N_{\operatorname{dim}} g
$$

where $g$ is 1 for linear growth or $1 / 2$ for parabolic (diffusion controlled) growth. It can further be shown ${ }^{116}$ that the influence of continuous nucleation is to increase $n$ by 1 , and hence the general equation for $n$ is

$$
n=N_{\operatorname{dim}} g+B
$$

where $B$ is 0 in the case of site saturation (no nucleation during the transformation), or 1 for continuous nucleation (at constant nucleation rate).

While it is often assumed that the (generalised) JMAK model is valid for solid state reactions, including precipitation and recrystallisation, there have been many reports of thermally activated solid state reactions that do not obey the JMAK model. ${ }^{1,166-175}$ Deviations from JMAK kinetics usually involve a reduced reaction rate in the later stages of the transformation, which is often detected as a deviation from the straight line expected in an Avrami plot (graph of $\ln [-\ln (1-\alpha)]$ versus $\omega$ ) at higher fractions transformed. This has instigated research into deviations from the JMAK models and a range of approaches to deal with these deviations have been proposed. Before reviewing these, it is first noted that recent theoretical work ${ }^{176,177}$ has proven that the JMAK kinetic equation (including its treatment of phantom nuclei ${ }^{178}$ ) is accurate for reactions with linear growth, provided: ${ }^{179}$

(i) product phases are randomly distributed

(ii) if nucleation occurs, nuclei are randomly distributed $^{180-183}$

(iii) average growth rates are independent of position in the sample ${ }^{184}$

(iv) impingement on objects other than neighbouring domains of the product phase is negligible

(v) blocking resulting from anisotropic growth ${ }^{185-188}$ is negligible

(vi) the reaction is not influenced by any timedependent process not directly related to the transformation studied (e.g. recrystallisation being influenced by recovery)

(vii) the equilibrium state is constant, i.e. the amount that can transform does not depend on time (this assumption can break down under nonisothermal conditions).

Hence, deviations from JMAK kinetics can only occur if one or more of these preconditions are not satisfied.

For diffusion controlled growth reactions, the growth rate is initially proportional to the square root of time (so-called parabolic growth) and impingement of diffusion fields around randomly distributed precipitates (so-called soft impingement) is an extremely complex mathematical problem. Various researchers have used simplifications and approximations, and generally observe that JMAK kinetics is a good approximation for diffusion controlled transformations with high supersaturation, which conform to assumptions (i)(vii), even though the JMAK type treatment of impingement is not valid. ${ }^{179}$ Early work by $\mathrm{Ham}^{189,190}$ has shown that for precipitates on a regular cubic array growing in three dimensions, JMAK kinetics is accurate up to a transformed fraction of about $0 \cdot 7$ to $0 \cdot 8$, while for later stages the reaction is slightly slower than JMAK kinetics. Also, Monte Carlo simulations of the transformations of grains which grow according to a diffusion controlled mechanism (i.e. growth rate is proportional to the inverse of the particle radius) indicate that JMAK kinetics is a good approximation for diffusion controlled transformations. ${ }^{191}$ A similar conclusion was reached by Uebele and Hermann ${ }^{192}$ who 
approximated diffusion controlled growth in a mathematical model which considers parabolic growth and hard impingement. Diffusion controlled growth reactions are further discussed at the end of this section and in Appendix 2.

It has been shown ${ }^{179}$ that if any of preconditions (i)(v) are not met this will in most cases result in a reaction for which the fraction transformed initially conforms to JMAK kinetics, while the reaction rate for later stages is reduced as compared to the JMAK kinetics. A wide range of approaches dealing with kinetics of precipitation and recrystallisation reactions incorporating variations from the JMAK model have been proposed. These methods include numerical simulation methods which require substantial computing time, such as Monte Carlo and cellular automata methods applied to recrystallisation, ${ }^{193}$ and numerical methods for precipitation based on simulations of diffusion fields, ${ }^{194}$ and mean field approximations. ${ }^{195-199}$ Results of these simulations and iterative methods can be compared with calorimetry data, but the simulations depend on the availability of various parameters and hence they are not flexible analysis methods that can be employed to analyse reactions for which certain characteristics are at the outset unknown. Hence, these simulations will not be considered here; for a detailed overview of these methods the reader is referred to the papers cited above and the overview of modelling and simulation of recrystallisation by Rollett. ${ }^{193}$ Instead, in the remainder of this section, attention is given to models that can be applied directly to analysis of transformation rate data on reactions for which no accurate simulations are available, and to recent models which are relevant to the understanding of such methods. The emphasis will be on models for precipitation, devitrivication, and recrystallisation reactions which have either been recently derived or have recently attracted increased attention, and which have been reported to be able to deal with deviations from JMAK kinetics. The model by Woldt ${ }^{200}$ considers recrystallisation, the models by Yavari and Negri ${ }^{174}$ and Gangopadhyay et $a l^{201}$ consider nanocrystallisation during devitrivication, Kelton's model ${ }^{202,203}$ considers transformations that involve coupled fluxes of interfacial attachment and long-range diffusion, the mean field model considers precipitation, and the work by Starink and Zahra ${ }^{170}$ describes a kinetic equation that can be valid for a range of reaction types.

In an attempt to find an explanation for deviations from JMAK kinetics observed for recrystallisation of several metals and alloys, Woldt ${ }^{200}$ presented a model for primary recrystallisation which includes two drastic modifications with respect to JMAK kinetics: a nucleation rate related to the size of the interfacial area of the recrystallised grains present and an exponentially decreasing growth rate for each grain. Thus, the Woldt model modifies the assumption of linear growth and modifies precondition (ii). The resulting mathematical treatment provides solutions for fractions transformed in an iterative scheme, i.e. no direct closed form solutions for the model are available. Some limited evidence on nucleation of grains at the recrystallised/ deformed interface in $\mathrm{Cu}-5 \mathrm{Al}(\mathrm{wt}-\mathrm{O})$ ) and nucleation rates in pure $\mathrm{Cu}$ at the surface of a recrystallising SEM sample was presented which is in line with the modifications, and computed transformation rates indeed show a resemblance to measured recrystallisation rates. However, as yet, the model has not been quantitatively verified on recrystallisation in material away from sample edges nor has it found any application beyond the paper in which it was first introduced. Thus, before this model for recrystallisation can be confidently used, further work is needed to verify its basic assumptions. It should also be noted that the approach by Woldt ${ }^{200}$ is by no means the only approach that can quantitatively explain the slowing down of the reaction in the later stages. For example, it has been shown ${ }^{179}$ that if any of preconditions (i)-(v) are not met, this will in most cases result in a reaction for which the transformation rate in the later stages is reduced as compared to the JMAK kinetics. Both Sun et al. ${ }^{184}$ and Starink ${ }^{179}$ considered the case of a transformation with growth rates and nucleation rates that are position dependent and found resulting kinetics very similar to predictions by Woldt's model. In practical terms, the non-transparent nature of the model caused by the extensive calculations that are needed to obtain solutions, can further hamper its application.

Even though nanocrystallisation in an amorphous Finimet $\left(\mathrm{Fe}_{73.5} \mathrm{Cu}_{1} \mathrm{Nb}_{3} \mathrm{Si}_{13 \cdot 5} \mathrm{~B}_{9}\right)$ alloy has been investigated by JMAK type expressions, ${ }^{204}$ it is mostly accepted that deviations from JMAK kinetics frequently occur. These deviations from JMAK kinetics observed in nanocrystallisation of amorphous alloys have been investigated by Yavari and $\mathrm{Negri}^{174}$ and by Gangopadhyay et $a l^{201}$ The work by Yavari and Negri ${ }^{174}$ indicates that, in Fe based amorphous alloys, rejection of solute from the growing nanocrystal will cause diffusion to become significant and that inclusion of the variation of the nucleation frequencies during the transformation process is needed if coherent results are to be obtained from an analysis of transformation kinetics. It was indicated that this analysis should also be applicable to nanocrystallisation of amorphous $\mathrm{Al}$ based alloys, but no detailed model was presented by these authors. Gangopadhyay et al. ${ }^{201}$ observed that JMAK failed to provide an adequate description of nanocrystallisation during devitrivication of melt spun $\mathrm{Al}_{88} \mathrm{Gd}_{6} \mathrm{La}_{2} \mathrm{Ni}_{4}$, and that Avrami plots showed at least three regions with different slope. They suggested a model in which the nanocrystals grow in a diffusion controlled reaction with each crystal growing in an area with a conical shape. This model results in transformation kinetics that initially follow JMAK kinetics, and in later stages a slowing down with respect to JMAK kinetics occurs. The Avrami plot shows two linear stages, which resembles the observation on the $\mathrm{Al}_{88} \mathrm{Gd}_{6} \mathrm{La}_{2} \mathrm{Ni}_{4}$ alloy. However, the unusual geometry of the diffusion field, makes it unlikely that the model has general validity.

Kelton $^{202,203}$ constructed a kinetic model for nucleation that couples the stochastic fluxes of interfacial attachment and long-range diffusion, and solved this coupled flux model numerically. It was found that these coupled fluxes decrease the steady state nucleation rate and increase the induction time compared to the classical theory. It was shown that the model could explain many of the microstructural features and kinetics observed in devitrivication in metallic glasses, especially the nanocrystallisation process. ${ }^{205}$ For example, the model shows how different average $n$ values 
obtained from an Avrami analysis are directly related to the concentration of the solutions, with $n$ increasing with concentration. The coupled flux model also captures the decrease in apparent $n$ with progress of the reaction, which is a direct consequence of the long-range diffusion becoming a dominant factor in the later stages. While the model is successful and can capture many of the aspects of the kinetics of nanocrystallisation, no direct application to analysis of transformation data, such as obtained through calorimetry, has as yet been presented. The need for numerical solution of the coupled flux equations will probably limit the model's applicability to analysing transformation data.

In a broad sense, all models discussed so far are consistent with the approach described by equation (6), i.e. for each set of parameters in the respective models, in principle, a function $f(\alpha)$ can be identified, but the philosophies are different. For the coupled flux model, defining $f(\alpha)$ would involve defining interfacial free energy, diffusion rate, start composition, metastable equilibrium composition at the interface with the nucleus and driving free energy, and also in Woldt's model a range of parameters would need to be defined before $f(\alpha)$ could be identified. Thus, the philosophies behind the approaches are very different and it is unlikely that the Kelton and Woldt models will be used for analysis of calorimetry data through defining $f(\alpha)$. A more fruitful approach to the relation between these models and calorimetry would be to use calorimetry to try to verify the models, but no such work has been published as yet.

Starink and Zahra $^{170}$ also noted the deviations between the JMAK model and data on a range of transformations, including recrystallisation and precipitation reactions, and devised a model to deal with this. In contrast with the type of modelling approaches used by Kelton and Woldt, the approach taken was specifically aimed at obtaining a closed form solution to the transformation rate and the reaction function $f(\alpha)$, and to apply this directly to the analysis of calorimetry data. The resulting model has been consistently successful in describing precipitation reactions in $\mathrm{Al}$ based alloys and selected other alloys, and, although no studies of application to recrystallisation have been published, the general trends in deviations from JMAK kinetics for recrystallisation reactions can also be captured by the model. The model contains an approximation for impingement that deviates from the JMAK treatment of impingement using the equation ${ }^{170,179}$

$$
\alpha=1-\left(\frac{\alpha_{\mathrm{ext}}}{\eta_{\mathrm{i}}}+1\right)^{-\eta_{\mathrm{i}}}
$$

where $\alpha$ is the fraction transformed, $\eta_{\mathrm{i}}$ is the impingement exponent, and $\alpha_{\text {ext }}$ is the extended fraction transformed. As in the JMAK model, $\alpha_{\text {ext }}$ can be taken as $\omega$ and equals $(k t)^{\mathrm{n}}$ for isothermal reactions. The resulting reaction function $f(\alpha)$ for the model is

$$
f(\alpha)=n\left[(1-\alpha)^{-1 / \eta_{\mathrm{i}}}-1\right]^{(\mathrm{n}-1) / \mathrm{n}}(1-\alpha)^{\left(\eta_{\mathrm{i}}+1\right) / \eta_{\mathrm{i}}}
$$

Equations (35) and (35a) incorporate the JMAK model as, in the limit of $\eta_{\mathrm{i}} \rightarrow \infty$, both are identical to the corresponding JMAK expressions. While initially the application of equation (35) with an adjustable impingement exponent was purely based on a good fit with experimental data, some new theoretical work and comparisons with existing theoretical work later showed that equation (35) can provide good approximations for transformations in which deviations from the JMAK assumptions (i)-(vi) occur. ${ }^{179}$

A further approach which is applied to the modelling of precipitation reactions is the mean field model. This approach considers that the influence of the impingement of diffusion field on the growth rate of precipitates of radius $R(t)$ can be described by considering the average solute content of the matrix through ${ }^{190,206}$

$$
\frac{\mathrm{d} R(t)}{\mathrm{d} t}=\left[\frac{c_{\mathrm{m}}-\bar{c}(t)}{c_{\mathrm{p}}-c_{\mathrm{m}}}\right] \frac{D}{R(t)}
$$

where $D$ is the diffusivity, $\bar{c}(t)$ is the average solute content of the matrix, and $c_{\mathrm{p}}$ and $c_{\mathrm{m}}$ are the precipitate and matrix compositions at the interface. This equation forms the basis of computer based iterative approaches to the modelling of precipitation in which the time evolution of the sizes of a collection of particles is calculated. It can be shown that approaches based on equation (36) are consistent with the approach based on equations (6) and (7), and specifically that, for a reaction with a dilute solution and a fixed number of particles present, equation (36) yields nearly exactly the same as equation (35) with $\eta_{\mathrm{i}}=5.67$ and $n=1.5$ (see Appendix 2). Also, for less dilute solutions, equation (35) with $n=1.5$ provides a very high accuracy approximate solution to equation (36). Thus, the mean field model for precipitation is generally not consistent with the JMAK model, but is, in good approximation, consistent with equation (35).

It appears clear that the analysis of the mean field model casts some severe doubts on the widespread practice of analysing precipitation reactions using the JMAK model, and especially for the later stages of the reaction such an analysis can be expected to become invalid. The Starink-Zahra equation is flexible and encompasses JMAK kinetics, the mean field model for precipitation, and a range of deviations from JMAK kinetics which occur in parabolic growth and linear growth reactions.

\section{Other models for precipitation in Al based alloys}

The approach based solely on equations (6) and (7), in combination with the table of $f(\alpha)$ functions (Table 1 ), or a more restricted selection of functions, can in many cases be inappropriate. Especially for precipitation reactions studied by DSC it is found that that the retrograde solubility curve will have a significant effect on the precipitation rates in the later stages of the reaction, and this invalidates fitting of the standard $f(\alpha)$ functions. Hence, a number of approaches have appeared in the literature which either circumvent this problem by only considering the start of the reaction, or which attempt to account for the retrograde solvus.

One treatment $\mathrm{t}^{207}$ of thermally activated reactions in the presence of a retrograde solvus starts by taking the basic equations (6) and (7) and considering that, in isothermal experiments, $\alpha$ is generally assumed to be given by

$$
\alpha=\frac{x(t)}{x_{\mathrm{end}}}
$$

where $x(t)$ is the amount precipitated at time $t$ and 
$x_{\text {end }}$ is the total amount that can precipitate at $T$. It was realised that, because of the temperature dependent solubility of alloying elements in the $\mathrm{Al}$ rich phase, the transformation rate cannot be the product of two separate functions, and the function $f(\alpha)$ in equation (6) must be dependent on the temperature. This was achieved in a general way by defining the following four equations (38)-(41) to replace equations (6) and (7)

$$
\xi=\frac{x(t)}{x_{\max }}
$$

and

$$
\alpha^{\prime}=x(t) / x_{\text {eq }}(T)
$$

in which $x_{\mathrm{eq}}(T)$ is the maximum amount that can precipitate at a given temperature, i.e.

$$
x_{\mathrm{eq}}(T)=\lim _{\mathrm{t} \rightarrow \infty} x(t, T)
$$

and $x_{\max }$ is a constant representing the maximum amount of material that can transform, i.e. the maximum value that $x_{\mathrm{eq}}(T)$ can attain. The transformation rate equation is now assumed to be

$$
\frac{\mathrm{d} \xi}{\mathrm{d} t}=k(T) f^{\prime}(\xi, T)
$$

For the kinetic model term $f^{\prime}(\xi, T)$, the Šesták and Berggren $^{115}$ equation was modified to yield an equation that incorporates the temperature dependency of $x_{\mathrm{eq}}(T)$

$$
\begin{aligned}
f^{\prime}(\xi, T)= & \left(1-\alpha^{\prime}\right)^{\mathrm{p} 1}(1-\xi)^{\mathrm{p} 2}\left[-\ln \left(1-\alpha^{\prime}\right)\right]^{\mathrm{q} 1} \\
& \times[-\ln (1-\xi)]^{\mathrm{q} 2}
\end{aligned}
$$

where $p 1, p 2, q 1, q 2 \geqslant 0, p 1+p 2=p$, and $q 1+q 2=q$.

The above set of equations was applied to data on precipitation in $\mathrm{Al}-1 \mathrm{Si}$ (at.- $\%$ ) alloys. The solubility of $\mathrm{Si}$ in the $\mathrm{Al}$ phase is well known, and can be described by ${ }^{208}$

$$
c_{\mathrm{Si}}(T)=c_{\infty} \exp \left(-\frac{\Delta H_{\mathrm{Si}}}{R T}\right)
$$

where $c_{\infty}=19$ and the enthalpy of solution $\Delta H_{\mathrm{Si}}=$ $0.52 \mathrm{eV}$. Hence

$$
x_{\mathrm{eq}}=x_{\max }-c_{\mathrm{Si}}(T)
$$

$x_{\max }=0 \cdot 01$. The results of the fitting of the DSC curves for $\mathrm{Al}-1 \mathrm{Si}($ at. $-\%)$ using this approach are presented in Fig. 25. The fitted curves in general show a good correspondence with the measured DSC curves, and in particular capture well the rapid transition from exothermic to endothermic heat flow, without a flat part of the curve with zero heat flow. Notwithstanding the good fit displayed in Fig. 25, this approach has some major drawbacks, most notably that the parameters $p$ and $q$ cannot be directly interpreted in terms of the reaction occurring in the material, i.e. in terms of the classification proposed above (in 'Introduction: general objectives'), this model is a generic model with a physical basis that is unclear. As a consequence, the model has not seen any application beyond the paper in which it was introduced, and more recent models (see below) have attempted to include physically meaningful parameters in the model.

Another model for analysing and fitting precipitation effects in Al based alloys during linear heating was

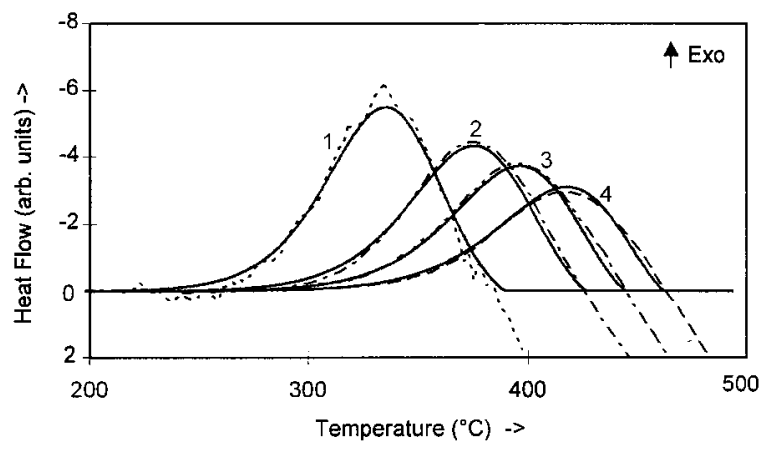

curve 1: $2.5 \mathrm{~K} \mathrm{~min}^{-1}$; curve 2: $10 \mathrm{~K} \mathrm{~min}^{-1}$; curve 3: $20 \mathrm{~K} \mathrm{~min}^{-1}$; curve 4: $40 \mathrm{~K} \mathrm{~min}^{-1}$

25 Experimental (dotted/dashed lines) and computer generated (solid lines) DSC curves obtained using equations $(40)-(43)$ and heating rates of $2 \cdot 5,10,20$ and $40 \mathrm{~K} \mathrm{~min}^{-1}$ (from Ref. 207)

proposed by Borrego and González-Doncel ${ }^{209}$ in a study of $6061-\mathrm{Al} / 15$ vol. $-\% \mathrm{SiC}_{\mathrm{w}} \mathrm{PM}$ composites. The main part of the model is identical to the JMAK model for the linear heating case, ${ }^{164}$ i.e. equation (30) is adopted, with the equation for the state variable for linear heating

$$
\omega=\int k_{\mathrm{o}} \exp \left[-\frac{E_{\mathrm{a}}}{k_{\mathrm{B}} T}\right] \mathrm{d} t \approx \frac{T^{2} R}{\beta E_{\mathrm{a}}} k_{\mathrm{o}} \exp \left[-\frac{E_{\mathrm{a}}}{R T}\right]
$$

As shown above, the reaction rate can be obtained by differentiation, yielding equation (32) or the variant given by Borrego and González-Doncel ${ }^{209}$

$$
\frac{\mathrm{d} \alpha}{\mathrm{d} t}=n \frac{\mathrm{d} \omega}{\mathrm{d} t} \omega^{\mathrm{n}-1} \exp \left(-\omega^{\mathrm{n}}\right)
$$

This reaction rate should be proportional to the heat effect measured in the DSC and hence the above equations represent a theoretical model, in closed form and with parameters $k_{\mathrm{o}}, E_{\mathrm{a}}$, and $n$, that can be fitted to DSC data. Novel in the approach is that the nucleation rate $I(t)$ of precipitates is assumed to be given by

$$
I(t)=c t^{\mathrm{q}_{\mathrm{N}}} \exp \left(-\frac{\Delta E_{\mathrm{n}}}{k_{\mathrm{B}} T}\right)
$$

where $\Delta E_{\mathrm{n}}$ is the activation energy for nucleation and exponent $q_{\mathrm{N}}$ is constant. The Borrego-González-Doncel model was fitted to DSC data on the precipitation in $6061(\mathrm{Al}-\mathrm{Si}-\mathrm{Mg})$ alloys and an example of the results is presented in Fig. 26. As has been noted elsewhere ${ }^{210}$ the quality of the fit is limited suggesting that the model is not particularly suited to describe precipitation in these $\mathrm{Al}-\mathrm{Si}-\mathrm{Mg}$ alloys. Borrego and González-Doncel later expanded their model to allow an $n$ value that varies during the progress of the reaction. ${ }^{211}$ This allowed highly accurate fits to DSC data, but this introduction of additional fittable parameters, without experimental verification of the physical basis, has attracted criticism. ${ }^{210}$ The Borrego and González-Doncel models have not been applied to $\mathrm{Al}$ based alloys beyond the papers in which they were initially introduced, but have been applied in other alloys. ${ }^{212-214}$ (In one of the studies, ${ }^{212}$ it was observed that 'a slight misfit between both experimental and theoretical DSC curves [..] is observed at the end of the first peak', while fits in other works ${ }^{213}$ are less perfect than has been achieved with other models.) 


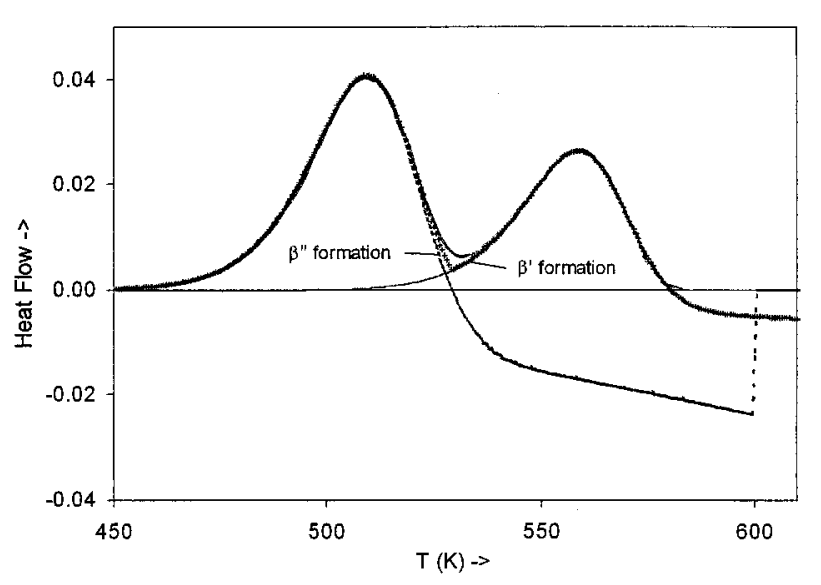

26 Part of DSC curve for solution treated 6061 alloy showing precipitation effects due to $\beta^{\prime \prime}$ and $\beta^{\prime}$ phase: thick, grey curve represents experimental DSC data, thinner curves are model fits (obtained with impingement exponents $\eta_{i, 1}=2 \cdot 5, \quad \eta_{i, 2}=3$ and transformation exponents $s_{1}=s_{2}=2 \cdot 5$ ) from Starink-Zahra model, and sum of the two is given by ++++ (from Ref. 210; note that, due to near perfect fit, curves cannot be distinguished over substantial sections)

Also, the approach of an adjustable impingement factor has been applied in the derivation of a model for precipitation and recrystallisation. For this model, $\alpha_{\text {ext }}$ was obtained on the basis of the temperature integral (see also the section devoted to multistage models, below)

$$
\alpha_{\mathrm{ext}} \cong\left\{\frac{\beta R}{E_{\mathrm{G}}} k_{\mathrm{c}} \exp \left[\frac{-E_{\mathrm{eff}}}{R T}\right]\left(\frac{T}{\beta}\right)^{2}\right\}^{\mathrm{s}}
$$

where $T$ is the temperature, $s$ is the transformation exponent, $E_{\text {eff }}$ is the effective activation energy, and $k_{\mathrm{c}}$ is a (pre-exponential) constant. Within the model also the variation of the (metastable-) equilibrium state with temperature is accounted for by using

$$
\dot{\xi}=\frac{\mathrm{d} \xi}{\mathrm{d} t}=\frac{\mathrm{d}}{\mathrm{d} t}\left[\alpha \frac{c_{\mathrm{o}}-c_{\mathrm{eq}}(T)}{c_{\mathrm{o}}}\right] A_{2}
$$

where $\xi$ is the amount of atoms incorporated in the growing nuclei divided by the maximum amount of atoms that can be incorporated according to the equilibrium phase diagram, $c_{\mathrm{o}}$ is the initial concentration of alloying element dissolved, and $A_{2}$ is a constant. The DSC signal is proportional to $\dot{\xi}$. The term $c_{\mathrm{eq}}(T)$ is approximated by regular solution expressions

$$
c_{\mathrm{eq}}(T)=c_{\infty} \exp \left(-\frac{\Delta H}{R T}\right)
$$

where $c_{\infty}$ is a constant and $\Delta H$ is the enthalpy of solution. The model has been applied to the analysis of DSC effects of precipitation in Al based alloys and generally good correspondence between model and data has been observed. ${ }^{11,39,46,170,210}$

\section{Determination of reaction exponent $n$}

In many cases of the analysis of thermally activated solid state reactions, the objective is to derive all three elements of the kinetic triplet and, hence, if the reaction corresponds to JMAK kinetics or Starink-Zahra kinetics, the reaction exponent $n$ will be obtained in the course of this procedure. However, instead of obtaining the full expression for $f(\alpha)$, in some cases the analysis can be limited to just obtaining $n$ without considering the full expression for $f(\alpha)$. Such a more limited analysis can be enforced if the later parts of the reaction cannot be analysed due to excessive overlap with a subsequent reaction, or if no satisfactory description of the later stages of the reaction can be found using the standard expressions for $f(\alpha)$.

Several methods to derive the reaction exponent $n$ for reactions occurring during linear heating have been proposed. ${ }^{215-219}$ Some of these methods ${ }^{215-217,219}$ pre-suppose that JMAK treatment of impingement is valid and some methods ${ }^{217,218}$ make use of Doyle's approximation $^{123-125}$ for the temperature integral. As it is clear from the above that both approximations introduce significant errors, they are not reviewed here and for a description of the well known derivation of $n$ exponents for reactions that correspond to JMAK kinetics through the so-called Avrami plot (a graph of $\ln [-\ln (1-\alpha)]$ versus $\omega)$ the reader is referred to standard works ${ }^{219}$ and various examples. ${ }^{161,205}$ Instead, here, a method ${ }^{170}$ for determining $n$ that does not suffer from inaccurate approximations for the temperature integral, and which is not limited to JMAK kinetics, is reviewed.

We assume that for a narrow temperature range at the beginning of the reaction both impingement and the variation of the equilibrium state with the temperature are negligible, and for reactions that conform to JMAK, Starink-Zahra, and mean field diffusion models we may approximate (see equation (47))

$$
A_{3} \xi \cong \alpha_{\mathrm{ext}} \cong\left\{\frac{\beta R}{E_{\mathrm{G}}} k_{\mathrm{c}} \exp \left[\frac{-E_{\mathrm{eff}}}{R T}\right]\left(\frac{T}{\beta}\right)^{2}\right\}^{\mathrm{n}}
$$

where $A_{3}$ and subsequent $A_{4}$ to $A_{8}$ are constants (different symbols $s$ and $n$ were used to allow for the possibility that linear heating and isothermal paths would yield different transformation exponents). Taking the logarithm yields

$$
\ln \xi \cong \frac{-n E_{\text {eff }}}{R T}+2 n \ln T+A_{4}
$$

As the variation in $n \ln T$ is generally much smaller than the variation in $E_{\text {eff }} / R T$, we may approximate

$$
R \frac{\mathrm{d} \ln \xi}{\mathrm{d}(1 / T)} \cong-n\left(E_{\text {eff }}+2 R T_{\text {av }}\right)
$$

where $T_{\mathrm{av}}$ stands for the average temperature of the (narrow) temperature range considered. Thus, $n$ can be obtained from the slope of a plot of $\ln \xi$ versus $-E_{\text {eff }} / R T$. It is further noted that, as a result of taking the logarithm and the derivative, we may, in equation (52), insert any variable proportional to $\xi$ in place of $\xi$. For DSC, this means that we can use the integrated evolved heat $\Delta Q(T)$, instead of $\xi$.

For a derivative type thermal analysis method like DSC the signal is proportional to $\mathrm{d} \xi / \mathrm{d} t$, and to obtain $n$ without the need for integration we can calculate the derivative of equation (50) and subsequently take the logarithm, which yields

$\ln \dot{\xi} \cong \frac{-n E_{\text {eff }}}{R T}+\ln \left(\frac{E_{\text {eff }}}{R}+2 T\right)+2(n-1) \ln T+A_{6}$ 
Considering again that the variation in $\ln T$ is generally much smaller than the variation in $E_{\text {eff }} / R T, \mathrm{~d} \xi / \mathrm{d} t$ may be plotted versus $-E_{\text {eff }} / R T$ and $n$ can be obtained from the slope using

$$
\begin{gathered}
R \frac{\mathrm{d} \ln \dot{\xi}}{\mathrm{d}(1 / T)} \cong-n E_{\text {eff }}-R T\left\{2(n-1)+\left[\frac{E_{\text {eff }}}{2 R T}+1\right]^{-1}\right\} \\
\cong-n\left(E_{\text {eff }}+2 R T\right)-R T\left\{-2+\left[\frac{E_{\text {eff }}}{2 R T}+1\right]^{-1}\right\}
\end{gathered}
$$

Using $E_{\mathrm{eff}} / R T \gg 1$, the second term on the righthand side in equation (55) is much smaller than the first and thus one can obtain the following useful approximation

$$
R \frac{\mathrm{d} \ln \xi}{\mathrm{d}(1 / T)} \cong-n\left(E_{\mathrm{eff}}+2 R T_{\mathrm{av}}\right) \approx R \frac{\mathrm{d} \ln \dot{\xi}}{\mathrm{d}(1 / T)}
$$

However, as indicated by the use of the $\approx$ symbol, the latter approximation in this equation is less accurate than the first. A significantly better approximation of equation (54) is

$$
R \frac{\mathrm{d} \ln \dot{\xi}}{\mathrm{d}(1 / T)} \cong-n\left(E_{\mathrm{eff}}+2 R T_{\mathrm{av}}\right)+2 R T_{\mathrm{av}}
$$

Here, we have again neglected the variation in $T$ over the temperature interval and used $T_{\mathrm{av}}$. From equation (57), it follows that $n$ can be obtained from the slope of a plot of $\ln (\mathrm{d} \xi / \mathrm{d} t)$ versus $1 / T$. In equation (57), we may insert any variable proportional to $\mathrm{d} \xi / \mathrm{d} t$ in place of $\mathrm{d} \xi / \mathrm{d} t$. For DSC, this means that we can use the heat flow $q(T)$ instead of $\mathrm{d} \xi / \mathrm{d} t$.

As examples of application, precipitation in slowly cooled Al-6Si (at.- $\%$ ), GPB zone formation in $\mathrm{Al}-\mathrm{Cu}-$ $\mathrm{Mg}$ based alloys, and recrystallisation of deformed fcc metals were analysed. ${ }^{170}$ For the slowly cooled Al-6Si (at.- \%), precipitation of $\mathrm{Si}$ starts with a process for which $s=0.5$, indicating growth of undissolved coarse $\mathrm{Si}$ particles. It was further shown ${ }^{170}$ that in $\mathrm{Al}-\mathrm{Cu}-\mathrm{Mg}$ and $\mathrm{Al}-\mathrm{Cu}-\mathrm{Mg}-\mathrm{Li}-\mathrm{Zr}$, GPB zone formation occurs mainly via the growth of pre-existing nuclei $(n=1 \cdot 5)$, while in $\mathrm{Al}-\mathrm{Cu}-\mathrm{Mg}-\mathrm{Zr}$ it occurs via nucleation and growth $(n=2 \cdot 5)$. Also, recrystallisation of deformed $\mathrm{Ag}$ and $\mathrm{Cu}$ could be analysed successfully. ${ }^{170}$

\section{Multistage models (multiple Arrhenius terms)}

The above treatment of the temperature integral is important in analysis and modelling of reactions that are governed by a single thermally activated process, which are related to a single activation energy. Such a process is said to exhibit an isokinetic relationship (IKR). ${ }^{220}$ However, many processes do not comply with these requirements, or only comply in approximation, be it a good or a less accurate approximation. To treat processes that do not exhibit isokinetic behaviour, approaches in which multiple processes with a range of activation energies occur have been proposed. These approaches, in general, lead to transformations that cannot be approximated by an isokinetic process, and which cannot be described by a single state variable. One type of process for which the thermal activation can often not be described by a single activation energy is a nucleation and growth reaction. A characteristic of this type of two-stage process that sets it aside from other two-stage processes is that here the first stage, nucleation, does in itself not lead to substantial amounts of transformed material, as only growth of the nuclei causes the transformation of substantial amounts of material. In this case, it can be shown that under specific conditions the overall process shows a behaviour that is in good approximation isokinetic and a treatment for this two-process reaction has been described by Woldt and co-workers. ${ }^{215,221}$ In the Woldt approach, both the nucleation rate $I(T)$ and the growth rate are assumed to follow an Arrhenius type temperature dependency (see also Krüger ${ }^{216}$ and de Bruijn et al. ${ }^{222}$ )

$$
\begin{aligned}
& G(T)=G_{\mathrm{o}} \exp \left(\frac{-E_{\mathrm{G}}}{R T}\right) \\
& I(T)=I_{\mathrm{o}} \exp \left(\frac{-E_{\mathrm{N}}}{R T}\right)
\end{aligned}
$$

where $E_{\mathrm{G}}$ and $E_{\mathrm{N}}$ are the activation energies for growth and nucleation, respectively. The latter equation implies that nucleation depends only on the mobility of atoms. Especially when the driving force for the formation of nuclei (i.e. the change in Gibbs free energy due to the transformation of a region) is small, this may become invalid.

We may now use the so-called extended volume concept to define the extent of the transformation. For the present case it is given by

$$
\alpha_{\mathrm{ext}}=\int_{0}^{\mathrm{t}} A_{1} I(z)[G(t-z)]^{\mathrm{m}} \mathrm{d} z
$$

where $A_{1}$ is a constant which is related to the initial supersaturation, the dimensionality of the growth and the mode of transformation, while $m$ is a constant related to the dimensionality of the growth and the mode of transformation (diffusion controlled growth or linear growth). If the difference between $E_{\mathrm{G}}$ and $E_{\mathrm{N}}$ is small, equations (58)-(60) lead to a relatively simple expression for $\alpha_{\text {ext }}$ (Refs. 215, 216)

$$
\alpha_{\mathrm{ext}} \cong\left\{\frac{\beta R}{E_{\mathrm{G}}} k_{\mathrm{c}} \exp \left[\frac{-E_{\mathrm{eff}}}{R T}\right]\left(\frac{T}{\beta}\right)^{2}\right\}^{\mathrm{n}}
$$

where

$$
\begin{aligned}
& E_{\text {eff }}=\frac{m E_{\mathrm{G}}+E_{\mathrm{N}}}{m+1} \\
& n=m+1
\end{aligned}
$$

and $k_{\mathrm{c}}$ is a constant. It should be noted that equation (61) is an approximation which is only accurate if $E_{\mathrm{N}} \approx E_{\mathrm{G}},{ }^{215,221}$ and the deviation increases with increasing difference between $E_{\mathrm{G}}$ and $E_{\mathrm{N}}{ }^{221}$

One point that was not considered in the papers in which equations (61)-(63) were derived and analysed is that an improvement in accuracy of calculation of $\alpha_{\text {ext }}$ can be achieved by using the more accurate approximation of the temperature integral given by equation (23). Applying this approximation for the temperature integral leads to

$$
\alpha_{\mathrm{ext}} \cong\left\{0.786 k_{\mathrm{c}} \frac{T}{\beta}\left(\frac{R T}{E_{\mathrm{G}}}\right)^{0.95} \exp \left[\frac{-E_{\mathrm{eff}}}{R T}\right]\right\}^{\mathrm{n}}
$$

One important element of the above treatment lies in the fact that it shows that, for a specific two-stage reaction 
(nucleation and growth) with a specific temperature dependence of the two stages (two Arrhenius type dependencies with $E_{\mathrm{N}} \approx E_{\mathrm{G}}$ ), the resulting transformation can, in most cases, still be described accurately with one effective activation energy.

\section{Determination of volume fractions of reaction products and phases}

\section{General objectives}

The volume fractions of precipitates and intermetallic phases in $\mathrm{Al}$ based alloys have a strong influence on the properties such as yield strength, work hardening, toughness, and conductivity. In studies of Al based alloys, it is thus often necessary to determine the volume fractions of precipitates or intermetallic phases present and to monitor the changes in the amounts of these phases during thermomechanical or heat treatments or determine the influence of composition changes on the amounts of precipitates and intermetallic phases present. Depending on size of precipitate, measurement of volume fraction of precipitates or intermetallic phases can, in many cases, be achieved by optical microscopy or electron microscopy, but these techniques can be cumbersome. In the case of TEM, the volume that can be studied is limited (to at best about $10 \times 10 \times 0 \cdot 1 \mu \mathrm{m}$ ) and especially TEM can be prone to error. It has been shown in a range of publications that DSC can be an efficient method for determining average volume fractions of precipitates or intermetallic phases and these methods are reviewed in this section.

\section{Volume fractions of precipitates measured from solid-solid reactions}

A method for obtaining the volume fractions of the precipitates based on the heat evolutions due to the precipitation of the phases as measured by DSC has been outlined in various works by Starink and coworkers. $^{20,47,223-225}$ (These methods were inspired by early work by van Rooyen and Mittemeijer. ${ }^{208}$ ) The main step in the analysis is the assumption that the heat of formation or dissolution of a precipitate or intermetallic phase is constant, i.e. if a precipitate of composition $\mathrm{M}_{\mathrm{m}} \mathrm{A}_{\mathrm{a}} \mathrm{B}_{\mathrm{b}} \mathrm{C}_{\mathrm{c}}$ forms, then the heat effect measured in the DSC is given by

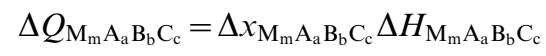

where $\Delta Q$ represents the heat effect in the DSC, $\Delta x$ represents the amount of phase formed, and $\Delta H$ represents the enthalpy of formation of that phase (per 'molecule' or unit of $\mathrm{M}_{\mathrm{m}} \mathrm{A}_{\mathrm{a}} \mathrm{B}_{\mathrm{b}} \mathrm{C}_{\mathrm{c}}$ ). The equation is also valid for dissolution reactions, in which case the reaction is endothermic and $\Delta Q$ will be negative; and as the amount of phase will reduce, $\Delta x$ will also be negative. To be able to apply the method, values of $\Delta H$ should be available. Values of $\Delta H$ for specific phases can be obtained in two ways. The first method is possible if an experiment can be performed in which $\Delta Q$ can be measured and $\Delta x$ is known, an example being a precipitation reaction for which initially all precipitating elements are dissolved while the remaining amount in solution after completion of the exothermic heat release $\Delta Q$ can be determined from thermodynamic data from other additional experiments. A second method can be applied when sufficient data on the thermodynamic functions (e.g. Gibbs free energy) are available to calculate, on a purely theoretical basis, the change in free energy involved in the precipitation or dissolution reaction. While CALPHAD approaches should, in principle, be able to provide such data, in practice, no detailed work using CALPHAD has been published, and the derivation of $\Delta H$ values from thermodynamic data has focused on an approach in which the thermodynamics of the system is simplified by assuming that a regular solution model approach is valid. ${ }^{223,226}$ This approach makes use of the theoretical result that for a phase that is (partially) soluble in the matrix phase and that adheres to the regular solution model, the solubilities $c$ of the individual elements $\mathrm{A}, \mathrm{B}, \mathrm{C}$, etc., are given by

$$
\left(c_{\mathrm{A}}\right)^{\mathrm{a}}\left(c_{\mathrm{B}}\right)^{\mathrm{b}}\left(c_{\mathrm{C}}\right)^{\mathrm{c}}=c_{1} \exp \left[\frac{-\Delta H}{R T}\right]
$$

where $\Delta H$ is again the enthalpy of formation per $\mathrm{M}_{\mathrm{m}} \mathrm{A}_{\mathrm{a}} \mathrm{B}_{\mathrm{b}} \mathrm{C}_{\mathrm{c}}$ unit, $R$ is the gas constant, $T$ is the temperature, and $c_{1}$ is a constant. Thus, if sufficient and reliable solubility data are available, $\Delta H$ can be calculated from that solubility data.

Application of the method is most straightforward when heat effects in the DSC curves are well separated, but in practice overlap often occurs. To be able to show all steps necessary in the analysis, application of the method is here reviewed by considering an example for an alloy that is relatively complex. The example used is that of precipitation in $\mathrm{Al}-\mathrm{Cu}-\mathrm{Mg}-\mathrm{Li}$ alloys and metal matrix composites (MMCs), including a monolithic 8090 alloy $(\mathrm{Al}-2 \cdot 34 \mathrm{Li}-1 \cdot 25 \mathrm{Cu}-1 \cdot 04 \mathrm{Mg}-0 \cdot 11 \mathrm{Zr}$, wt- $\%$ ) and three MMCs containing $20 \mathrm{wt}-\%$ SiC particles. In these alloys, two precipitation sequences occur. ${ }^{132,223,227-229}$ One precipitation sequence involves $\mathrm{Li}$

\section{$\mathrm{Li}$ in $\mathrm{Al}$ rich phase $\rightarrow \delta^{\prime} \rightarrow \delta$}

where $\delta^{\prime}$ is an $L 1_{2}$ ordered phase $\left(\mathrm{Al}_{3} \mathrm{Li}\right)$, fully coherent with the $\mathrm{Al}$ matrix and $\delta$ is the equilibrium $\mathrm{Al}-\mathrm{Li}$ phase (AlLi, bcc structure), which forms mainly at grain boundaries. $^{230}$ The second precipitation sequence involves $\mathrm{Cu}$ and $\mathrm{Mg},{ }^{18,34,231}$ and is represented as

\section{$\mathrm{Cu}, \mathrm{Mg}$ in $\mathrm{Al}$ rich phase $\rightarrow$}

$$
\text { (co-)clusters/GPB zones } \rightarrow \mathrm{S}
$$

where the cluster stage involves $\mathrm{Mg}-\mathrm{Mg}, \mathrm{Cu}-\mathrm{Cu}$, as well as $\mathrm{Cu}-\mathrm{Mg}$ clusters. ${ }^{34}$

The DSC curves obtained for an 8090 MMC aged for various times at $170^{\circ} \mathrm{C}$ are presented in Fig. 27. For this alloy, the $\mathrm{S}$ precipitation effect (exothermic effect peaking at about $300^{\circ} \mathrm{C}$ ) decreases with aging time, reflecting $\mathrm{S}$ precipitation during aging at $170^{\circ} \mathrm{C}$. (A similar change is observed for other $\mathrm{Al}-\mathrm{Cu}-\mathrm{Mg}$ based alloys, see e.g. Fig. 12.) Also, the heat contents of the other effects change during aging. In order to calculate the heat due to the formation/dissolution of one specific precipitate, correction must be made for overlap between effects. Correction methods can be devised based on assumptions of the kinetic model for the reaction. In principle, one might consider that the reaction follows a specific model (e.g. a JMAK model) and fit predicted transformation rates to parts of the 


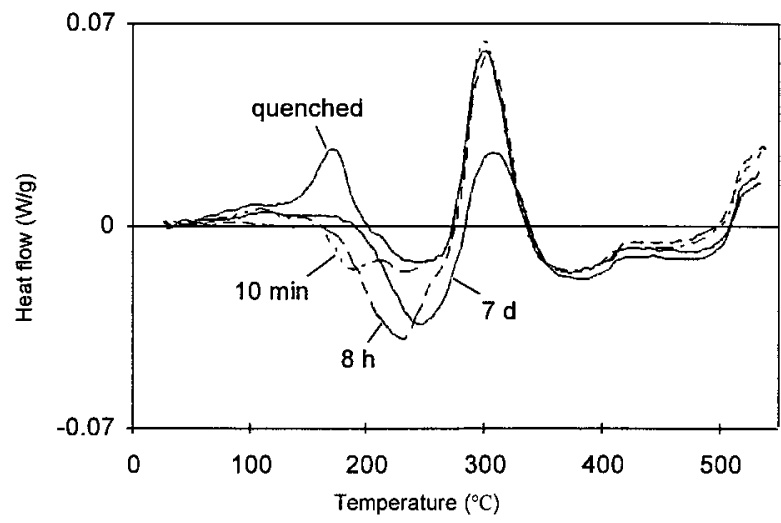

27 DSC curves of solution treated, quenched, and aged $8090 / 20 \mathrm{wt}-\% \mathrm{SiC}_{\mathrm{p}} \mathrm{MMC}$ at $10 \mathrm{~K} \mathrm{~min}^{-1}$ for various aging times at $170^{\circ} \mathrm{C}$ (from Ref. 132)

heat effect that appear to be not affected by overlap and thus derive the total heat evolved corrected for overlap. In practice, such a cumbersome procedure is often not necessary and, in the present example, an overlap correction was based on the assumption that the peak heat flow always occurs at a constant fraction transformed. ${ }^{223}$ The overlap-corrected values of the heat evolution of the phases/zones will be referred to as $\Delta Q_{\mathrm{S}, \mathrm{p}}$ (heat evolution due to $\mathrm{S}$ precipitation), $\Delta Q_{\delta^{\prime}, \mathrm{d}}$ (heat evolution due to $\delta^{\prime}$ dissolution), $\Delta Q_{\mathrm{GPB}, \mathrm{d}}$ (heat evolution due to GPB zone dissolution), etc. The amounts of GPB zones and $\delta^{\prime}$ phase present can be obtained from

$$
\begin{aligned}
& x_{\mathrm{GPB}}=\frac{\Delta Q_{\mathrm{GPB}, \mathrm{d}}}{\Delta H_{\mathrm{GPB}}} \\
& x_{\delta^{\prime}}=\frac{\Delta Q_{\delta^{\prime}, \mathrm{d}}}{\Delta H_{\delta^{\prime}}}
\end{aligned}
$$

where $\Delta H_{\mathrm{GPB}}$ and $\Delta H \delta^{\prime}$ are the heats of formation of GPB zones and $\delta^{\prime}$ phase, respectively. Due to overlap with the exothermic effect caused by the formation of $\mathrm{Li}$ containing oxides or nitrides on the surfaces of the DSC samples, the $\mathrm{S}$ dissolution effect cannot be measured accurately. Hence, the amount of semicoherent $\mathrm{S}$ formed during aging is derived from the heat effect due to $\mathrm{S}$ precipitation using

$$
x_{\mathrm{S}}=\frac{\Delta Q_{\mathrm{S}, \mathrm{p}}(\mathrm{WQ})-\Delta Q_{\mathrm{S}, \mathrm{p}}(t)}{\Delta H_{\mathrm{S}}}
$$

This expression is valid because: (i) TEM work showed that in the water quenched (WQ) condition no $\mathrm{S}$ is present, and (ii) the end temperature of the $\mathrm{S}$ precipitation is independent of isothermal aging time, which indicates that at the end of the $\mathrm{S}$ precipitation effect in the DSC run (at $330^{\circ} \mathrm{C}$ in this example) the amount of $\mathrm{S}$ phase present in the DSC samples is independent of isothermal aging time.

Using this method, the amount of phases present in the four alloys can be determined and data points are presented in Fig. 28. The results in this figure show that the amount of $\mathrm{S}$ phase forming is significantly reduced when the Li content of the alloy is reduced, and also shows that the addition of ceramic reinforcement greatly enhances the rate of formation of $\mathrm{S}$ phase. The volume fractions of strengthening phases determined with the method were used as input into a dislocation model for

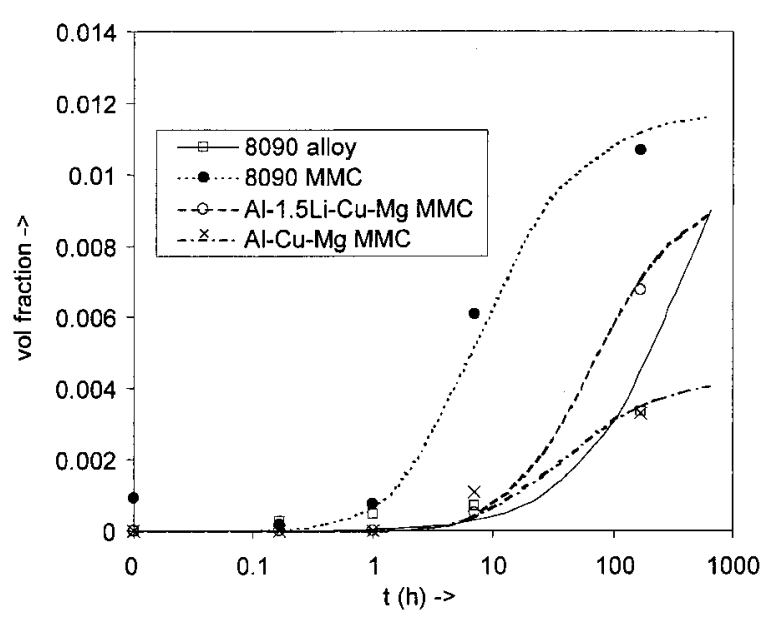

28 Amounts of semicoherent $S$ phase present in water quenched and aged alloys versus aging time at $170^{\circ} \mathrm{C}$ (MMCs all contain $20 \mathrm{wt}-\% \mathrm{SiC}_{\mathrm{p}}$ ): data points from method using DSC and curves from model fit (from Ref. 20)

the strengthening of these alloys and a good correspondence with measured data was observed. ${ }^{232}$

While the analyses of volume fractions using calorimetry reviewed above generally provided results that seemed reliable, it should be noted that no direct proof of the proportionality of heat effect with volume fraction of phase was provided. In order to provide such a proof, the volume fractions of phases measured from an analysis of heat contents should be compared with volume fractions determined from a direct microscopy technique, such as 3DAP, TEM, or, if phases are sufficiently coarse, FEG-SEM (a high resolution SEM with field emission gun). Unfortunately, determination of volume fractions of precipitates, generally necessitates 3DAP or TEM, and determination of volume fractions with these techniques is not straightforward, and significant experimental uncertainties or even systematic errors can arise. Hence, it is unlikely that presently available techniques can provide a conclusive verification for the measurement of volume fractions by calorimetry. In view of this, it is relevant to consider the preconditions for the proportionality of heat effects to volume fractions of reaction product, both for precipitation reaction and in a more generic sense for transformations studied by calorimetry. For this proportionality to hold, it is required that in all samples the same reaction occurs, and thus it is required that:

(i) the composition of reacting phases must be the same for all samples

(ii) the composition of the product phases must be the same for all samples

(iii) the ratios of the different phases involved must be the same for all samples

Further conditions are:

(iv) the energy related to interfaces created in the reaction must be negligible as compared to the total heat effect of the reaction, or proportional to the amount of phases formed

(v) the energy related to strains generated in the phases must be either negligible as compared to the total heat effect of the reaction, or proportional to the amount of phases formed 


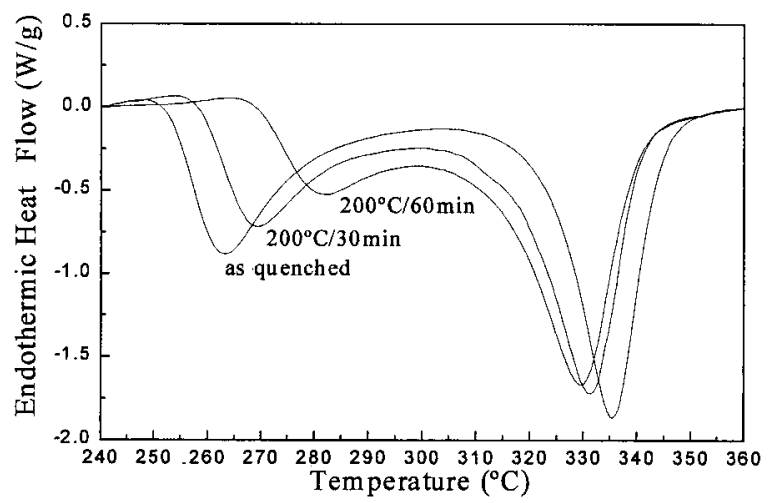

29 DSC curves at $40 \mathrm{~K} \mathrm{~min}^{-1}$ of rapidly solidified amorphous $\mathrm{Al}_{88} \mathrm{Ni}_{4} \mathrm{Sm}_{8}$ alloy and $\mathrm{Al}_{88} \mathrm{Ni}_{4} \mathrm{Sm}_{8}$ aged for 30 and $60 \mathrm{~min}$ at $200^{\circ} \mathrm{C}$ (from Ref. 233)

(vi) any temperature dependence of $\Delta H$ should be negligible in the temperature range in which heat effects occur.

When considering precipitation reactions, especially conditions (ii), (iv), and (v) need to be considered carefully. For example, if the composition of a precipitate would change in the course of the transformation, condition (ii) would not be satisfied, and it would have to be considered that the energy release per volume of precipitate formed will vary in the course of the reaction. Another example could be coherency strain or strains in the matrix generated by precipitates, which, if they are related to substantial stored energy, would contradict condition (v). Notwithstanding the wide range of preconditions, no publications have as yet questioned the proportionality of heat evolved to amount of phase formed for precipitation reactions. One example that highlights complications is provided by DSC studies on melt spun hypoeutectic Al-Si alloys. ${ }^{208}$ In these rapidly solidified alloys, $\mathrm{Si}$ is present both dissolved in the $\mathrm{Al}$ rich phase and as very fine $\mathrm{Si}$ particles, and the heat effect due to coarsening of the fine Si particles during DSC is significant and partly overlapping with the heat effect due to precipitation of $\mathrm{Si}$. This example is one case in which condition (iv) is not satisfied.

\section{Volume fractions crystallised during devitrivication}

Differential scanning calorimetry has been used extensively to analyse crystallisation during devitrivication of rapidly solidified Al based alloys, and some attempts have been made to interpret changes in heat content of the devitrivication effects quantitatively, in terms of the volume fraction of amorphous phase formed. For many amorphous alloys, DSC experiments reveal three exothermic reactions that have been ascribed to

$$
\begin{aligned}
& \text { A : amorphous } \rightarrow \alpha-\mathrm{Al}+\text { amorphous }^{\prime} \\
& \mathrm{B}: \text { amorphous }^{\prime} \rightarrow \alpha-\mathrm{Al}+\text { intermetallic phases } \\
& \mathrm{C}: \text { transformation of intermetallic phases }
\end{aligned}
$$

On isothermal aging at temperatures close to or below the peak of reaction $A$, this reaction will occur and the effects A and B in the DSC curves will change (Fig. 29). To be able to quantitatively assess the volume fraction

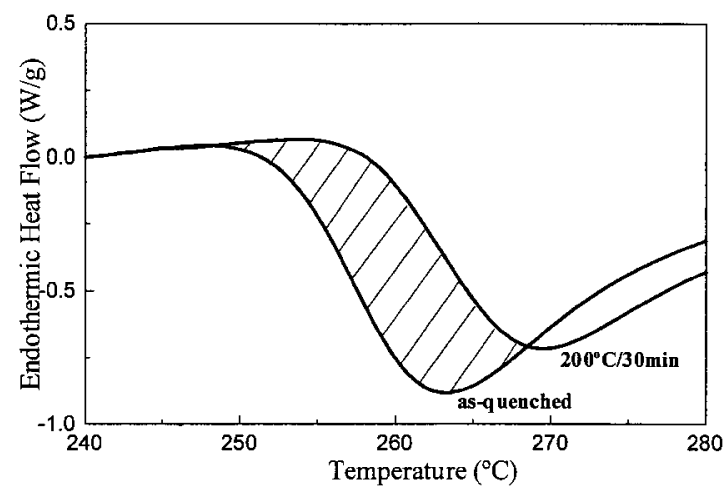

30 DSC curves at $40 \mathrm{~K} \mathrm{~min}^{-1}$ of rapidly solidified amorphous $\mathrm{Al}_{88} \mathrm{Ni}_{4} \mathrm{Sm}_{8}$ alloy and $\mathrm{Al}_{88} \mathrm{Ni}_{4} \mathrm{Sm}_{8}$ that was aged for $30 \mathrm{~min}$ at $200^{\circ} \mathrm{C}$ (from Ref. 233)

of $\alpha$-Al formed we need to consider that the two devitrivication reactions $\mathrm{A}$ and $\mathrm{B}$ will have two different enthalpies of formation per mole $\alpha$-Al formed. If the reactions have a constant enthalpy of formation per mole $\alpha$-Al formed, and only the reaction A has progressed, the volume fraction of $\alpha$-Al formed will be given by

$$
\begin{aligned}
\frac{V_{\alpha}(t, T)}{1-V_{\text {int }}} & =\frac{\left[\Delta Q_{\mathrm{A}}(t=0)-\Delta Q_{\mathrm{A}}(t)\right] / \Delta H_{\mathrm{A}}}{\left[\Delta Q_{\mathrm{A}}(t=0) / \Delta H_{\mathrm{A}}\right]+\left[\Delta Q_{\mathrm{B}}(t=0) / \Delta H_{\mathrm{B}}\right]} \\
& =\frac{\Delta Q_{\mathrm{A}}(t=0)-\Delta Q_{\mathrm{A}}(t)}{\Delta Q_{\mathrm{A}}(t=0)+\left[\Delta Q_{\mathrm{B}}(t=0) /\left(\Delta H_{\mathrm{A}} / \Delta H_{\mathrm{B}}\right)\right]}(70)
\end{aligned}
$$

where $V_{\alpha}$ is the volume fraction of $\alpha-\mathrm{Al}, V_{\text {int }}$ is the volume fraction of intermetallic phases present after reaction $\mathrm{B}, \Delta H_{\mathrm{A}}$ and $\Delta H_{\mathrm{B}}$ are the enthalpies of the two reactions per mole $\alpha$-Al formed. No values for these two enthalpies are known in the literature, and hence approximations have been made. Gloriant et al. ${ }^{233}$ investigated two methods to derive the volume fraction of $\alpha$-Al phase formed in this isothermal aging. In the first method, they considered that $\Delta H_{\mathrm{A}}=\Delta H_{\mathrm{B}}$ and ignored the volume of the intermetallic phases, which yields

$$
V_{\alpha}=\frac{\Delta Q_{\mathrm{A}}(t=0)-\Delta Q_{\mathrm{A}}(t)}{\Delta Q_{\mathrm{A}}(t=0)+\Delta Q_{\mathrm{B}}}
$$

However, as the authors realised, this method is unreliable as $\Delta H_{\mathrm{A}}$ in general should be different from $\Delta H_{\mathrm{B}}$, and it was argued that especially the different compositions of the matrix for the two devitrivication reactions cause deviations from equation (71). Comparison with 3DAP data on $V_{\alpha}$ confirmed that equation (71) is not accurate. In a second method, the amount of $\alpha$-Al phase formed during the nanocrystallisation was considered to be proportional to the change of heat evolution in effect A that occurs during the stage where the heat flow is reduced as a result of pre-aging, i.e. the amount of $\alpha$-Al phase formed would be proportional to the hatched area in Fig. 30

$$
V_{\alpha}=\frac{\Delta Q_{\text {hatch }}}{\Delta Q_{\mathrm{A}}(t=0)+\Delta Q_{\mathrm{B}}}
$$

The results of the latter method indeed corresponded well with volume fractions of $\alpha-\mathrm{Al}$ phase obtained from 3DAP analysis.

It should be noted that even though results obtained with the latter method seem reasonable, there is no 
proof that the method holds general validity. In the present case, where one phase $(\alpha-\mathrm{Al})$ is formed in two reactions that are coupled and with different enthalpies per mole transformed, accurate analysis of fractions transformed is possible only if the ratio $\Delta H_{\mathrm{A}} / \Delta H_{\mathrm{B}}$ is known.

\section{Volume fractions of intermetallic phases measured from solid-liquid reactions}

Undissolvable intermetallic phases present in an Al based alloy will generally be coarse and these particles will be detrimental for a range of properties, most notably the toughness, and the strength is also adversely affected. Hence, determination of the volume fraction of the undissolvable phases is often important. As shown above in the subsection 'Homogenisation and solution treatment studies', the dissolution of intermetallic phases can be monitored in a qualitative fashion through measuring the incipient melting effects of these phases using DSC. Some attempts have been made to relate these incipient melting effects quantitatively to amounts of phases. Lasa and Rodriguez-Ibabe ${ }^{48}$ analysed their DSC data on the incipient melting after different homogenisation treatments of two $\mathrm{Al}-\mathrm{Si}-\mathrm{Cu}-$ $\mathrm{Mg}$ alloys that were cast using different procedures (Fig. 11). The heat content of the incipient melting effects in the different samples was calculated through integration, and these data were compared with measured volume fractions of $\mathrm{Al}_{2} \mathrm{Cu}$ phase obtained from image analysis of backscattered SEM micrographs. It was found that, in order to assure that the incipient melting effect is a true reflection of the melting of phases present, the dissolution of these phases during heating needed to be avoided, and hence a very fast heating to about $460^{\circ} \mathrm{C}$ followed by heating at a rate no lower than $10 \mathrm{~K} \mathrm{~min}^{-1}$ was recommended. According to the authors, the fractions of $\mathrm{Al}_{2} \mathrm{Cu}$ phase obtained from analysis of the incipient melting effect were in good agreement with metallographic measurements'. ${ }^{48}$ However, a closer look at Fig. 31 shows that, especially for the thixoformed $\mathrm{Al}-15 \mathrm{Si}-4.4 \mathrm{Cu}-0.6 \mathrm{Mg}$, the two determinations of amounts of $\mathrm{Al}_{2} \mathrm{Cu}$ phase differ considerably, and hence this work was unable to show that in these alloys the heat content of the incipient melting effect was proportional to the amount of $\mathrm{Al}_{2} \mathrm{Cu}$ phase.

For the heat contents of the incipient melting reactions in a set of samples to be directly proportional to amount of a specific phase present in the samples, all preconditions set out above in the discussion of solid-solid reactions must be satisfied and, as interfacial energies and strain energies can be expected to be negligible, conditions (i)-(iii) especially are important. Hence, it is required that: (i) the composition of reacting phases must be the same for all samples; (ii) the composition of the product phases must be the same for all samples; and (iii) the ratios of the different phases involved must be the same for all samples. It would be generally very difficult and time consuming to verify these conditions. However, if all preconditions are met, the onset temperature of the reaction should be constant, and hence, the onset temperature is an convenient indicator for the validity of the conditions. Figure 11 shows that in the alloys studied the onset temperature is not constant, and hence we can expect that one or more of conditions (i)-(iii) are not satisfied,
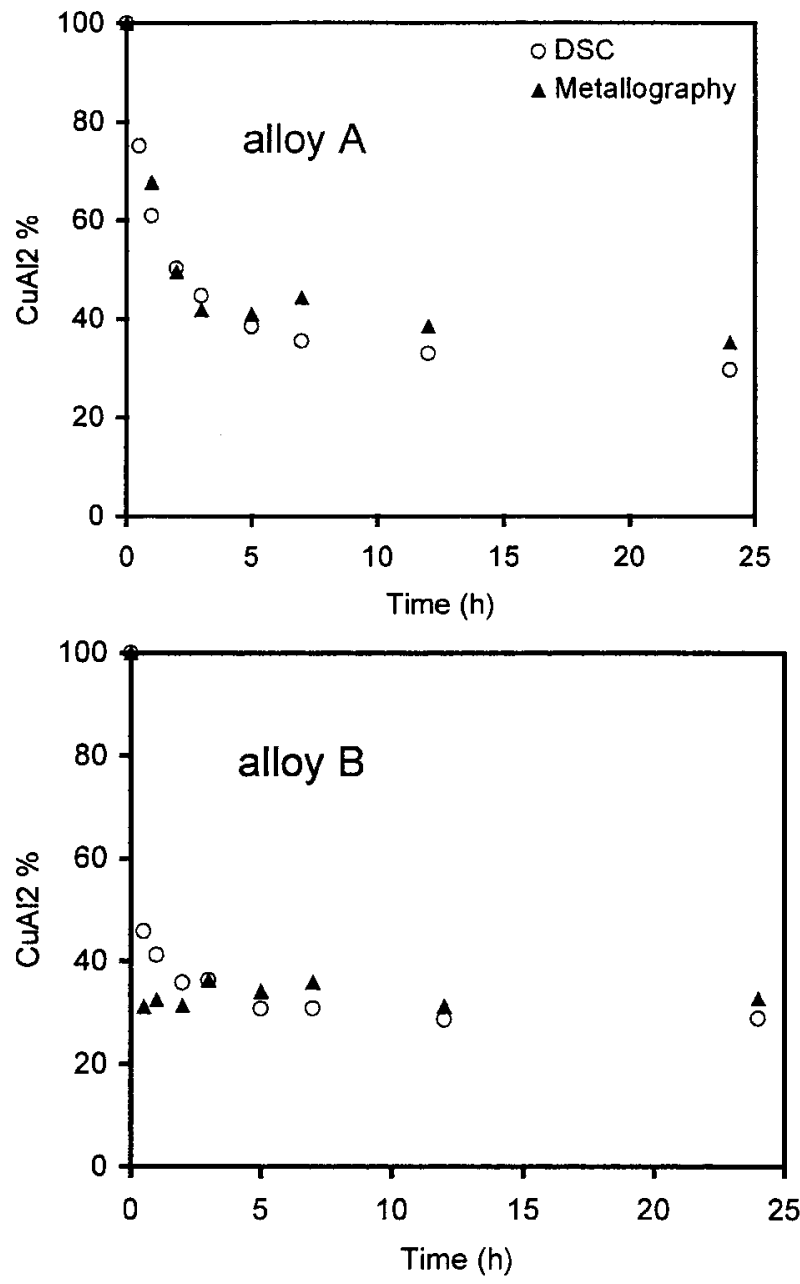

31 Evolution of amount of $\mathrm{Al}_{2} \mathrm{Cu}$ in conventionally cast Al-12Si-4.4Cu-1.3Mg (wt-\%) ingot sample (alloy A) and thixoformed Al-15Si-4.4Cu-0.6Mg (wt-\%) alloy (alloy B) heat treated for various times at $500^{\circ} \mathrm{C}$ as calculated both from reduction of DSC peak area and measured from image analysis of SEM images: amounts in as received condition were taken as $100 \%$ (from Ref. 48)

and thus the heat content of the incipient melting effect is not proportional to amount of an intermetallic phase involved in the reaction. In agreement with this, deviations from proportionality in Fig. 31 correlate with rapid variations in onset temperature in Fig. 11. (Consider the thixoformed $\mathrm{Al}-15 \mathrm{Si}-4 \cdot 4 \mathrm{Cu}-0 \cdot 6 \mathrm{Mg}$ alloy homogenised for $0 \cdot 5-2 \mathrm{~h}$.)

It should be noted that the highlighted problems with a true quantitative analysis of volume fractions of intermetallics from DSC incipient melting peaks does not detract from the useful results that can be obtained from a qualitative study.

\section{Concluding remarks}

The present review has illustrated that calorimetry, and especially differential scanning calorimetry, are widely used in the study of Al based alloys. Differential scanning calorimetry in particular allows the rapid qualitative characterisation of a wide range of reactions that are important in determining the properties of the alloys. However, the relative ease of sample preparation and 
performance of experiments can be deceptive: sample preparation and baseline instability can influence results. Also, identification of heat effects in the more complex alloys is not straightforward, and requires extensive supporting microstructural investigation. In the analysis of the kinetics of reactions during linear heating in the DSC, recent developments in approximations of the temperature integral are crucial in understanding the limits of accuracy of methods that rely on such approximations, and also deviations from the widely used JMAK (Johnson-Mehl-Avrami-Kolmogorov) models need to be considered. Analysis of calorimetry data in terms of amounts of reacting phases has attracted some attention, but the requirements for the validity of this quantitative application are strict, and in some cases assumed proportionality of heat contents of reactions to the amount of single phase formed cannot be proven.

\section{Appendices}

\section{Appendix 1: Calculation of accuracies of isoconversion methods}

The deviations by factors (i)-(vi) can be estimated as follows.

\section{Error source (i)}

For type B methods it holds ${ }^{120}$

$$
\ln \left[\frac{p\left(y_{\mathrm{f}}\right)}{\beta}\right]=\mathrm{const}
$$

The general form for the approximation of $p$ is given by

$$
p_{\mathrm{a}}(y)=\exp (-y) q(y)
$$

If the ratio between $p$ and the approximation $p_{\mathrm{a}}$ is $r(y)$, then we can rearrange equation (73) to

$$
\begin{aligned}
\ln \left[\frac{p_{\mathrm{a}}\left(y_{\mathrm{f}}\right) r(y)}{\beta}\right] & =\ln \left[\frac{\exp (-y) q\left(y_{\mathrm{f}}\right) r(y)}{\beta}\right] \\
& =-y+\ln \left[\frac{q\left(y_{\mathrm{f}}\right)}{\beta}\right]+\ln [r(y)]=\mathrm{const}
\end{aligned}
$$

and thus it follows

$\frac{\mathrm{d} \ln \left[q\left(y_{\mathrm{f}}\right) / \beta\right]}{\mathrm{d}(1 / T)}=\frac{E}{R}-\frac{\mathrm{d} \ln (r(y))}{\mathrm{d}(1 / T)}=\frac{E}{R}\left(1-\frac{\mathrm{d} \ln [r(y)]}{\mathrm{d}(y)}\right)$

Thus, we can conclude that the error introduced by approximating the temperature integral, $\Delta E_{\mathrm{m}}(T$-int $)$, is given by

$$
\frac{\Delta E_{\mathrm{m}}(T \text {-int })}{E_{\mathrm{m}}}=\frac{\mathrm{d} \ln [r(y)]}{\mathrm{d}(y)}=\frac{\mathrm{d} \ln \left(p_{\mathrm{a}} / p\right)}{\mathrm{d}(y)}
$$

The right-hand side of the equation (77) has been evaluated elsewhere ${ }^{120}$ and results are presented in Fig. 24. This figure shows that for the best $p(y)$ isoconversion method (type B 1.92 method) the deviations introduced by approximation of the temperature integral are less than $0.25 \%$ for $y>15$ and less than $0.75 \%$ for $y>10$. For the Lyon method, ${ }^{122}$ in addition to the approximation of the temperature integral, a further mathematical approximation is introduced which is evaluated elsewhere. ${ }^{120}$ The relative error in $E$ introduced is about $-2[y(2+y)]^{-1}$, and hence accuracy is better than $1.7 \%$ for $y>10$ and better than $0.8 \%$ for $y>15$.

\section{Error sources (ii), (iii), and (iv)}

If the activation energy is derived from two constant heating rate experiments, I and II, the activation energy for a $p(y)$-isoconversion method (type B method) is given by ${ }^{120}$

$$
E_{\mathrm{m}}=R\left[\ln \frac{\beta_{\mathrm{I}}}{T_{\mathrm{f}, \mathrm{I}}^{\kappa}}-\ln \frac{\beta_{\mathrm{II}}}{T_{\mathrm{f}, \mathrm{II}}^{\kappa}}\right]\left(\frac{1}{T_{\mathrm{f}, \mathrm{I}}}-\frac{1}{T_{\mathrm{f}, \mathrm{II}}}\right)^{-1}
$$

where $E_{\mathrm{m}}$ represents the measured value of $E$. We can approximate the deviation introduced by the sources of error (ii) and (iii) for type B methods as

$$
\begin{aligned}
\Delta E_{\mathrm{m}}(i i)-(i v)= & \frac{\partial E_{\mathrm{m}}}{\partial T_{\mathrm{I}}} \Delta T_{\mathrm{I}}+\frac{\partial E_{\mathrm{m}}}{\partial T_{\mathrm{II}}} \Delta T_{\mathrm{II}}+\frac{\partial E_{\mathrm{m}}}{\partial \beta_{\mathrm{I}}} \Delta \beta_{\mathrm{I}} \\
& +\frac{\partial E_{\mathrm{m}}}{\partial \beta_{\mathrm{II}}} \Delta \beta_{\mathrm{II}}
\end{aligned}
$$

where the four terms on the right-hand side relate to the inaccuracies in determination of the temperatures at fixed fraction transformed and the inaccuracies in determination of heating rate. The accuracy of the type A methods (rate-isoconversion methods, Friedman method) was analysed in a similar fashion, and this yielded

$$
\begin{aligned}
\Delta E_{\mathrm{m}}(i i)-(i v)= & \frac{\partial E_{\mathrm{m}}}{\partial T_{\mathrm{I}}} \Delta T_{\mathrm{I}}+\frac{\partial E_{\mathrm{m}}}{\partial T_{\mathrm{II}}} \Delta T_{\mathrm{II}}+\frac{\partial E_{\mathrm{m}}}{\partial \beta_{\mathrm{I}}} \Delta \beta_{\mathrm{I}}+ \\
& \frac{\partial E_{\mathrm{m}}}{\partial \beta_{\mathrm{II}}} \Delta \beta_{\mathrm{II}}+\frac{\partial E_{\mathrm{m}}}{\partial q_{\mathrm{I}}} \Delta q_{\mathrm{I}}+\frac{\partial E_{\mathrm{m}}}{\partial q_{\mathrm{II}}} \Delta q_{\mathrm{II}}
\end{aligned}
$$

where $q=\mathrm{d} \alpha / \mathrm{d} T$. The first four terms on the right-hand side are identical to the four terms in the previous equation. As the heating rate can generally be determined to a very high accuracy, we can ignore the $\Delta \beta_{\text {I }}$ and $\Delta \beta_{\mathrm{II}}$ terms in equation (80). The first term on the right-hand side of equation (80) is evaluated as

$$
\frac{\partial E_{\mathrm{m}}}{\partial T_{\mathrm{I}}} \Delta T_{\mathrm{I}}=R\left(\frac{T_{\mathrm{II}}}{T_{\mathrm{I}}-T_{\mathrm{II}}}\left[\kappa+\frac{E_{\mathrm{m}}}{R T_{\mathrm{I}}}\right]\right) \Delta T_{\mathrm{I}}
$$

As $\kappa \ll E / R T$ we can approximate

$$
\frac{\partial E_{\mathrm{m}}}{\partial T_{\mathrm{I}}} \Delta T_{\mathrm{I}} \cong E_{\mathrm{m}}\left(\frac{\Delta T_{\mathrm{I}}}{T_{\mathrm{I}}-T_{\mathrm{II}}} \frac{T_{\mathrm{II}}}{T_{\mathrm{I}}}\right)
$$

Thus, for type B methods, the errors introduced by error sources (ii)-(iv) are mostly dominated by error source (ii), and the errors can be approximated

$$
\frac{\Delta E_{\mathrm{m}}(i i)-(i v)}{E_{\mathrm{m}}} \cong \frac{\Delta T_{\mathrm{I}}}{T_{\mathrm{I}}-T_{\mathrm{II}}} \frac{T_{\mathrm{II}}}{T_{\mathrm{I}}}+\frac{\Delta T_{\mathrm{II}}}{T_{\mathrm{II}}-T_{\mathrm{I}}} \frac{T_{\mathrm{I}}}{T_{\mathrm{II}}}
$$

This can be further approximated by considering that in most cases

$$
T_{\mathrm{I}}-T_{\mathrm{II}} \ll T_{\mathrm{II}}, T_{\mathrm{I}}
$$

and hence

$$
\frac{\Delta E_{\mathrm{m}}(i i-i v)}{E_{\mathrm{m}}} \cong \frac{\Delta T_{\mathrm{I}}}{T_{\mathrm{I}}-T_{\mathrm{II}}}+\frac{\Delta T_{\mathrm{II}}}{T_{\mathrm{II}}-T_{\mathrm{I}}}
$$

Accuracy of determination of $q$ may depend on a range of factors including baseline stability and dependency of heat flow calibration on heating rate and temperature, and it is thought that $\Delta q / q$ may vary between 0.5 and $5 \%$ depending on experimental conditions. Considering 
some typical values for solid state reactions would yield as indication of the magnitude

$$
\frac{R T_{\mathrm{I}}}{E} \frac{T_{\mathrm{I}}}{T_{\mathrm{II}}-T_{\mathrm{I}}} \approx \frac{1}{20} \frac{500}{50}=0 \cdot 5
$$

\section{Error source (v)}

The magnitude of this error depends on the type of reaction operating. The errors for various choices of $f(\alpha)$ have been analysed by Gao et al. ${ }^{151}$ In the present work, the error was estimated by considering the maximum error introduced by any of these methods in the range $15<y<60$.

\section{Error source (vi)}

The errors introduced by variations of the equilibrium state during the reaction have attracted little attention in the literature. Attempts at analysis for precipitation reactions have shown that this source of errors can be significant. ${ }^{149}$

\section{Appendix 2: Mean field model and impingement factor model}

The mean field model considers that the influence of the impingement of diffusion field on the growth rate of spherical precipitates of radius $R(t)$ is related to the average solute content of the matrix $\bar{c}(t)$ through

$$
\frac{\mathrm{d} R(t)}{\mathrm{d} t}=\left[\frac{c_{\mathrm{m}}-\bar{c}(t)}{c_{\mathrm{p}}-c_{\mathrm{m}}}\right] \frac{D}{R(t)}
$$

where $D$ is the diffusivity and $c_{\mathrm{p}}$ and $c_{\mathrm{m}}$ are the precipitate and matrix compositions at the interface. Conservation of solute requires that

$$
f_{\mathrm{p}} c_{\mathrm{p}}+\left(1-f_{\mathrm{p}}\right) \bar{c}(t)=c_{\mathrm{o}} \Leftrightarrow f_{\mathrm{p}}\left[c_{\mathrm{p}}-\bar{c}(t)\right]=c_{\mathrm{o}}-\bar{c}(t)
$$

where $c_{\mathrm{o}}$ is the initial matrix concentration, $f_{\mathrm{p}}$ is the volume fraction of precipitates, which equals $4 / 3 \pi R(t)^{3} N$ ( $N$ being the number density of growing precipitates). Eliminating $R(t)$ from these equations yields

$$
\begin{aligned}
\frac{\mathrm{d} \bar{c}(t)}{\mathrm{d} t}= & \frac{D(4 / 3 \pi N)^{2 / 3}}{\left(c_{\mathrm{p}}-c_{\mathrm{m}}\right)\left(c_{\mathrm{p}}-c_{\mathrm{o}}\right)}\left[c_{\mathrm{p}}-\bar{c}(t)\right]^{5 / 3}\left[c_{\mathrm{m}}-\bar{c}(t)\right] \\
& \times\left[c_{\mathrm{o}}-\bar{c}(t)\right]^{1 / 3} \\
= & A_{1}(T)\left[c_{\mathrm{p}}-\bar{c}(t)\right]^{5 / 3}\left[c_{\mathrm{m}}-\bar{c}(t)\right]\left[c_{\mathrm{o}}-\bar{c}(t)\right]^{1 / 3}
\end{aligned}
$$

where $A_{1}(T)$ is a time-independent factor depending on $D, N$, and initial and equilibrium compositions. The progress of the reaction (evaluated by iteration) can be compared with the Starink-Zahra model ${ }^{170,179}$

$$
\alpha=1-\left(\frac{[k t]^{\mathrm{n}}}{\eta_{\mathrm{i}}}+1\right)^{-\eta_{\mathrm{i}}}
$$

This comparison shows that the Starink-Zahra model can fit the reaction curves to a very high degree of accuracy with $n=1.5$ and $\eta_{\mathrm{i}}>5.67$, provided the initial concentration of solute is sufficiently dilute as compared to the concentration in the precipitate, e.g.

$$
c_{\mathrm{p}}-c_{\mathrm{m}}>10\left(c_{\mathrm{o}}-c_{\mathrm{m}}\right)
$$

Of special interest, is the limit for infinitely dilute solutions, e.g. where $\left[c_{\mathrm{p}}-\bar{c}(t)\right]$ can be considered a constant. In this case equation (88) can be reduced as follows

$$
\begin{aligned}
\frac{\mathrm{d} \bar{c}(t)}{\mathrm{d} t}= & \frac{D(4 / 3 \pi N)^{2 / 3}}{\left(c_{\mathrm{p}}-c_{\mathrm{m}}\right)\left(c_{\mathrm{p}}-c_{\mathrm{o}}\right)}\left[c_{\mathrm{p}}-c_{\mathrm{o}}\right]^{5 / 3}\left[c_{\mathrm{m}}-\bar{c}(t)\right] \\
& \times\left[c_{\mathrm{o}}-\bar{c}(t)\right]^{1 / 3} \\
= & A_{2}(T)\left[c_{\mathrm{m}}-\bar{c}(t)\right]\left[c_{\mathrm{o}}-\bar{c}(t)\right]^{1 / 3}
\end{aligned}
$$

where $A_{2}(T)$ is a time-independent factor depending on $D, N$, and initial and equilibrium compositions. Considering that $c_{\mathrm{o}}-\bar{c}(t)$ is proportional to $\alpha$ and that $c_{\mathrm{m}}-\bar{c}(t)$ is proportional to $1-\alpha$, we can rewrite equation (90) $\mathrm{as}^{204}$

$$
\frac{\mathrm{d} \alpha}{\mathrm{d} t}=A_{3}(T)[1-\alpha] \alpha^{1 / 3}
$$

Thus, the mean field model for precipitation is compatible with equations (6) and (7) with $f(\alpha)=[1-\alpha] \alpha^{1 / 3}$. A highly accurate approximate solution for the latter equation is the Starink-Zahra equation with $\eta_{\mathrm{i}}=5.67$ and $n=1 \cdot 5$, i.e.

$$
[1-\alpha] \alpha^{1 / 3} \cong n\left[(1-\alpha)^{-1 / \eta}-1\right]^{(\mathrm{n}-1) / \mathrm{n}}(1-\alpha)^{(\eta+1) / \eta}
$$

with the $\eta_{\mathrm{i}}$ and $n$ values indicated.

\section{Acknowledgements}

The provision of original graphs of calorimetry curves and other data by several of the authors cited in this review is gratefully acknowledged. Through the years Dr A.-M. Zahra, Professor E. J. Mittemeijer, and Professor P. J. Gregson contributed useful discussions on several of the topics included in this work.

\section{References}

1. T. Gloriant and A. L. Greer: Nanostr. Mater., 1998, 10, 389-396.

2. Shushan Dong, Guangtian Zou and Haibin Yang: $\underline{\text { Scr. Mater. }}$ 2001, 44, 17-23.

3. T. P Prasad, S. B. Kanungo and H. S. Ray: Thermochim. Acta. 1992, 203, 503-514.

4. R. Sabbah, A.-M. Zahra, R. Castanet and G. Bardon de Segonzac: personal communications, CTM-CNRS, Marseille, France, 1996.

5. 'Calorimeters Calvet', SETARAM group, Caluire, France, 2001 (descriptions of SETARAM calorimeters).

6. J. H. Rechardson and R. V. Peterson: 'Systematic materials analysis'; 1978, New York, Academic Press.

7. C. Michaelsen, K. Barmak and T. P. Weihs: Phys. D, 1997, 30, 3167-3186

8. M. J. Richardson and E. L. Charsley: in 'Handbook of thermal analysis and calorimetry', (ed. M. E. Brown), Vol. 1, 547; 1998, Amsterdam, Elsevier.

9. W. Lacom: Thermochim. Acta, 1996, 271, 93-100.

10. A. Zahra, C. Y. Zahra and M. Laffitte: Z. Metallkd., 1979, 70, 669.

11. M. J. Starink and A.-M. Zahra: Philos. Mag. A, 1998, 77, 187-199.

12. A. Charai, T. Walther, C. Alfonso, A.-M. Zahra and C. Y. Zahra: Acta Mater., 2000, 48, 2751-2764.

13. L. F. Mondolfo: 'Aluminium alloys: structure and properties'; 1976, London, Butterworths.

14. I. J. Polmear: 'Light alloys, the metallurgy of the light metals', 3rd edn; 1995, London, Arnold.

15. C. Garcia-Cordovilla and E. Louis: Metall. Trans. A, 1984, 15A 389-391.

16. C. Garcia-Cordovilla and E. Louis: Thermochim. Acta, 1985, $\underline{\mathbf{9 3}}$, 653-656.

17. M. J. Starink, A. J. Hobson and P. J. Gregson: Scr. Mater., 1996 , 34, 1711-1716.

18. S. P. Ringer, K. Hono, I. J. Polmear and T. Sakurai: Appl. Surf. Sci., 1996, 94-95, 253-260.

19. A. K. Gupta, P. Gaunt and M. C. Chaturvedi: Philos. Mag. A, 1987, 55, 375-387. 
20. M. J. Starink, P. Wang, I. Sinclair and P. J. Gregson: Acta Mater. 1999, 47, 3841-3853.

21. T. Sato: Mater. Sci. Forum, 2000, 331-337, 85.

22. P. B. Prangnell and W. M. Stobbs: Proc. 7th Int. Conf. on 'Composite materials', ICCM7, (ed. W. Yunshu et al.), 573; 1989, Oxford, Pergamon Press.

23. M. Cieslar, P. Vostry, I. Stuliková and B. Smola: in Proc. 6th Al-Li Conf., (ed. M. Peters and P.-J. Winkler), 155; 1992, Oberursel, DGM Informationsgesellschaft.

24. P. B. Prangnell and W. M. Stobbs: Proc. 12th Risø Int. Symp. on 'Metal matrix composites - processing, microstructure and properties', (ed. N. Hansen et al.), 603; 1991, Roskilde, Risø.

25. G. W. Smith: Scr. Metall. Mater., 1994, 31, 357-362.

26. G. W. Smith: Thermochim. Acta: 1997, 291, 59-64.

27. C. Y. Zahra and A.-M. Zahra: Thermochimica Acta, 1996, 276, $\underline{161-174 .}$

28. J. Y. Yao, D. A. Graham, B. Rinderer and M. J. Couper: Micron. 2001, 32, 865-870.

29. R. D. Sá Lisboa and C. S. Kiminami: J. Non-Cryst. Solids, 2002, 304, 36-43.

30. S. Ikeno, H. Matsui, K. Matsuda, K. Terayama and Y. Uetani: J. Jpn Inst. Met., 2001, 65, 404408.

31. G. A. Edwards, K. Stiller, G. L. Dunlop and M. J. Couper: Acta Mater., 1998, 46, 3893-3904.

32. Y. Ohmori, L. C. Doan, Y. Matsuura, S. Kobayashi and K. Nakai: Mater. Trans., 2001, 42, 2576-2583.

33. S. Abis, M. Massazza, P. Mengucci and G. Riontino: Scr. Mater., 2001, 45, 685-691.

34. S. P. Ringer, S. K. Caraher and I. J. Polmear: Scr. Mater., 1998, 39 1559-1567.

35. S. P. Ringer, T. Sakurai and I. J. Polmear: Acta Mater., 1997, 45, 3731-3744.

36. A. M. Zahra, C. Y. Zahra, C. Alfonso and A. Charaï: Scr. Mater. 1998, 39, 1553-1558.

37. A. K. Jena, A. K. Gupta and M. C. Chaturvedi: Acta Metall., 1989. 37, 885-895.

38. A. K. Gupta, A. K. Jena and M. C. Chaturvedi: Scr. Metall., 1988 22, 369-371

39. M. J. Starink and A.-M. Zahra: Thermochim. Acta, 1997, 298, 179 189.

40. A.-M. Zahra and C. Y. Zahra: J. Thermal Anal., 1990, 36, 1465 1470 .

41. A.-M. Zahra, C. Y. Zahra, R. Castanet, G. Jaromaweiland, G. Neuer: J. Thermal Anal., 1992, 38, 781-788.

42. B. Noble and S. E. Bray: Acta Mater., 1998, 46, 6163-6171.

43. J. M. Martin, T. Gomez-Acebo and F. Castro: Powder Metall. 2002, 45, 173-180.

44. S. P. Chen, M. S. Vossenberg, F. J. Vermolen, J. van de Langkruis and S. van der Zwaag: Mater. Sci. Eng. A, 1999, 272, 250-256.

45. X. Li and M. J. Starink: Mater. Sci. Forum, 2000, 331, 1071-1076.

46. M. J. Starink and A.-M. Zahra: Acta Mater., 1998, 46, 3381-3397.

47. M. J. Starink and P. van Mourik: Mater. Sci. Eng. A, 1992, 156, 183-194.

48. L. Lasa and J. M. Rodriguez-Ibabe: Mater. Charact., 2002, 48 371-378.

49. Guiqing Wang, Xiufang Bian, Weimin Wang and Junyan Zhang: Mater. Lett., 2003, 57, 4083-4087.

50. L. B. Ber and V. G. Davydov: Mater. Sci. Forum, 2002, 396-402, 983-988.

51. I. N. A. Oguocha, M. Radjabi and S. Yannacopoulos: J. Mater. Sci., 2000, 35, 5629-5634.

52. P. A. Rometsch and G. B. Schaffer: Int. J. Cast Met. Res., 2000, 12 431-439.

53. D. C. Balderach, J. A. Hamilton, E. Leung, M. Cristina Tejeda, J. Qiao and E. M. Taleff: Mater. Sci. Eng. A, 2003, 339, 194-204.

54. X. J. Jiang, B. Noble, V. Hansen and J. Tafto: Metall. Mater. Trans. A, 2001, 32A, 1063-1073.

55. X. J. Jiang, B. Noble, B. Holme, G. Waterloo and J. Tafto: Metall. Mater. Trans. A, 2000, 31A, 339-348.

56. F. Lefebvre, S. Wang, M. J. Starink and I. Sinclair: Mater. Sci. Forum, 2002, 396-402, 1555-1600.

57. M. H. Chen, R. Y. Hwang and C. P. Chou: Sci. Technol. Weld. Join., 1999, 4, 21-27.

58. I. N. A. Oguocha, M. Radjabi and S. Yannacopoulos: Can. Metall. Q., 2001, 40, 245-254.

59. T. Maeguchi, K. Yamada and T. Sato: J. Jpn. Inst. Met., 2002, 66 127-130.

60. J. M. G. De Salazar and M. I. Barrena: J. Mater. Sci., 2002, 37, 1497-1502.
61. S. Ikeno, H. Matsui, K. Matsuda and Y. Uetani: Mater. Sci. Forum, 2000, 331-333, 1193-1197.

62. J. L. Ortiz, V. Amigo, M. D. Salvador and C. R. Perez: Rev. Metall., 2000, 36, 348-356.

63. V. Massardier, L. Pelletier and P. Merle: Mater. Sci. Eng. A, 1998, 249, 121-133.

64. N. Gao, L. Davin, S. Wang, A. Cerezo and M. J. Starink: Mater. Sci. Forum, 2002, 396-402, 923-928.

65. C. J. Tseng, S. L. Lee, S. C. Tsai and C. J. Cheng: J. Mater. Res., 2002, 17, 2243-2250.

66. V. G. Davydov, L. B. Ber, E. Ya. Kaputkin, V. I. Komov, O. G. Ukolova and E. A. Lukina: Mater. Sci. Eng. A, 2000, 280, 76-82.

67. D. J. Lloyd, D. R. Evans and A. K. Gupta: Can. Metall. Q., 2000, 39, 475-482.

68. J. M. Papazian: Metall. Trans. A, 1981, 12A, 269-279.

69. N. Kamp, I. Sinclair and M. J. Starink: Metall. Mater. Trans. A, 2002. 33A, 1125-1136.

R. C. Dorward: Mater. Sci. Technol, 1999, 15, 1133-1138.

71. X. Li: 'Microstructure-property modelling and predictions of 7xxx alloys', PhD thesis, University of Southampton, 2002.

72. M. J. Starink and S. C. Wang: Acta Mater., 2003, 51, 5131-5150.

73. F. Zhou, X. Z. Liao, Y. T. Zhu, S. Dallek and E. J. Lavernia, Acta Mater., 2003, 51, 2777-2791.

74. L. Shaw, H. Luo, J. Villegas and D. Miracle: Acta Mater., 2003, 51, 2647-2663.

75. M. T. Clavaguera-Mora, J. Rodriguez-Viejo, D. Jacovkis, J. L. Touron, N. Clavaguera and W. S. Howells: J. Non-Cryst. Solids, 2001, 287, 162-166.

76. N. Clavaguera, J. A. Diego, M. T. Clavaguera-Mora and A. Inoue: NanoStruct. Mater., 1995, 6, 485-488.

77. A. S. Aronin, G. E. Abrosimova and Y. V. Kir'yanov: Phys. Solid State, 2001, 43, 2003-2011.

78. N. Bassim, C. S. Kiminami, M. J. Kaufman, M. F. Oliveira, M. N R. V. Perdigao and W. J. Botta Filho: Mater. Sci. Eng. A, 2001, 304-306, 332-337.

79. C. A. D. Rodriguez and W. J. Botta: Adv. Powder Technol. II, Key Eng. Mater., 2001, 189-191, 573-577.

80. D. V. Louzguine and A. Inoue: J. Mater. Res., 2002, 17, 1014 1018.

81. C. J. Zhang, Y. S. Wu, X. L. Cai, G. R. Zhou, Y. C. Shi, H. Yang and S. Wu: J. Phys., Condens. Matter, 2001, 13, L647-L653.

82. M. Gich, T. Gloriant, S. Surinach, A. L. Greer and M. D. Baro: J. Non-Crvst. Solids, 2001, 289, 214-220.

83. K. Hono, Y. Zhang, A. P. Tsai, A. Inoue and T. Sakurai: $\underline{S c r}$. Metall. Mater., 1995, 32, 191-196.

84. G. Lucadamo, K. Barmak, D. T. Carpenter and J. M. Rickman: Acta Mater., 2001, 49, 2813-2826.

85. G. Lucadamo, K. Barmak and S. Hyun: Thermochim. Acta, 2000 348, 53-59.

86. C. Michaelsen and M. Dahms: Thermochim. Acta, 1996, 288, 9-27.

87. K. Barmak, C. Michaelsen and G. Lucadamo: J. Mater. Res., 1997, 12, 133-146.

88. C. Bergman, E. Emeric, G. Clugnet and P. Gas: Defects Diffusion Forum, 2001, 194-199, 1533-1538.

89. G. W. Smith, W. J. Baxter and A. K. Sachdev: Mater. Sci. Eng. A, 2000, 284, 246-253.

90. T. X. Fan, D. Zhang, Z. L. Shi, R. J. Wu, T. Shibayanagai, M. Naka and H. Mori: J. Mater. Sci. 1999, 34, 5175-80.

91. D. Larouche, C. Laroche and M. Bouchard: Acta Mater., 2003, 51, 2161-2170.

92. Z. Zhang, X. Bian and Y. Wang: Mater. Lett., 2003, 57, 1261-1265.

93. C. Hsu, K. A. Q. O'Reilly, B. Cantor and R. Hamerton: Mater. Sci. Eng. A, 2001, 304-306, 119-124.

94. R. T. Southin and G. A. Chadwick: Acta Metall., 1978, 26, 223 231

95. Y. M. Youssef, R. W. Hamilton, R. J. Dashwood and P. D. Lee: Mater. Sci. Forum, 2002, 396-402, 259-264.

96. D. J. Chakrabarti and J. L. Murray: Mater. Sci. Forum, 1996, 217, 177-181

97. G. Sha, K. A. Q. O'Reilly, B. Cantor, J. Worth and R. Hamerton: Mater. Sci. Eng. A, 2001, 304-306, 612-616.

98. P. Sainfort, J. Domeyne and T. Warner: 'Process for the desensitisation to intercrystalline corrosion of 2000 and 6000 series Al alloys and corresponding products', US patent 5,643,372 (1997).

99. P. Sainfort and P. Gomiero: '7000 Alloy having high mechanical strength and a process for obtaining it', US patent 5,560,789 (1996)

100. H. J. Brinkman, J. Duszczyk and L. Katgerman: Scr. Mater. 1997, 37, 293-297. 
101. C. A. Ahravci and M. Ö. Pekgüleryüz: Calphad, 1998, 22, 147155.

102. J. Fjellstedt, A. E. W. Jarfors and T. El-Benawy: Mater. Des., 2001, 22, 443-449.

103. R. E. Hackenberg, M. C. Gao, L. Kaufman and G. J. Shiflet: $\underline{\text { Acta }}$ Mater., 2002, 50, 2245-2258.

104. M. Nassik, F. Z. Chrifi-Alaoui, K. Mahdouk and J. C. Gachon: J. Alloys Compd., 2003, 350, 151-154.

105. D. Kevorkov, R. Schmid-Fetzer, A. Pisch, F. Hodaj and C. Colinet: Z. Metallkd., 2001, 92, 953-958.

106. J. C. Anglezio, C. Servant and I. Ansara: Calphad, 1994, 18, $273-$ 309.

107. Y. Feutelais, B. Legendre, M. Guymont and P. Ochin: $\underline{J}$. Alloys Compd. 2001, 322, 184-189.

108. V. T. Witusiewicz, I. Arpshofen, H.-J. Seifert, F. Sommer and F. Aldinger: Thermochim. Acta, 2000, 356, 39-57,

109. A. W. Zhu, B. M. Gable, G. J. Shiflet and E. A. Starke: Mater. Sci. Forum, 2002, 396-402, 21-30.

110. P. Saltykov, V. T. Witusiewicz, I. Arpshofen, O. Fabrichnaya, H. J. Seifert, F. Aldinger: Scand. J. Metall., 2001, 30, 297-301.

111. V. Witusiewicz, U. K. Stolz, I. Arpshofen and F. Sommer: Z. Metallkd., 1998, 89, 704-713.

112. L. B. Ber and E. Y. Kaputkin: Phys. Met. Metallogr., 2001, 92, 199-209.

113. K. Bouche, F. Barbier and A. Coulet: Z. Metallkd. 1997 $\underline{\mathbf{8 8}} \underline{446-}$ 451

114. J. Málek: Thermochim. Acta, 1995, 267, 61.

115. J. Šesták and G. Berggren: Thermochim. Acta, 1971, 3, 1.

116. M. J. Starink: J. Mater. Sci., 1997, 32, 4061-4070.

117. E. G. Prout and F. C. Tompkins: Trans. Faraday Soc., 1946, 42, 468

118. S. Vyazovkin and C. A. Wright: Int. Rev. Phys. Chem., 1998, 17. 407-433.

119. A. K. Galwey and M. E. Brown: in 'Handbook of thermal analysis and calorimetry', (ed. M. E. Brown), Vol. 1, 147; 1998, Amsterdam, Elsevier.

120. M. J. Starink: Thermochim. Acta, 2003, 404, 163-176.

121. O. Schlömilch: 'Vorlesungen über höheren Analysis', 2nd edn, 266; 1874, Braunschweig

122. R. E. Lyon: Thermochim. Acta, 1997, 297, 117.

123. C. D. Doyle: J. Appl. Polvm. Sci., 1961, 5, 285.

124. C. D. Doyle: J. Appl. Polym. Sci., 1962, 6, 693.

125. C. D. Doyle: Nature, 1965, 207, 290.

126. P. Murray and J. White: Trans. Brit. Ceram. Soc., 1955, 54, 204.

127. A. W. Coats and J. P. Redfern: Nature, 1964, 201, 68-69.

128. G. I. Senum and R. T. Yang: J. Therm. Anal., 1977, 16, 1033.

129. M. J. Starink: Thermochim. Acta., 1996, 288, 97-104.

130. J. W. Graydon, S. J. Thorpe and D. W. Kirk: Acta Metall. Mater., 1994, 42, 3163-3166.

131. E. J. Mittemeijer: J. Mater. Sci. 1992, 27.3977-3987.

132. M. J. Starink and P. J. Gregson: Mater. Sci. Eng. A, 1996, 211, 54-65.

133. H. E. Kissinger: J. Res. Natl Bur. Stand., 1956, 57, 217.

134. T. Akahira and T. Sunose: Trans. 1969 Joint Convention Four Electrical Institutes, 1969, paper 246.

135. H. Flynn and L. A. Wall: J. Polym. Sci., 1966, 4, 323.

136. T. Ozawa: J. Therm. Anal. $1970,2,301$.

137. T. Ozawa: Thermochim. Acta, $1992, \mathbf{2 0 3}, 159$.

138. P. G. Boswell: J. Thermal Anal., 1980, 18, 353 .

139. H. L. Friedman: J. Polym. Sci. C, 1964, 6, 183-195.

140. C.-R. Li and T. B. Tang: Thermochim. Acta, 1999, 325, 43-46.

141. R. DeIasi and P. N. Adler: Metall. Trans. A, 1977, 8A, 1177.

142. L. V. Meisel and P. J. Cote: Acta Metall. 1983, 31, 1053-1059.

143. A. Ortega: Int. J. Chem. Kinet., 2002, 34, 193.

144. P. Bárczy and F. Tranta: Scand. J. Metall., 1975, 4, 284-288.

145. L. C. Chen and F. Spaepen: J. Appl. Phys., 1991, 69, 679

146. S. Vyazovkin: J. Comput. Chem., 1997, 18, 393-402.

147. A. Ortega: Thermochim. Acta, 1996, 284, 379-387.

148. J. M. Criado and A. Ortega: J. Non-Cryst. Solids, 1986, 87, 302311.

149. M. J. Starink: J. Mater. Sci., 1997, 32, 6505-6512.

150. J. H. Flynn: J. Therm. Anal., 1983, 27, 95.

151. Xiang Gao, Dun Chen and D. Dollimore: Thermochim. Acta, 1993, 223, 75-82.

152. Dun Chen, Xiang Gao and D. Dollimore: Thermochim. Acta, 1993, 215, 109.

153. M. B. Berkenpas, J. A. Barnard, R. V. Ramanujan and H. I. Aaronson: Scr. Metall. . 1986, 20, 323.

154. J. M. Criado and A. Ortega: J. Therm. Anal., 1984, 29, 1225.

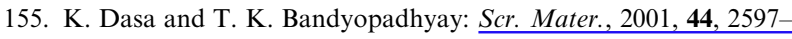
2603.

156. E. A. Brandes (ed.): 'Smithells metals reference book'; 1983, Oxford, Butterworths

157. R. W. Siegel: J. Nucl. Mater., 1978, 69-70, 117-146.

158. W. DeSorbo and D. Turnbull: Acta Metall., 1959, 7, 83-85.

159. N. C. W. Kuijpers, W. H. Kool, S. van der Zwaag: Mater. Sci. Forum, 2002, 396-402, 675-680.

160. N. Kamp: 'Toughness-strength relationships in high strength $7 \mathrm{xxx}$ Al alloys', $\mathrm{PhD}$ thesis, University of Southampton, 2002.

161. B. J. McKay, P. Cizek, P. Schumacher and K. A. Q. O'Reilly: Mater. Sci. Eng. A, 2001, 304-306, 240-244.

162. O. N. Senkov, J. M. Scotta and D. B. Miracle: J. Alloys Compd. 2002, 337, 83-88.

163. I. N. A. Oguocha and S. Yannacopoulos: J. Mater. Sci. 1999. 34 3335-3340.

164. S. P. Chen, K. M. Mussert and S. van der Zwaag: J. Mater. Sci. 1998, 33, 4477-4493.

165. A. Varschavski and E. Donoso: J. Therm. Anal. Calorim. 2002. 68, 231-241.

166. Eon-Sik Lee and Young G. Kim: Acta Metall. Mater., 1990, 38, 1669.

167. J. B. Austin and R. L. Rickett: Trans. Am. Inst. Min. Eng., 1939, 135, 396

168. R. A. Vandermeer and P. Gordon: in 'Recovery and recrystallization in metals', (ed. L. Himmel), 211; 1963, New York, Gordon and Breach Science Publishers.

169. L. Q. Xing, J. Eckert, W. Loser, L. Schultz and D. M. Herlach: Philos. Mag. A, 1999, 79, 1095.

170. M. J. Starink and A.-M. Zahra: Thermochim. Acta, 1997, 292 159-168.

171. M. J. Starink and A.-M. Zahra: Acta Mater., 1998, 46, 3381-3397.

172. M. J. Starink, C. Y. Zahra and A.-M. Zahra: J. Therm. Anal. Calorim., 1998, 51, 933-942.

173. M. K. Miller, K. F. Russell, P. J. Pareige, M. J. Starink and R. C. Thomson: Mater. Sci. Eng. A, 1998, 250, 49-54.

174. A. R. Yavari and D. Negri: Nanostruct. Mater., 1997 8, 969-986.

175. E. Pineda and D. Crespo: J. Non-Cryst. Solids, 2003, 317, 85-90.

176. V. Sessa, M. Fanfoni and M. Tomellini: Phvs. Rev. B, 1996, 54, $\underline{836}$.

177. Ge Yu and J. K. L. Lai: J. Appl. Phys., 1996, 79, 3504.

178. C. Michaelsen, M. Dahms and M. Pfuff: Phys. Rev. B, 1996, 53, $11877-78$

179. M. J. Starink: J. Mater. Sci., 2001, 36, 4433-4441.

180. E. Pineda, T. Pradell and D. Crespo: Philos. Mag. A, 2002, 82 107-121.

181. W. S. Tong, J. M. Rickman and K. Barmak: J. Chem. Phvs., 2001. 114. 915

182. J. M. Rickman, W. S. Tong and K. Barmak: Acta Mater., 1997. 45, 1153

183. M. Tomellini, M. Fanfoni and M. Volpe: Phys. Rev. B, 2000, 62. $11300-03$.

184. N. X. Sun, X. D. Liu and K. Lu: Scr. Mater., 1996, 34, 1201.

185. D. P. Birnie III and M. C. Weinberg: J. Chem. Phys., 1995, 103 $\underline{3742 .}$

186. M. C. Weinberg and D. P. Birnie III: J. Chem. Phys., 1996, 105 5139.

187. D. P. Birnie III and M. C. Weinberg: Physica A, 1996, 230, 484.


202. 290.

189. F. S. Ham: J. Appl. Phys., 1959, 30, 1518

190. F. S. Ham: Q. Appl. Math., 1959, 17, 137.

191. E. Pineda and D. Crespo: Phys. Rev B., 1999, 60, 3104

192. P. Uebele and H. Hermann: Modell. Simul. Mater. Sci. Eng. 1996, 4, 203.

193. A. D. Rollett: Progr. Mater. Sci., 1997, 42, 79-99.

194. M. P. Jackson, M. J. Starink and R. C. Reed: Mater. Sci. Eng. A. 1999, 264, 26-38.

195. O. R. Myhr and Ø. Grong: Acta Mater. $2000,48,1605$

196. A. Deschamps and Y. Brechet: Acta Mater. 1999, 47, 293.

197. J. S. Langer and A. J. Schwartz: Phys. Rev. A., 1980, 21, 948.

198. C. Sigli: Mater. Sci. Forum, 2000, 331-337, 513.

199. R. Kampmann and R. Wagner: in 'Decomposition of alloys: the early stages', (ed. P. Haasen et al.), 91-103; 1984, New York, Pergamon Press.

200. E. Woldt: Metall. Mater. Trans. A, 2001, 32, 2465-2473.

201. A. K. Gangopadhyay, T. K. Croat and K. F. Kelton: Acta Mater., 2000, 48, 4035-4043.

202. K. F. Kelton: Acta Mater., 2000, 48, 1967-1980. 
203. K. F. Kelton: J. Non-Cryst. Solids, 2000, 274 147-154.

204. M. Baricco, M. Groppi, E. Bosco and A. Catellero: Mater. Sci. Forum, 2001, 360-362, 445-450.

205. K. F. Kelton, T. K. Croat, A. K. Gangopadhyay, L.-Q. Xing, A. L. Greer, M. Weyland, X. Li and K. Rajan: J. Non-Cryst. Solids, 2003, 317, 71-77.

206. M. Tomellini: J. Alloys Compd., 2003, 348, 189-94.

207. M. J. Starink: J. Mater. Sci. Lett., 1996, 15, 1747-1748.

208. M. van Rooyen and E. J. Mittemeijer: Metall. Trans. A, 1989 , 20A, 1207-1214.

209. A. Borrego and G. González-Doncel: Mater. Sci. Eng. A, 1998 , A245, 10-18

210. M. J. Starink: Mater. Sci. Eng. A, 1999, A276, 289-292.

211. A. Borrego and G. González-Doncel: Mater. Sci. Eng. A, 1998, A252, 149 .

212. G. Garcés and P. Adeva: J. Allovs Compd. 2002, 347. 188-192.

213. A. Varschavsky and E. Donoso: Mater. Lett., 2003, 57, 1266 1271

214. A. Varschavsky and E. Donoso: J. Therm. Anal. Calorim., 2002, 68, 231-241.

215. E. Woldt: J. Phys. Chem. Solids, 1992, 53, 521

216. P. Krüger: J. Phys. Chem. Solids, 1993, 54, 1549.

217. J. M. Criado and A. Ortega: Acta Metall., 1987, 35, 1715-1721.

218. Eon-Sik Lee and Young G. Kim: Acta Metall. Mater., 1990, 38, 1677.

219. J. W. Christian: 'The theory of transformations in metals and alloys', 542; 1975, Oxford, Pergamon Press.
220. S. Vyazovkin and W. Linert: J. Solid State. Chem. 1995, 114, 392.

221. G. Ruitenberg, E. Woldt and A. K. Petford-Long: Thermochim. Acta, 2001, 378, 97

222. T. J. W. de Bruijn, W. A. de Jong and P. J. van den Berg: Thermochim. Acta, 1981, 45, 315.

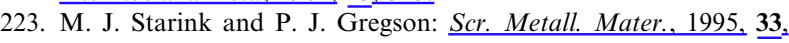
$\underline{893-900 .}$.

224. M. J. Starink, A. J. Hobson, I. Sinclair and P. J. Gregson: Mater. Sci. Eng. A, 2000, 289, 130-142.

225. M. J. Starink, A. J. Hobson and P. J. Gregson: Mater. Sci. Forum, 2000, 331-337, 1321-1326.

226. M. J. Starink and P. J. Gregson: Mater. Sci. Forum, 1996, 217222, 673 .

227. A. Luo, D. J. Lloyd, A. Gupta and W. V. Youdelis: Acta Metall. Mater., 1993, 41, 769-776.

228. Tsung-Rong Chen, Guan-Jye Peng and J. C. Huang: Metall. Mater. Trans. A, 1996, 27, 2923-2933.

229. A. Gaber and N. Afify: Appl. Phys. A, 1997, 65, 57-62.

230. K. Satya Prasad, A. K. Mukhopadhyay, A. A. Gokhale, D. Banerjee and D. B. Goel: Scr. Metall. Mater., 1994, 30, 1299.

231. H.-C. Shih, N. J. Ho and J. C. Huang: Metall. Mater. Trans. A, 1996, 27A, 2479.

232. M. J. Starink, P. Wang, I. Sinclair and P. J. Gregson: Acta Mater. 1999, 47, 3855-3868

233. T. Gloriant, M. Gich, S. Surinach, M. D. Baro and A. L. Greer: Mater. Sci. Forum, 2000, 343-346, 365-370. 